\title{
فاعلية برنامج قائم على استراتيجية دراسة الدرس \\ في تنمية مهارات التدريس التأملي لدى معلمي العلوم قبل الخدمة
}

\author{
إعداد \\ د/ شيرين مرقس مصري قيس \\ مدرس المناهج وطرق تدريس العظوم \\ بكلية التربية بقتا- جامعة جنوب الوادي
}

$\Delta 1 \leq \varepsilon \cdot p^{r} \cdot 19$ 


$$
\begin{aligned}
& \text { |المستخلص } \\
& \text { من خلال الملاحظة الشخصية، ونتائج الدراسات السابقة، ظهر قصور مهارات التدريس التأملي لدى } \\
& \text { معلمي العلوم قبل الخدمـة؛ لذلك سعت الدراسـة الحاليـة إلى التعرف على فاعلية برنامج قائم على استراتيجية } \\
& \text { دراسة الدرس في تتمية مهارات التدريس التأملي لدى معلمي العلوم قبل الخدمة، ولتحقيق هذا الهدف تم اتباع } \\
& \text { المنهج شبه التجريبي (تصميم المجموعة الواحدة مع قياس قبلي - بعدي)؛ من خلال الإجراءات التالية: إعداد } \\
& \text { قائمة بمهارات التدريس التأملي الواجب توافرها لاى معلمي العلوم قبل الخدمة-إعداد اختبار مدى توافر مهارات }
\end{aligned}
$$

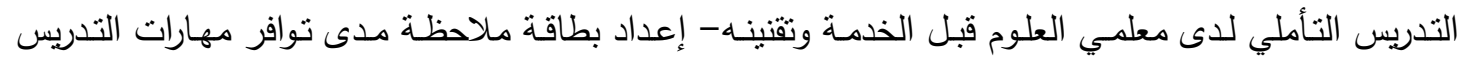

$$
\begin{aligned}
& \text { التأملي لدى معلمي العلوم قبل الخدمة وتقنينها- اعداد كتيب المُتدرب ودليل المُدرب لبرنامج قائم على استراتيجية } \\
& \text { دراسة الدرس لتتمية مهارات التدريس التأملي لدى معلمي العلوم قبل الخدمة- اختيار مجموعة الدراسة عشوائياً } \\
& \text { من طلاب كلية التربية بقنا الفرقة الرابعة تعليم عام تخصصات العلوم، وتطبيق تجربة الدراسة عليها، وقد أنثارت }
\end{aligned}
$$

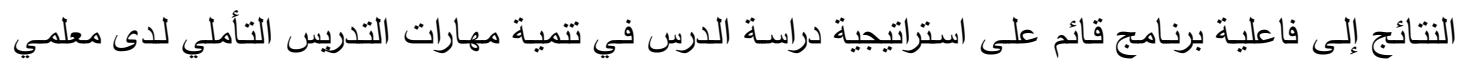

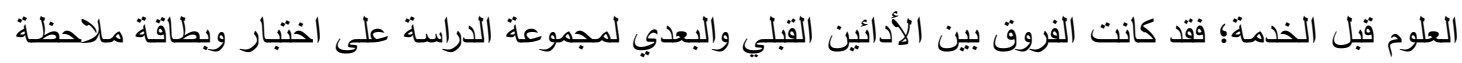

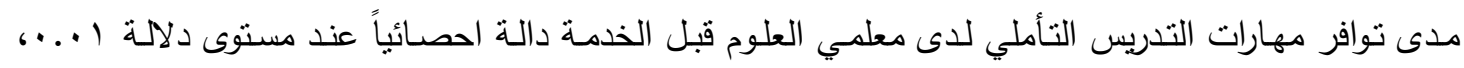

$$
\begin{aligned}
& \text { وبحجم نأثير مرتفع. } \\
& \text { الكلمات المفتاحية: دراسة الدرس- التدريس التأملي - مهارات التدريس التأملي. }
\end{aligned}
$$

\begin{abstract}
Based on self observation \& previous studies' results, it appeared that there is a shortage in reflective teaching skills for pre-service science teachers, so this study tried to recognize the effectiveness of lesson study strategy based program in developing reflective teaching skills for pre-service science teachers, to achieve such aim; quasi-experimental approach (one group design with pre-post measuring), committed throgh next procedures: preparing a list of reflective teaching skills for pre-service science teachers- preparing a measure $\&$ an observation rating scale for measuring the extent to which pre-service science teachers have reflective teaching skills, Preparing the trainee's and trainer's guide for a lesson study strategy based program to develop reflective teaching skills for pre-service science teachers, choose the study group randomly among the $\varepsilon^{\text {th }}$ year science specialties from Qena faculty of education, \& apply the experiment of the study on them, results of the study indicate the effectiveness of lesson study strategy based program in developing reflective teaching skills for pre-service science teachers; the differences between pre- post performance of the study group at both the measure \& observation rating scale for the extent to which pre-service science teachers have reflective teaching skills, were statistically significant at the level of $\cdot . \cdot$ with high size effect.
\end{abstract}

Keywords: lesson study - reflective teaching - reflective teaching skills. 
يُعتبر المعلم أحد الركائز التي تقوم عليها العملية التعليمية؛ لأنه المسئول الرئيس عن

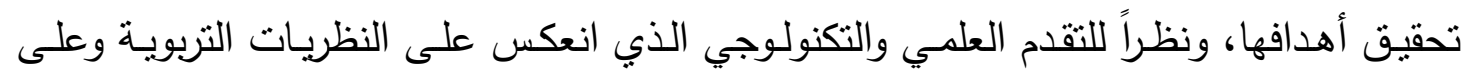

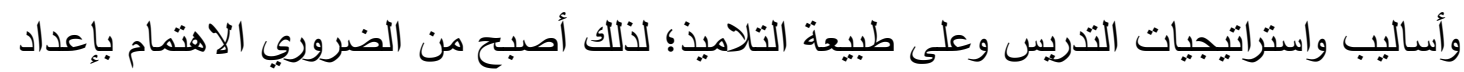
المعلم بما يتتاسب مع ذللك الثقام وانعكاساته ومنطلباته.

ونظراً لأن مادة العلوم تُعد من أكثر المواد تأثراً بهذه التغيرات؛ لأن محتواها وأسلوب

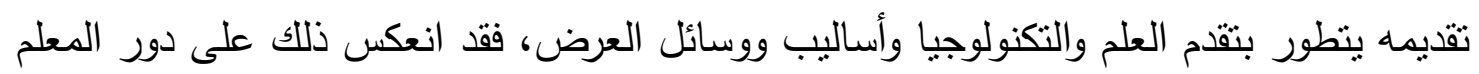
عامة ومعلم العلوم خاصة؛ لأنه مسئول عن غرس الميول والاتجاهات والقيم العلمية لدى تلاميذه ولئه

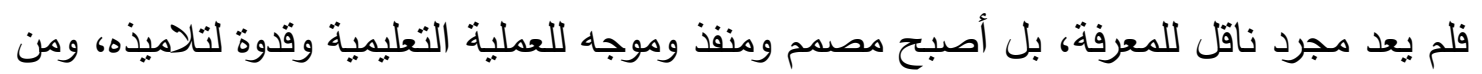
هنا لابد أن يحرص المعلم على الدقة ومواكبة العصر ومراعاة أسلوب تقديم المادة العلمية وطريقة تعامله مع تلاميذه، وردود أفعاله وأفعال تلاميذه لكل كبيرة وصغيرة في العطلية النعليمية.

ويعتبر التأمل من سمات المعلم الجيد (بارسونز ر. د. وبراون ك. س.، 0. . ب؟ 0)؛ لأن

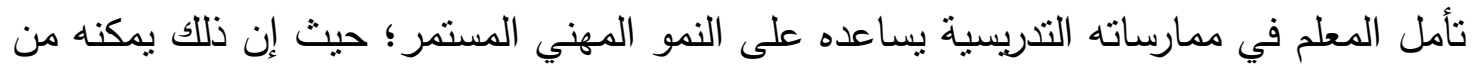

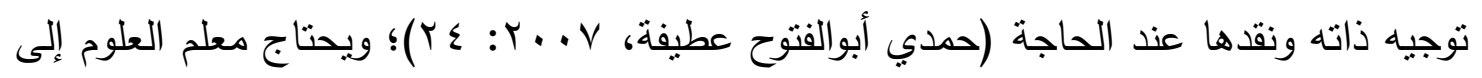
التفكير في أفعاله؛ من حيث: ماذا يفعل ولماذا وكيف يفعل؛ فيما يُعرف بالتدريس التأملي

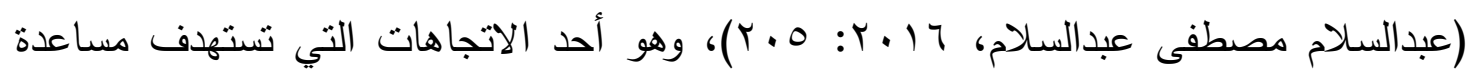

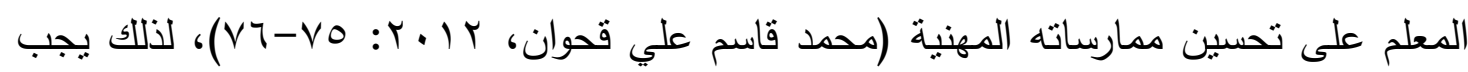

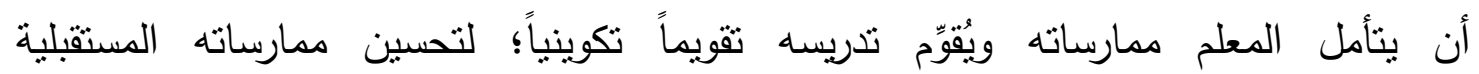

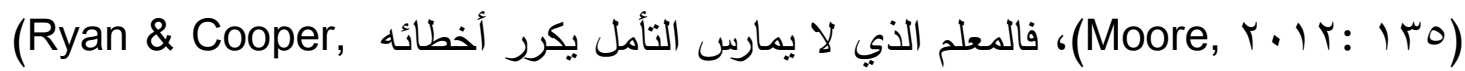

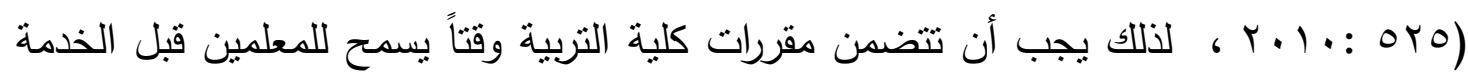

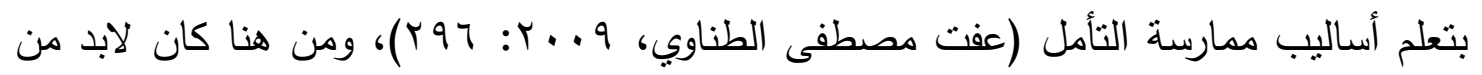
توجيه الاهتمام لتتمية مهارات التدريس التأملي لاى معلمي العلوم قبل الخدمة.

وتعتبر استراتيجية دراسة الدرس من الاتجاهات الحديثة للتطوير المهني التي ترتكز على تأملات المعلمين لتحسين الممارسات التدريسية وتعليم التناميذ بتوجيه ودعم الآخرين (فريق خبراء

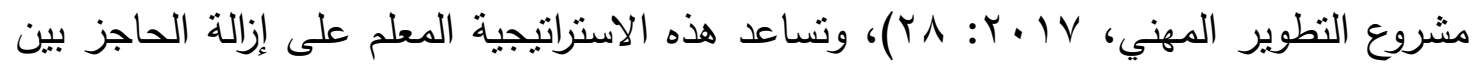

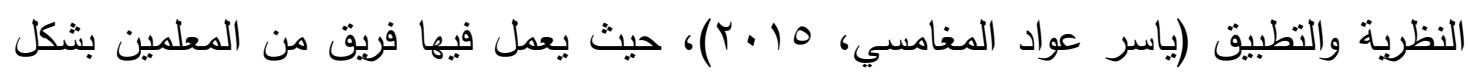

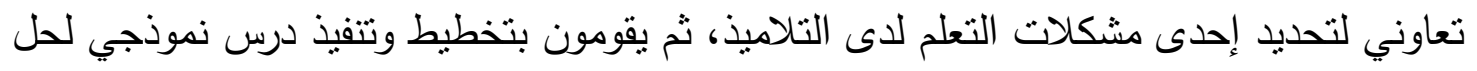


تلاك المشكلة، ويتم تتقيح الدرس من خلال الفريق نفسه، وعندما يثبت نجاح الدرس في حل

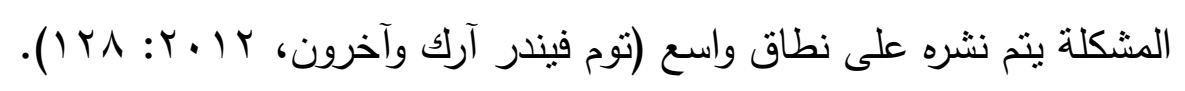

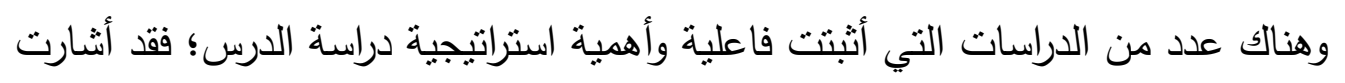

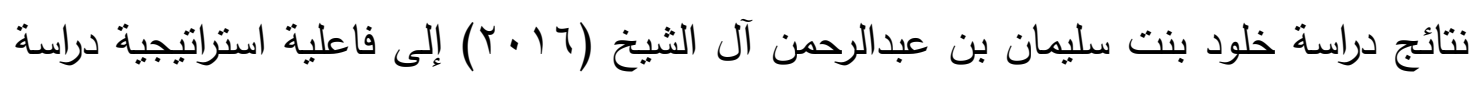

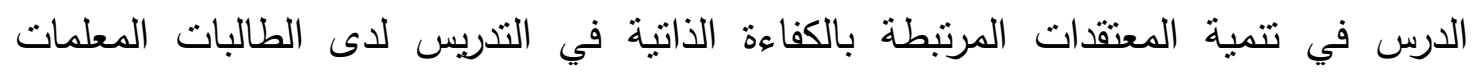

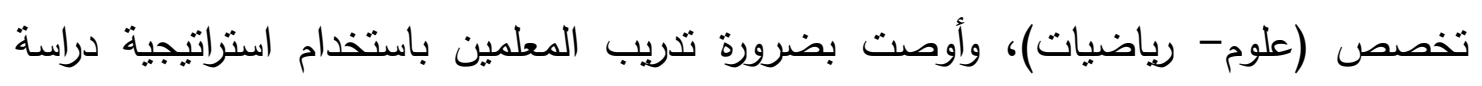

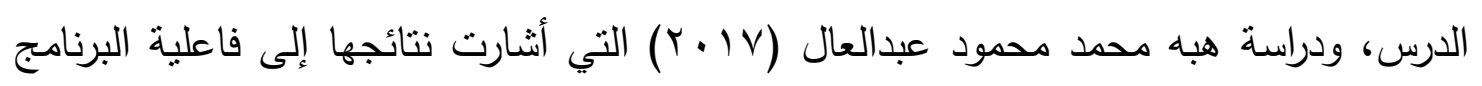

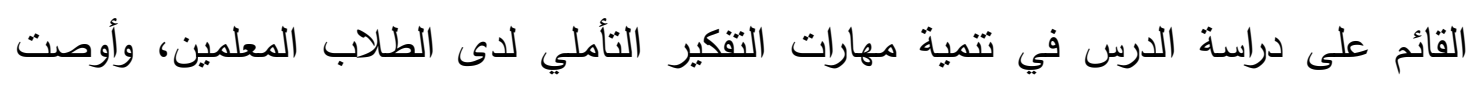

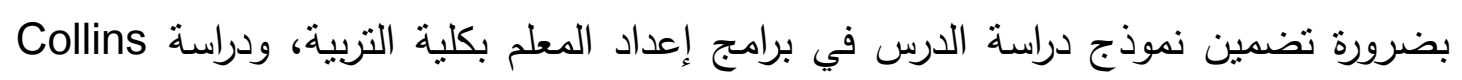

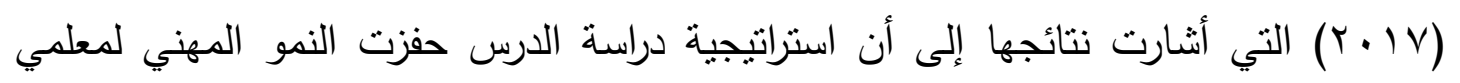

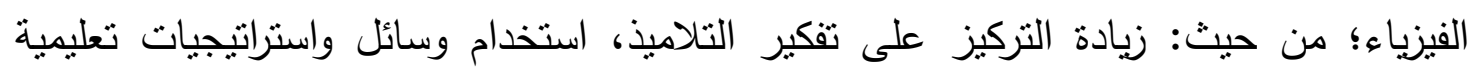

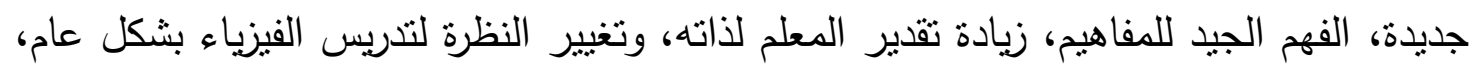

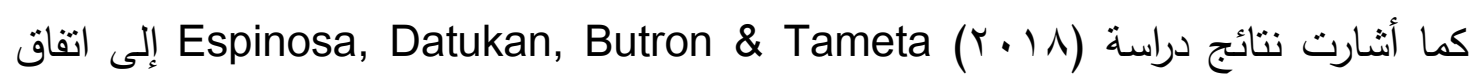
آراء معلمي الكيمياء قبل الخدمة على أن دراسة الدرس الانتاجية ثُسهم في تحسين مهارات

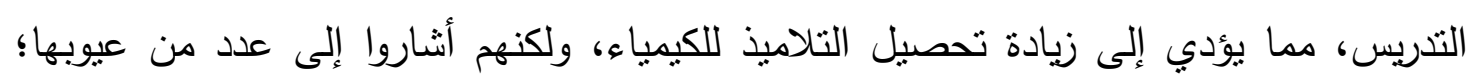

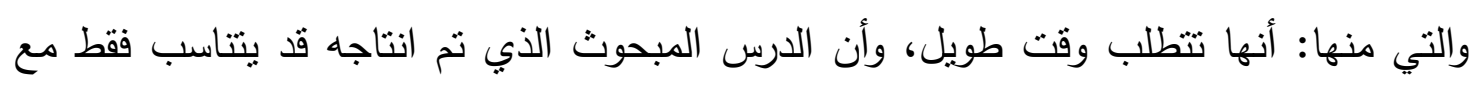

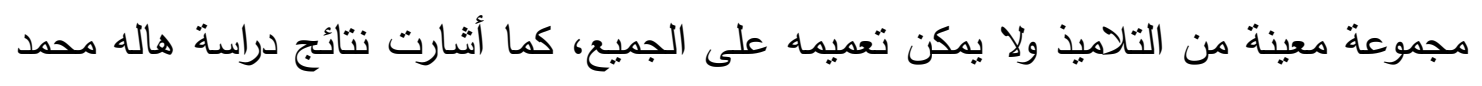

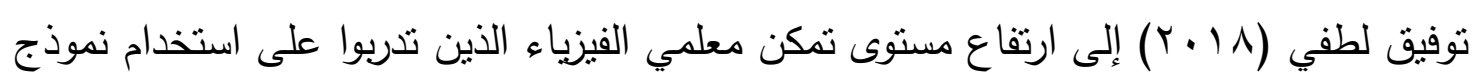

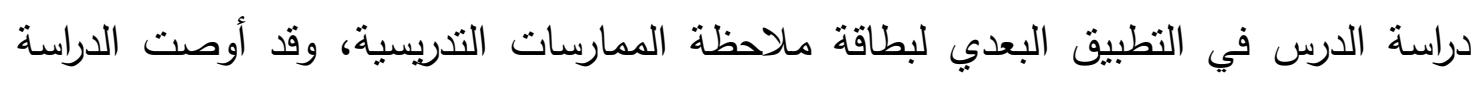

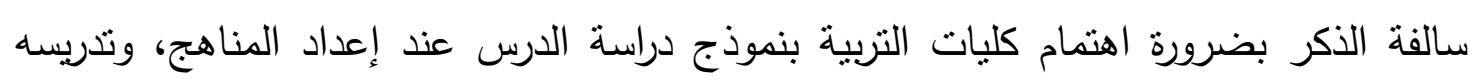
للطلاب المعلمين.

ونظراً لفاعلية استراتيجية دراسـة الدرس في تتميـة مهارات التدريس كما أنشارت نتائج

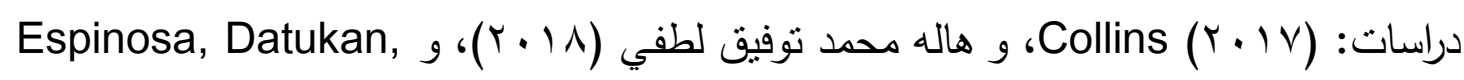

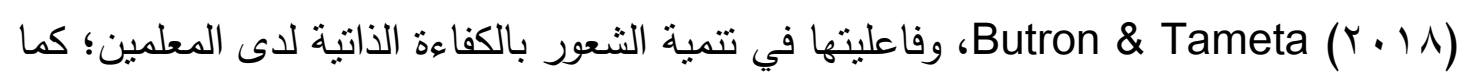

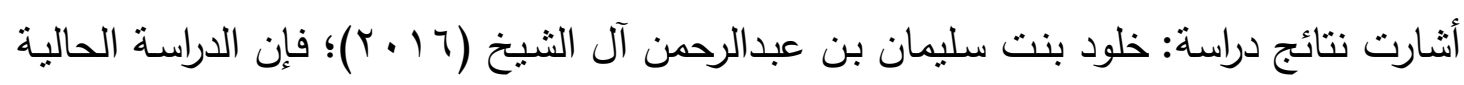

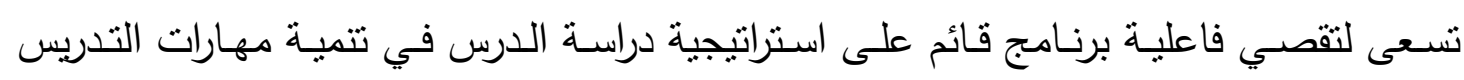
التأملي لدى معلمي العلوم قبل الخدمة. 
مشكلة الدراسة وتحديدها :- نبع الإحساس بالمشكلة من خلال:-

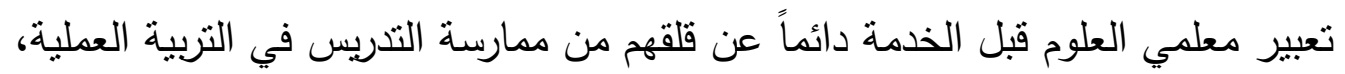

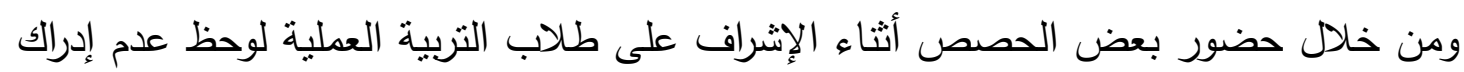
معلمي العلوم قبل الخدمة للأخطاء التي يقعون فيها أثناء التدريس، وعدم تفكيرهم في كيفية

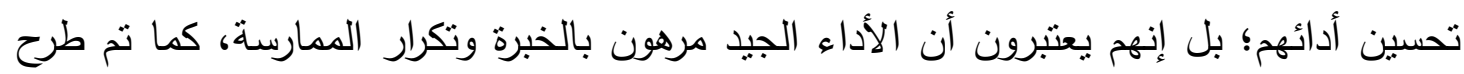
عدد من الأسئلة التي تدور حول مدى تفكيرهم في تحليل ممارساتهم التدريسية وتخطيطهم

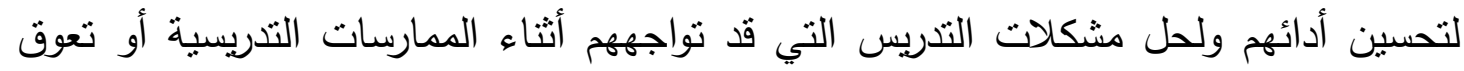
أدائهم؛ فأنشارت غالبية الآراء إلى سلبية معلمي العلوم قبل الخدمة في هذا الثنأن وعدم تفكيرهم في تقييم أو تحسين أدائهم.

كما أثنارت نتائج عدد من الدراسات إلى قصور مهارات التنريس التأملي لدى معظم

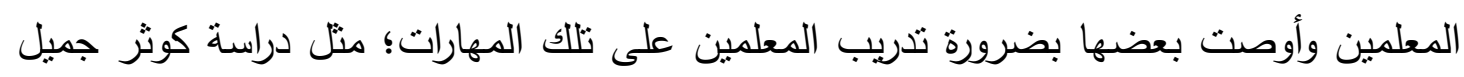

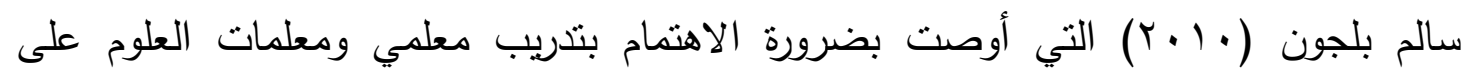

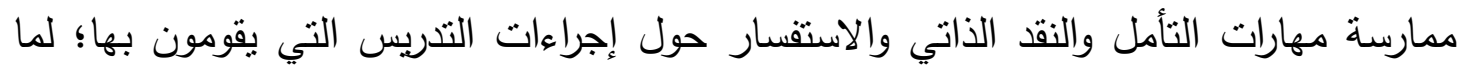

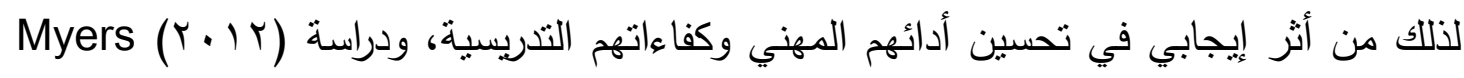
التي نم فيها تحليل كيفي لنقارير دراسة درس نمّ تقديمها بواسطة عشرين معلم من المعلمين قبل

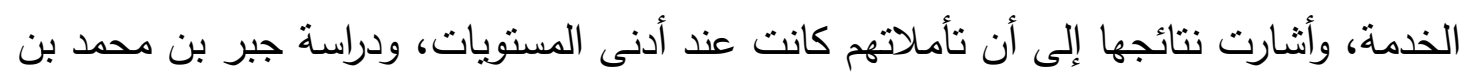

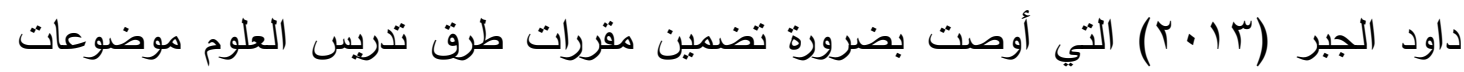

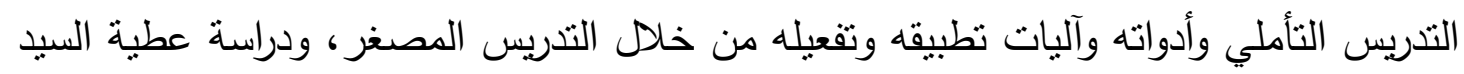

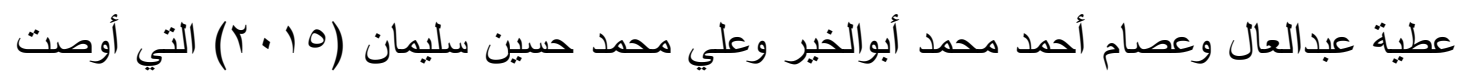

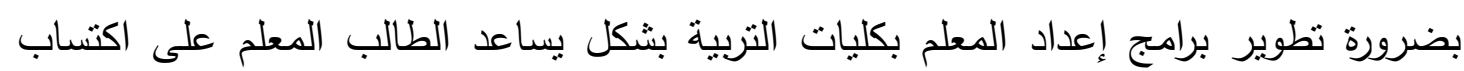

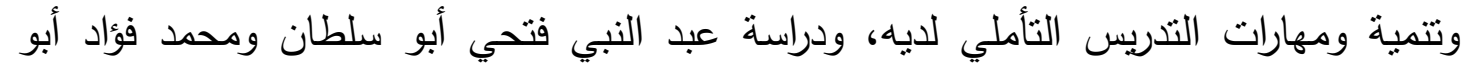

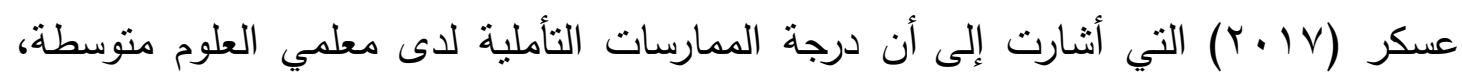

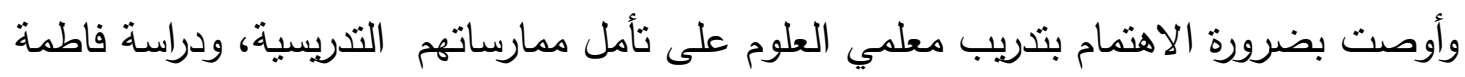

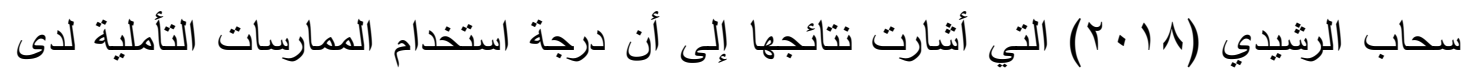

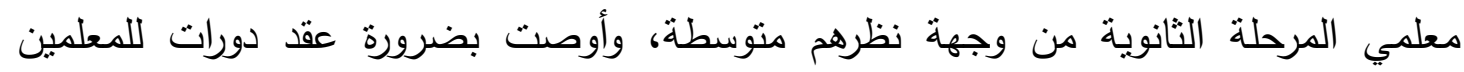
لتزويدهم بفهم أكبر للممارسات التأملية ومجالات تطبيقها، وضرورة العطل على تهئل تهيئة بيئة تعليمية محفزة للممارسات التأملية لاى المعلمين. 
يتضح من خلال العرض السابق قلة الدراسات التي حاولت تتمية مهارات التدريس

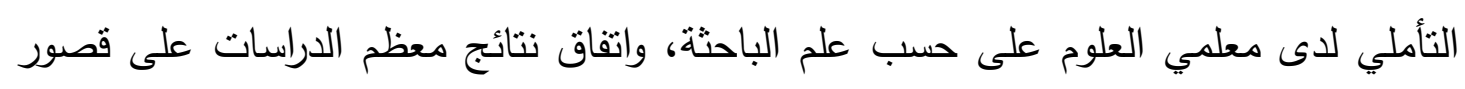
مهارات التدريس التأملي لدى معظم معلمي العلوم.

\section{من خلال العرض السابق يمكن تحديد مشكلة الدراسة في:

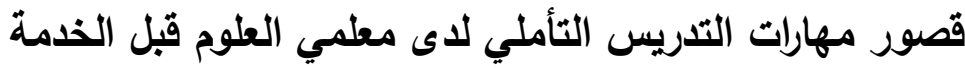

$$
\text { سؤال الدراسة:- - حاولت الدراسة الحالية الإجابة عن السؤال التالي: }
$$

- ما فاعلية برنامج قائم على استراتيجية دراسة الدرس في تتمية مهارات التدريس التأملي التئي

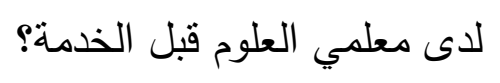

فرضا الاراسة:- تمت الإجابة عن سؤال الدراسة من خلال اختبار صحة الفرضين التاليين:

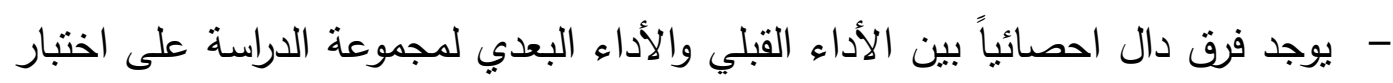

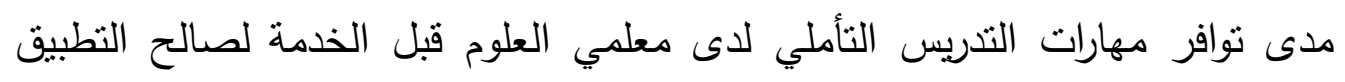

$$
\text { البعدي. }
$$

- يوجد فرق دال احصائياً بين الأداء القبلي والأداء البعدي لمجموعة الدراسة على بطاقة

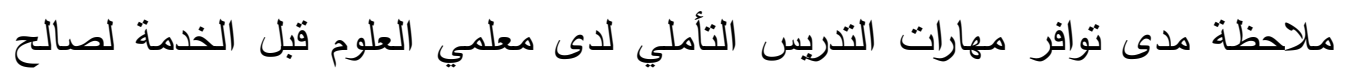
التطبيق البعدي.

محدات الاراسة:- سوف تلثزم الدراسة الحالية بالمحددات التالية:-

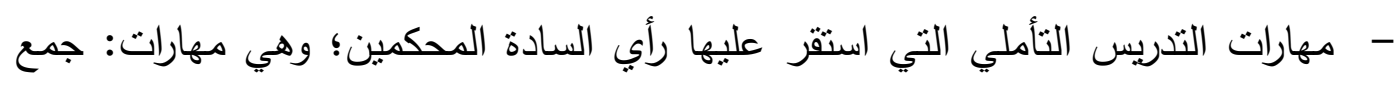

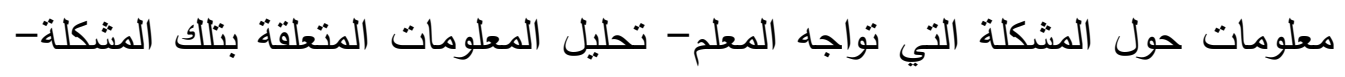
تقييم المعلومات- التأمل فيها- التخطيط لحل تلاك المشكلة- التخطيط لإدارة الأزمات

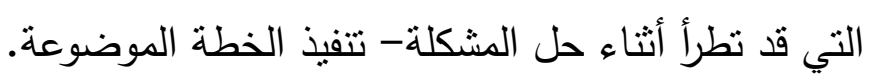
- عينة من معلمي العلوم قبل الخدمة تخصص (علوم بيولوجية وجيولوجية- فيزياءكيمياء) بكلية التربية بقنا؛ لأنهم يتعاملون مع تلاميذ في سن المراهقة (المرحلتين

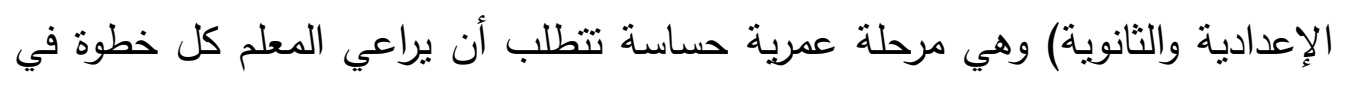

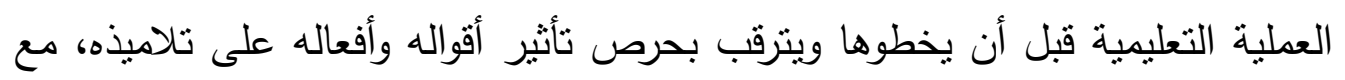

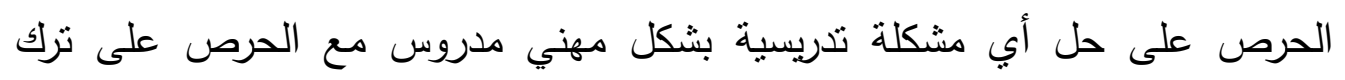
انطباعات جيدة لدى تلاميذه، لما لذلك من تأثير عليهم في تلك المرحلة السنية الدقيقة. 
- - برنامج مقترح لتنمية مهارات التدريس التأملي لدى معلمي العلوم قبل الخدمة.

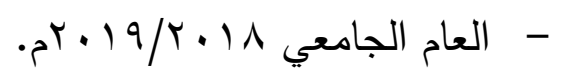

هدف الدراسة:- تهدف الدراسة الحالية إلى:

- التعرف على فاعلية برنامج قائم على استراتيجية دراسة الدرس في تتمية مهارات التدريس التأملي لاى معلمي العلوم قبل الخدمة.

أهمية الاراسة:- قد تقبد الدراسة الحالية في:

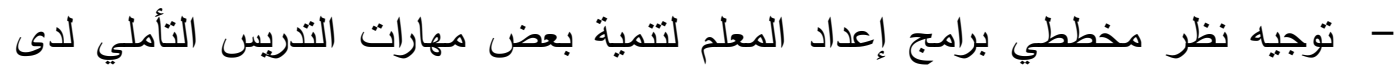

$$
\text { معلمي العلوم قبل الخدمة. }
$$

- توجيه نظر مخططي برامج إعداد المعلم لاستخدام استراتيجية دراسة الدرس عند تدريب معلمي العلوم قبل الخدمة على مهارات التدريس المختلفة.

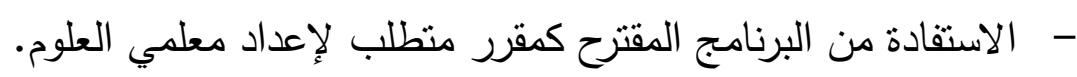

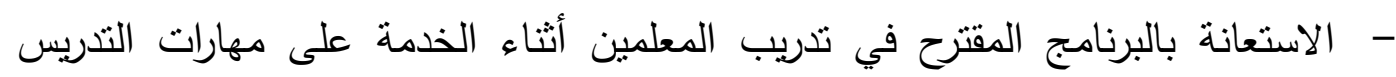
التأملي.

- توفير اختبار لمدى توافر مهارات التدريس التأملي لدى معلمي العلوم قبل الخدمة.

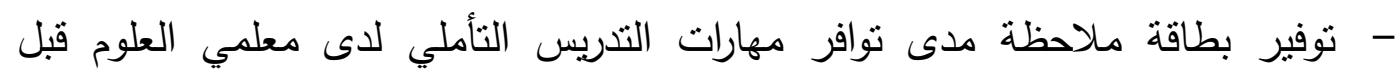
الخدمة.

منهج الدراسة:- اعتمدت الدراسة الحالية على المنهج شبه التجريبي (تصميم المجموعة الواحدة

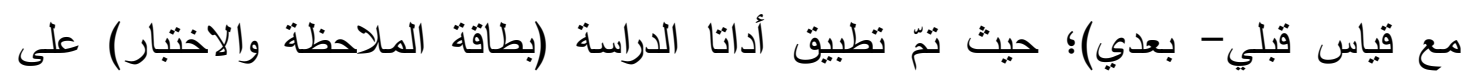
مجموعة الدراسة قبلياً، ثم تعريضها للمتغير التجريبي (تدريس البرنامج المقترح باستخدام استراتيجية دراسة الدرس) لفترة من الزمن، ثم إعادة نطبيق أداتا الدراسة على مجموعة الدراسة لإنة

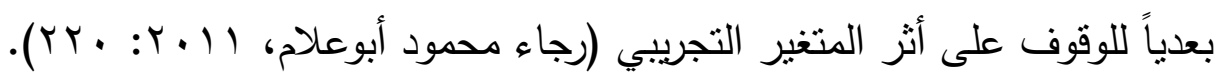

أداتا القياس:-

- بطاقة ملاحظة مدى توافر مهارات التدريس التأملي لدى معلمي العلوم قبل الخدمة. - اختبار مدى توافر مهارات التدريس التأملي لدى معلمي العلوم قبل الخدمة. 
يمكن تعريف التدريس التأملي في الدراسة الحالية إجرائياً بأنه:

مدخل استقصائي بنائي يهتم بالتدريس والحل الابتكاري للمشكلات، ويستخدم في إعداد المعلم قبل الخدمة أو تدريب المعلم أثناء الخدمة من خلال تتجيعه على التفكير حول ممارساته التدريسية بشكل تحليلي نقدي بهدف تحسينها لتحقيق أهداف معينة، وذللك من خلال المرور بخطوات تتطلب مهارة في أدائها؛ هي: جمع معلومات حول المشكلة التي نواجه المعلم- تحليل

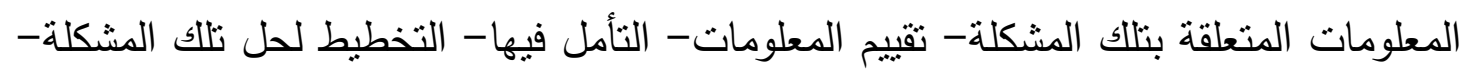

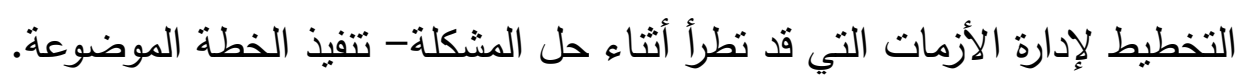

\section{استراتيجية دراسة الاربس:}

يمكن تعريف استراتيجية دراسة الدرس في الدراسة الحالية إجرائياً بأنها:

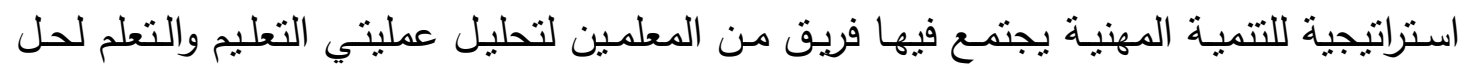

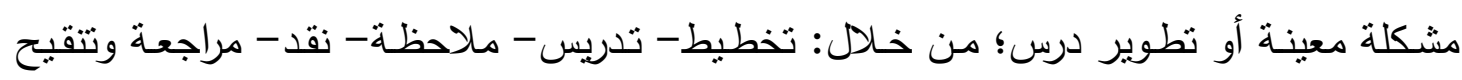

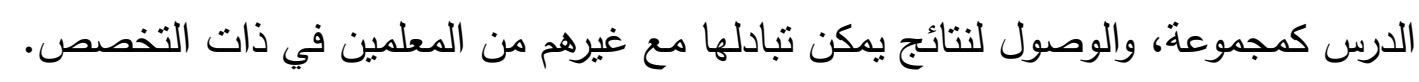

(**) تمّ التوصل للتعريف الإجرائي لمصطلحي الدراسة بعد تحليل ومراجعة التعريفات الواردة لهما في الإطار النظري 


\section{استراتيجية دراسة الدرس ودورها في تتمية مهارات التدريس التأملي \\ لاى معلمي العلوم قبل الخدمة}

تعريف التدريس التأملي:

وهناك عدة تعريفات للتدريس التأملي منها؛ تعريفه بأنه أحد توجهات إعداد المعلم؛ وفيه

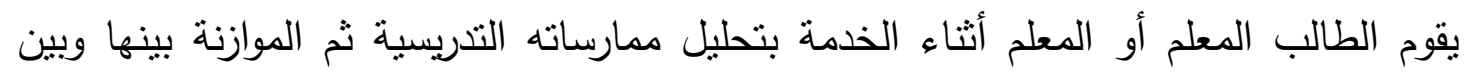

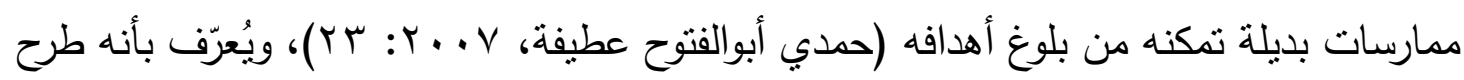

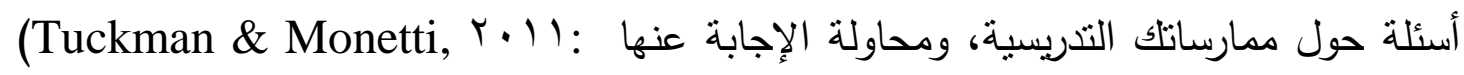
( V) وهو تقكير المعلم بشكل تحليلي نقدي لممارساته التدريسية بهدف تحسينها (عبدالسلام

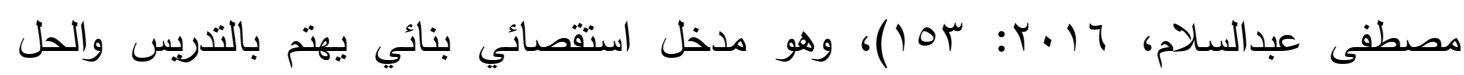

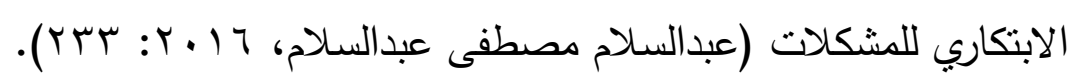

يتضح من خلال العرض السابق لتعريفات التدريس التأملي بأنه يصلح كمخل لإعداد

المعلم قبل الخدمة أو لتندريب المعلم أثناء الخدمة، ويستهدف تناول الممارسات التنريسية بالتحليل والنقد لتحسينها أو للتوصل لحلول ابتكارية للمشكلات التي قد تعترض العملية التدريسية.

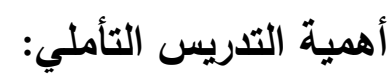

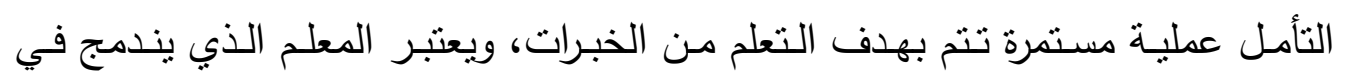

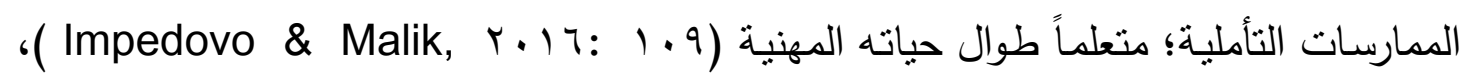
ويساعد التأمل المعلم على: اتخاذ قرارات شجاعة لتغيير بعض ممارساته التدريسية، وتحديد

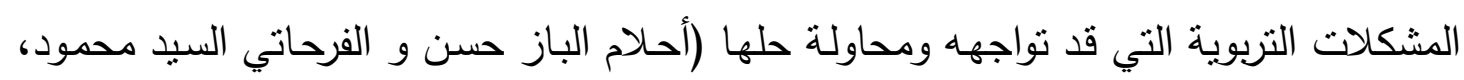

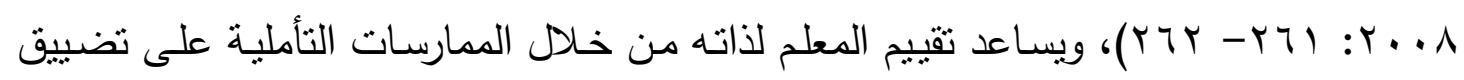

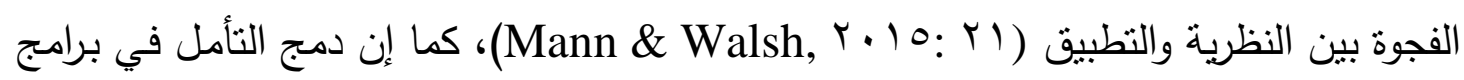

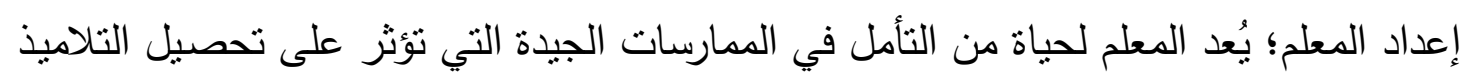

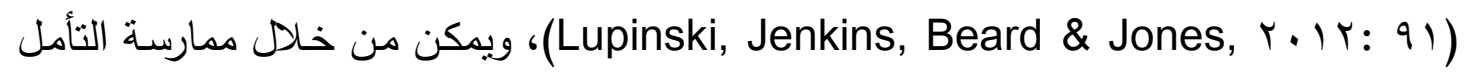

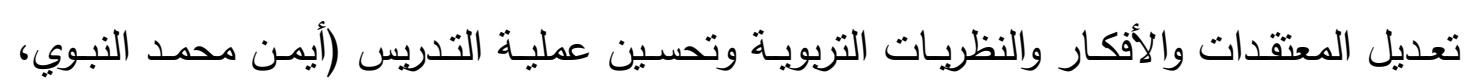

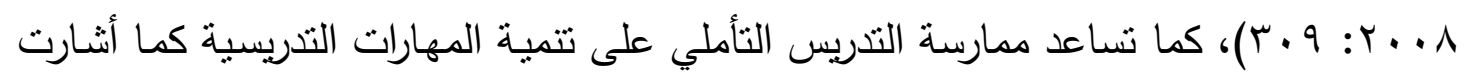

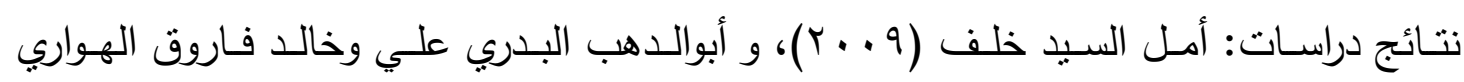
$\cdot(r \cdot I V)$ 
يُستخلص مما سبق أهمية التدريس التأملي من عدة نواحي؛ منها: زيادة الاستفادة من

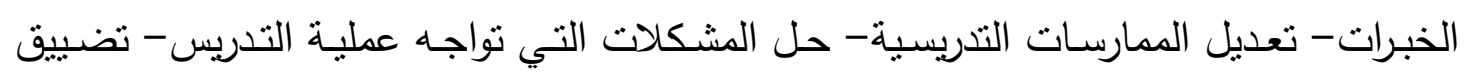
الفجوة بين النظرية والتطبيق - تتمية مهارات التدريس.

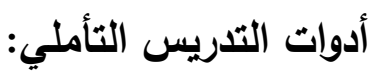

هناك عدد من الأدوات التي يستخدمها المعلم بغرض التأمل؛ منل:

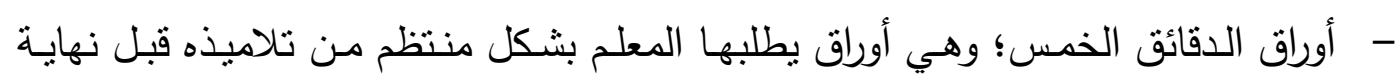

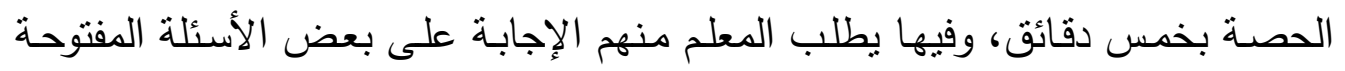

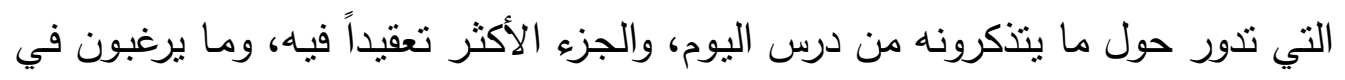

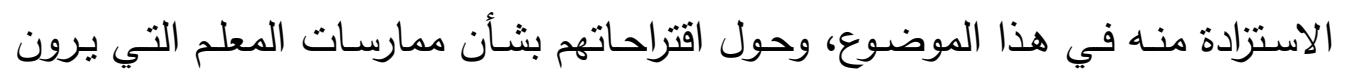
حاجتها للتحسين، وذلك بدون كتابة التلميذ لاسمه فيها.

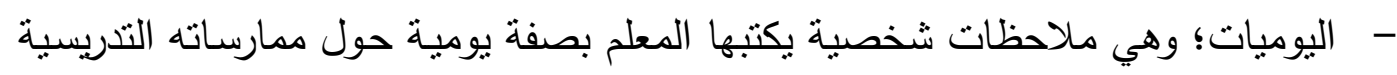

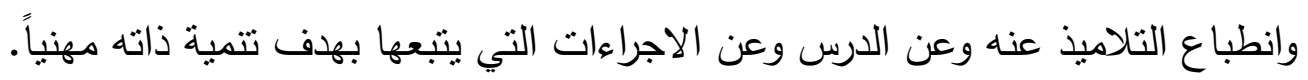

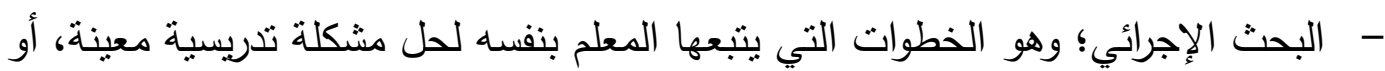

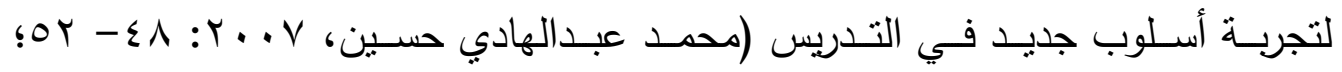

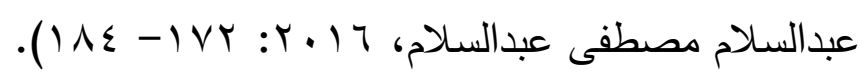

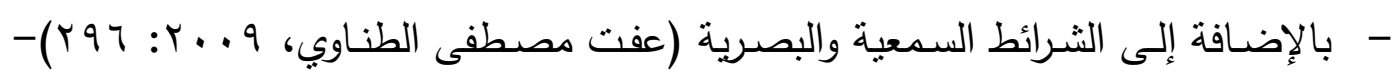

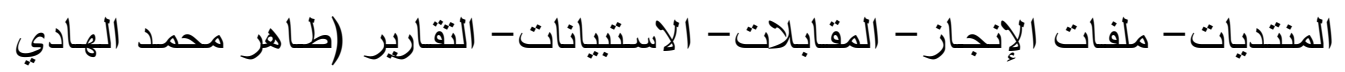

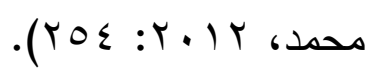

من خـلال مـا سبق يتضـح أن عمليـة التأمل قد تفقد قيمتها إذا اقتصرت على العدل

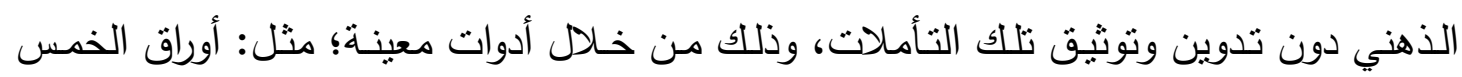

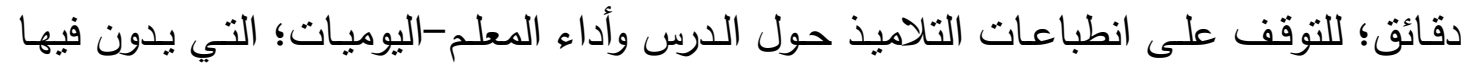

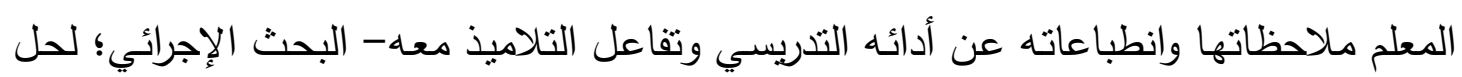
مشكلة تدريسية معينة- التسجيل السمعي والبصري-.... وغيرها.

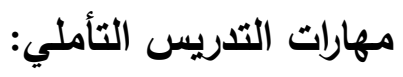

تتمثل مهارات التدريس التأملي في: تحديد مشكلات الممارسـة الصفية- مناقثـة

الافتراضـات والقيم المتضمنة في التدريس - ممارسـة التدريس وفقاً للتقافـة السـائدة ببيئة

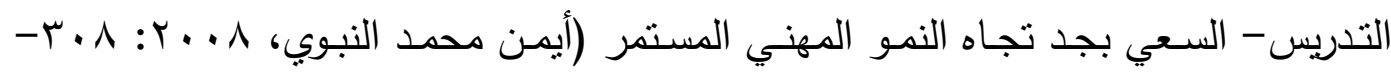




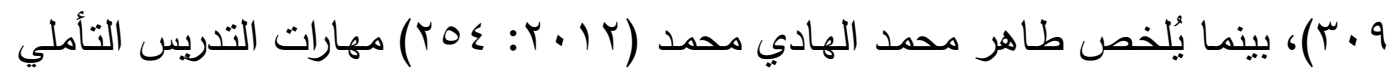

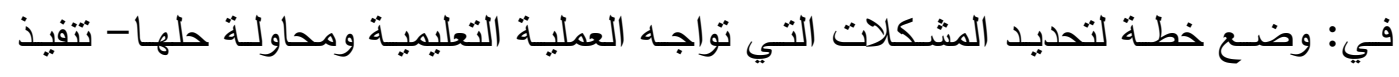
الخطة- مراجعة الخطة وتعديلها من وقت لآخر والتعلم من الخبرات اليومية.

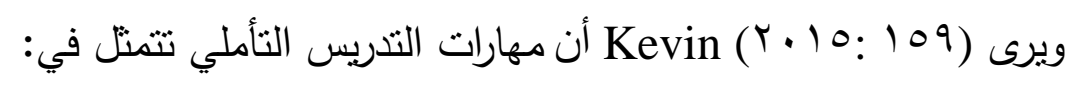

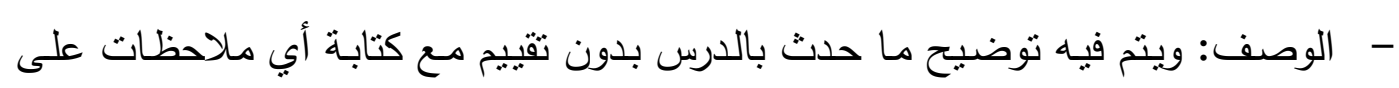

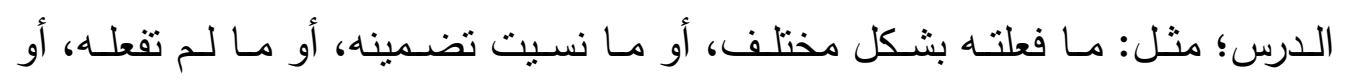

$$
\text { المشكلات التي واجهتها، أو أي شيء حدث بشكل يختلف عما كنت تنوقع. }
$$

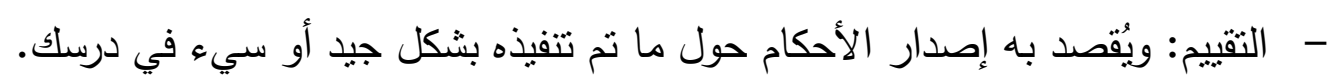

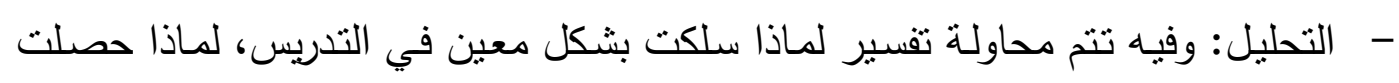

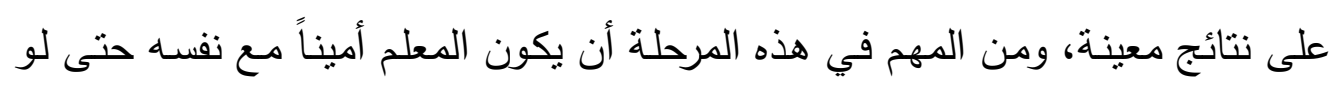
كان ذلك غبر مريح له. - الاقتراحات: وفي هذه المرحلة يحاول المعلم اقتراح أعمال أخرى، خطط عمل، أهداف لتحسين الذات.

وقد تمت الاستفادة من العرض السابق في إعداد قائمة بمهارات التدريس التأملي الواجب توافرها لدى معلمي العلوم قبل الخدمة، والتي تمنتات في المهارات التالية:

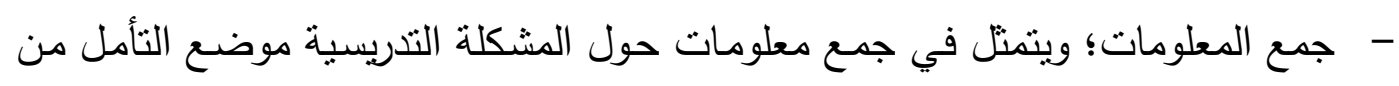
مصادر المعلومات المتعددة، أو من الزملاء أو الخبراء.

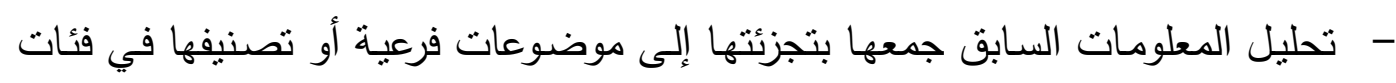
وفقاً لفاعليتها في حل المشكلة. - تقييم المعلومات من حيث مدى ارتباطها بالمشكلة موضع التأمل، ومدى مصداقيتها، ومدى تضارب المعلومات الواردة من مصادر مختلفة أو تطابقها.

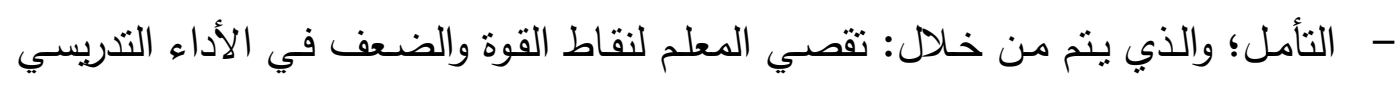

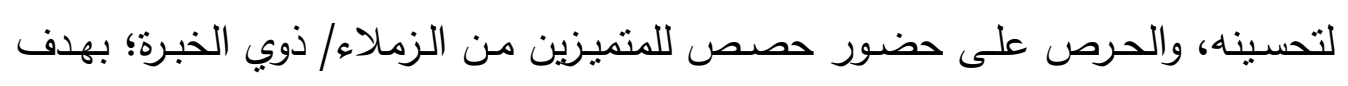

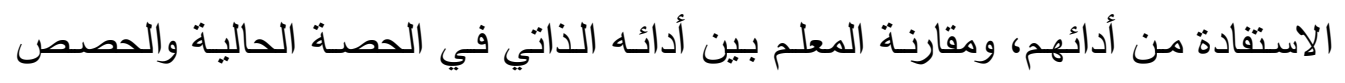

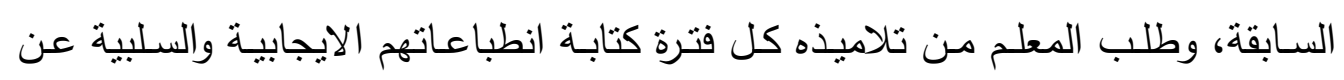

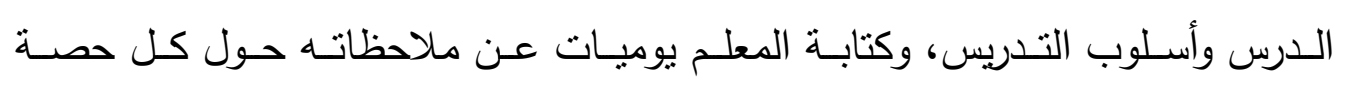

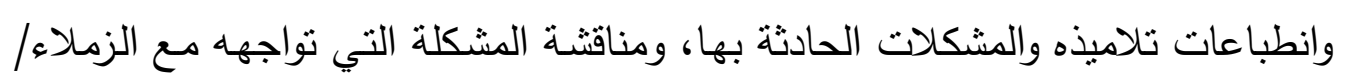
ذوي الخبرة. 
- التخطيط؛ ويقوم بـه المعلم باستمرار لتلاشي نقاط ضـففه وتعزيز نقاط قوته، والحرص

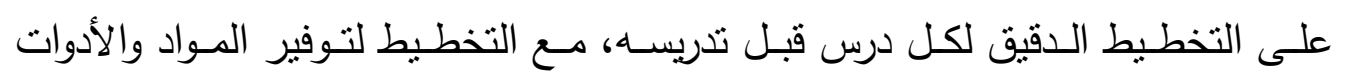
والأجهزة التي قد تعينه على تحقيق أهدافه، وتصميم تصور متكامل لحل المشكلة.

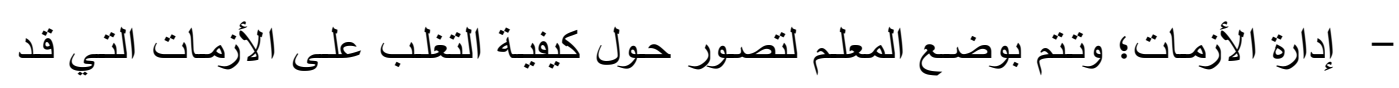

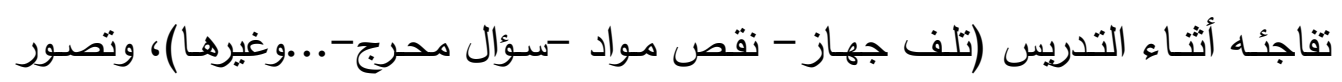
لردود فعل التلاميذ المختلفة تجاه كل موقف تعليمي.

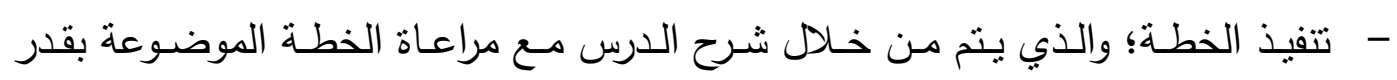

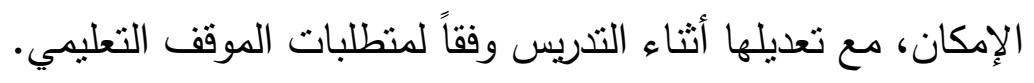

تعريف استراتيجية دراسة الدرس: وهناك عدة تعريفات لاستراتيجية دراسـة الدرس منها؛ أنها استراتيجية للتتميـة المنيـة دوراتية

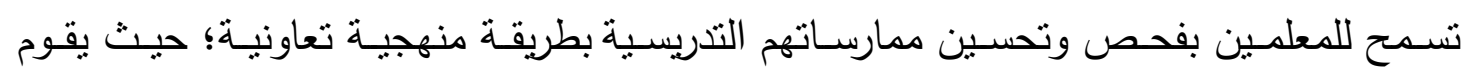
المعلمون بدراسـة الدرس معاً من خـلال: تخطيط- تدريس - ملاحظة- نقد - مراجعة وتتقيح

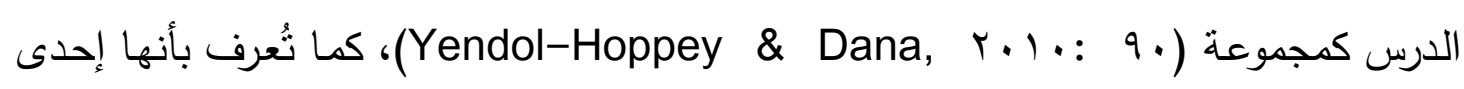
أثكال التتمية المهنية للمعلم؛ وفيها يجتمع فريق من المعلمين لتحليل عمليتي التعليم والتعلم لحل

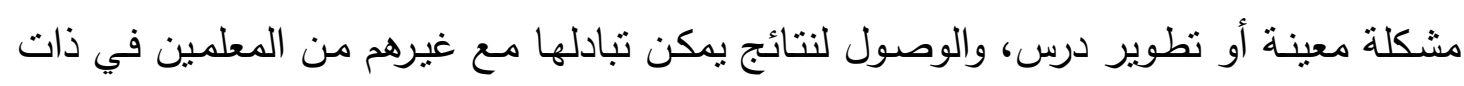

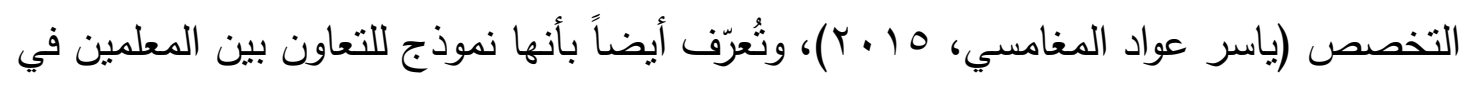

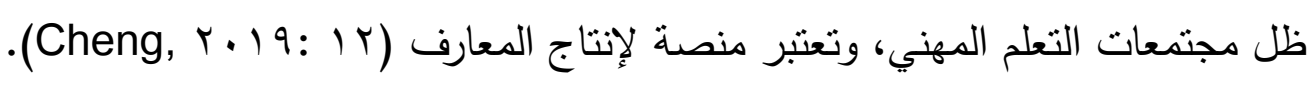

يتضـح من خـلال العرض السـابق اتفـاق تعريفات استراتيجية دراسـة الدرس على أنها

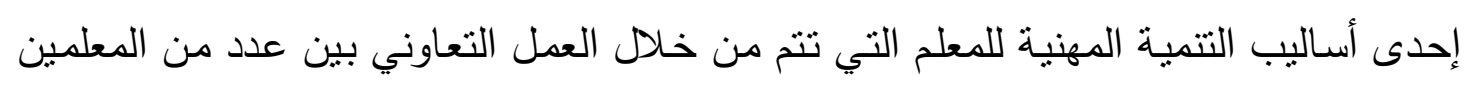
للوصول إلى معلومات جديدة لنطوير أحد الدروس أو لحل مشكلة تدريسية معينة.

\section{أهمية استراتيجية دراسة الدرس:}

تساعد استراتيجية دراسة الدرس على زيادة دافعية المعلمين لتحسين ممارساتهم التدريسية

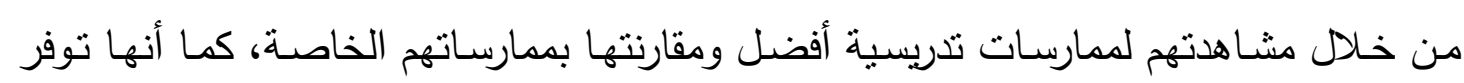

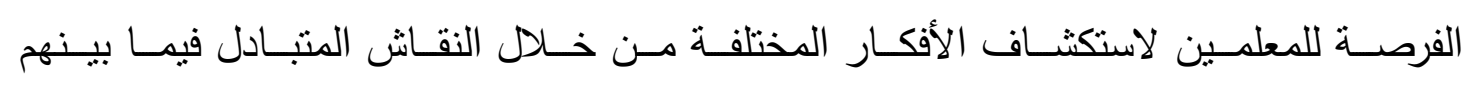
(Doig \& Groves, r. I) : Av)

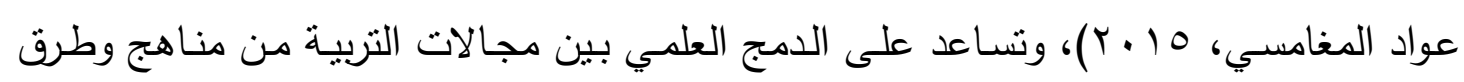

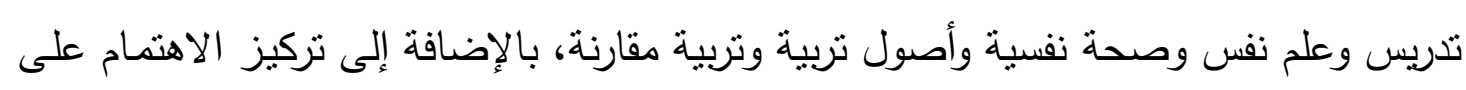




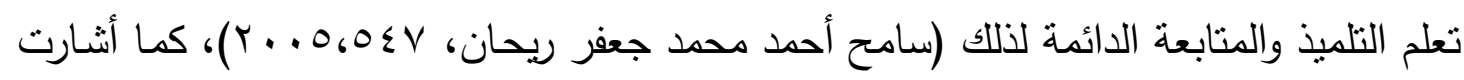

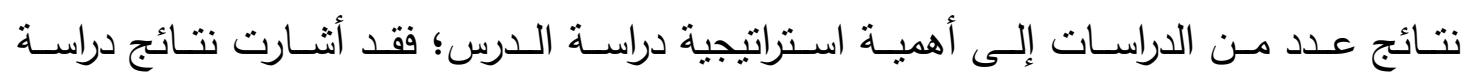

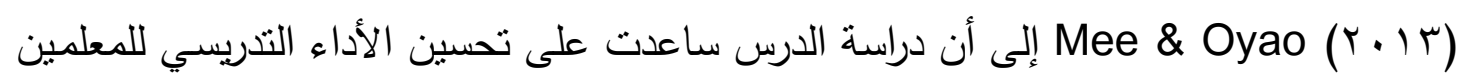

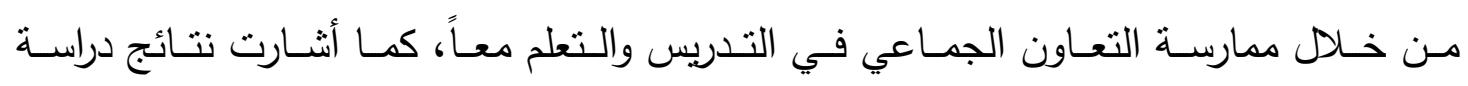

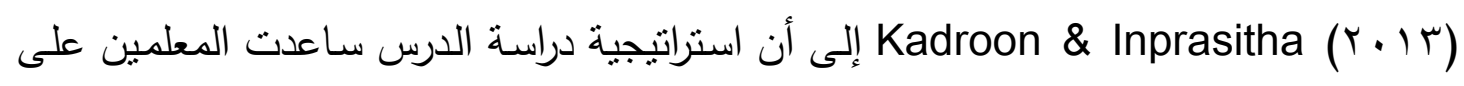

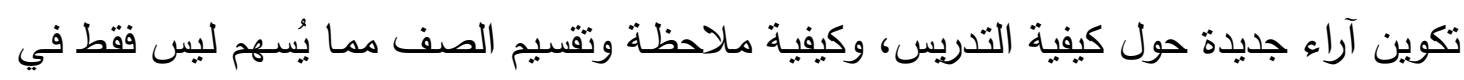

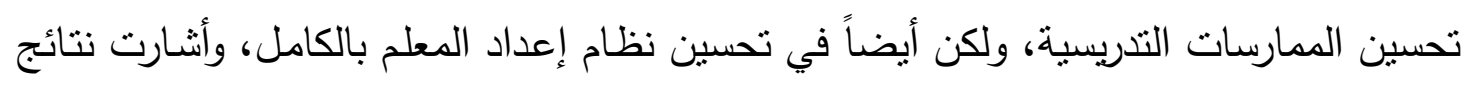

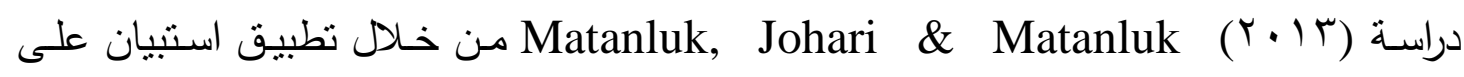
المعلمين؛ إلى أن استخدام دراسة الدرس قدم للمعلمين معلومات جديدة في مجال طرق التدريس

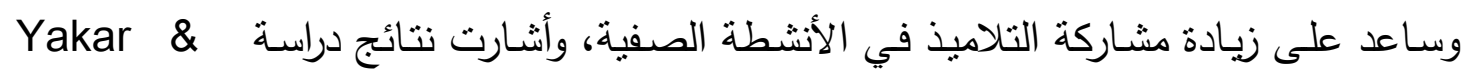
Turgaut (Y. lV)

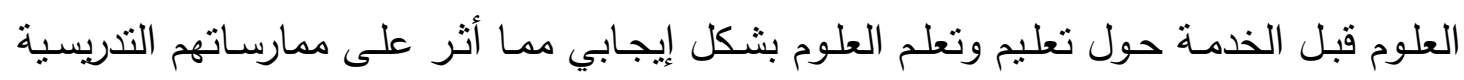

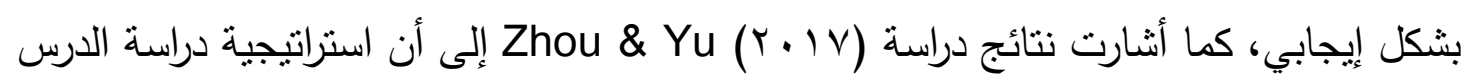

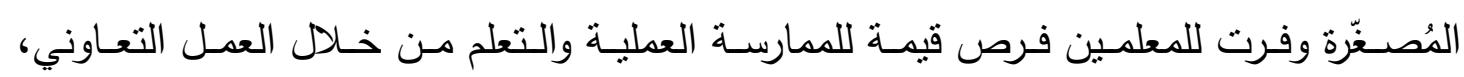

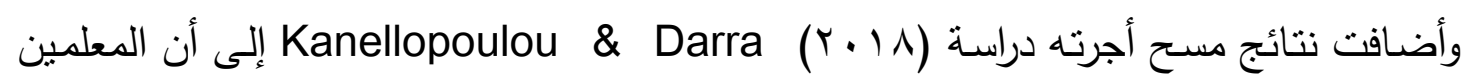

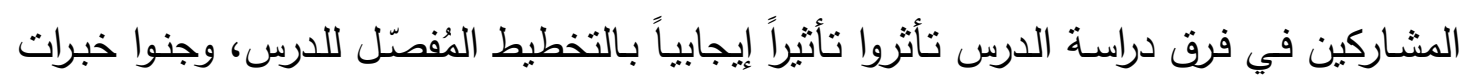

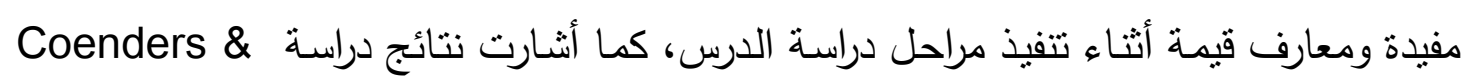

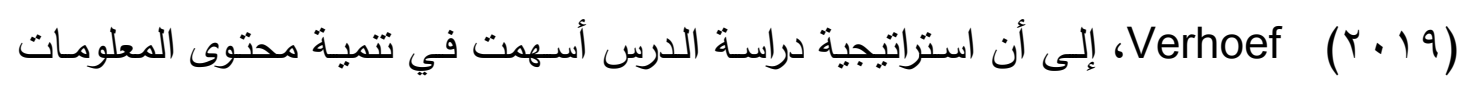

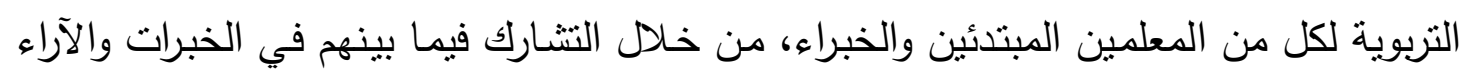

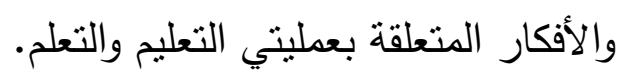

يُستخلص مما سبق أن لاستراتيجية دراسة الدرس أهمية كبرى؛ تتمثل في أنها: نساعد

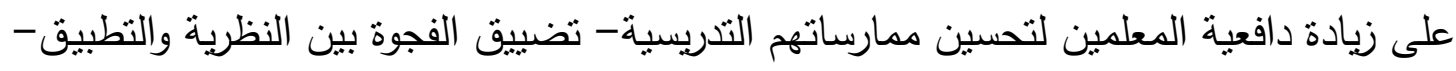

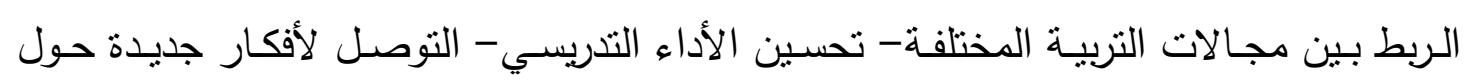

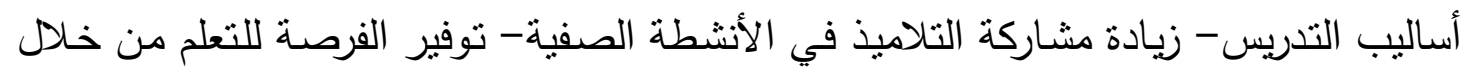

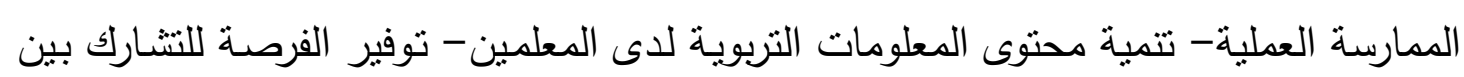
المعلمين في الخبرات والأفكار المرتبطة بعمليتي التعليم والتعلم. 


\section{خطوات استراتيجية دراسة الدرس:}

تسير استراتيجية دراسة الدرس؛ وفقا للخطوات التالية: في البداية يجتمع فريق يتكون من (T-7) معلمين؛ وعادة يتغير أفراد الفريق من عام لآخر لتوفير فرص جديدة للتعاون مع مختلف

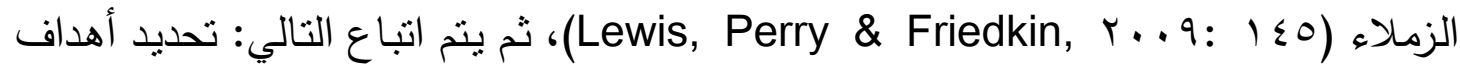
بعيدة المدى لتعلم التلاميذ- تخطيط، تتفيذ، ملاحظـة الدرس موضـع الدراسـة، بشـكل يحقق الأهداف بعيدة المدى السابق تحديدها- الملاحظة الدقيقة لتعلم التلاميذ واندماجهم وسلوكهم أثثاء

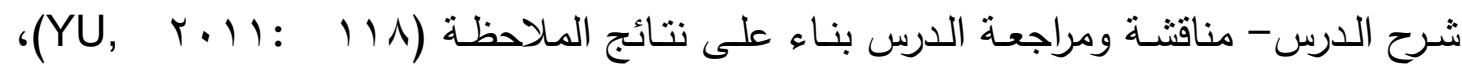
وتُضاف للخطوات السابقة: مراجعة خطة الدرس - تدريس النسخة المُنقِّة من الدرس- مشـاركة

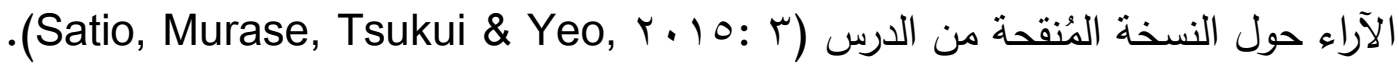

وبشكل أكثر تفصيلاً؛ تتم استراتيجية دراسة الدرس وفقاً للخطوات التالية: ا ـ تحديد المشكلة: وفيها يتم تحديد المشكلة التي تواجه فريق دراسة الدرس.

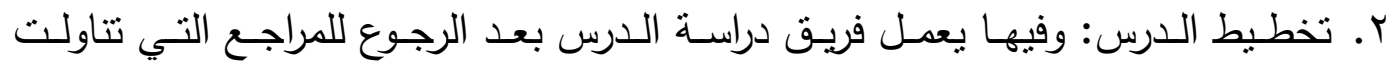
المشكلة، على تخطيط الدرس مع الاستعانة بخبراتهم الثخصية. ب. تتفيذ وتجربـة الدرس: حيـث بتطوع أحد أفراد فريـق دراسـة الدرس لتتفيذ الدرس بأحد الفصول في حضور بـاقي أفراد الفريق الذين يقومون بتدوين ملاحظاتهم حول الدرس وأداء التلاميذ، ويمكن تصوير فيديو للشرح للرجوع إليه فيما بعد عند التحليل والمناقنة. ع. تقويم الدرس: وتتم هذه الخطوة عقب التنفيذ لتوضيح نقاط الضعف التي لوحظت. ه. تتقيح الدرس: وفيه يتم تعديل تخطيط الدرس في ضوء ما ظهر من ملاحظات. 7 ـ تدربس الدرس المُعدّل: وفيه يتم تتفبذ الدرس المُعدّل في فصل آخر بواسطة معلم آخر , V. تقويم وتتقيح الدرس المُعدّل: وتتم فيه مناقنة ما لوحظ أثتاء التتفيذ للوصول إلى الصورة النهائية للارس. ^. مشـاركة النتائج: وفيها يتت نشر ما توصلت إليه المجموعة على باقي المعلمين (ياسر

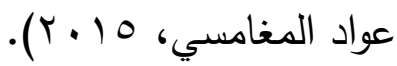

وقد تمّت الاستفادة من الخطوات السـابقة عند التخطيط لبرنـامج قائم على استراتيجية دراسة الدرس لتتمية مهارات التدريس التأملي لدى معلمي العلوم قبل الخدمة. 


\section{العلاقة بين استراتيجية دراسة الدرس وتنمية مهارات التدريس التأملي:}

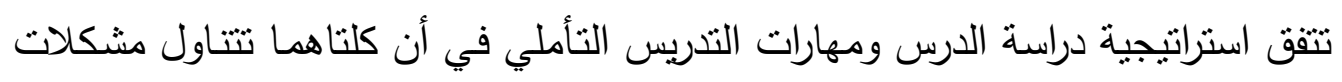

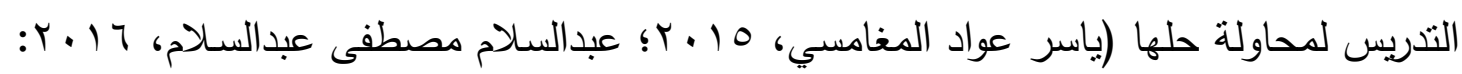

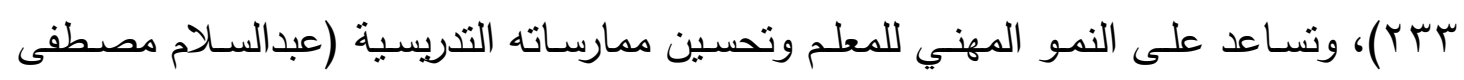

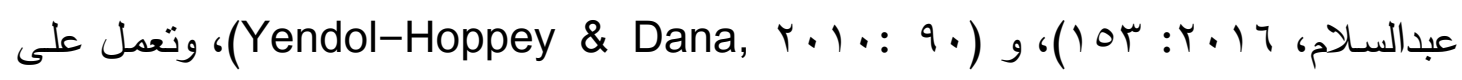

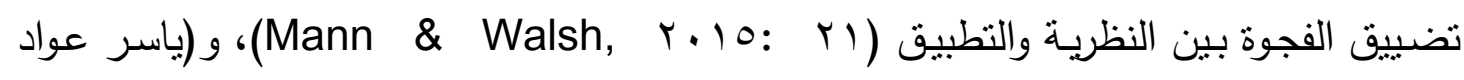

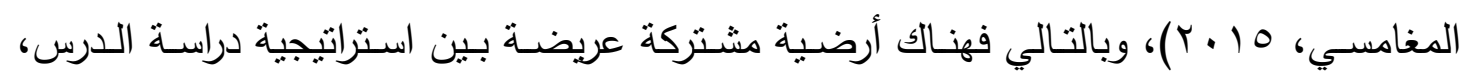

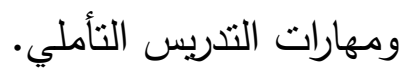

كما يساعد استخدام استراتيجية دراسـة الدرس على تتمية مهارات التفكير التأملي كما

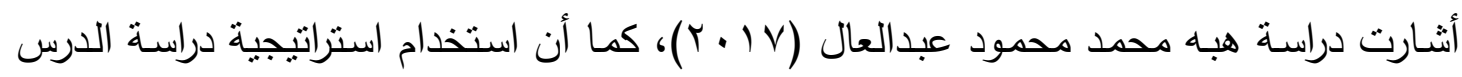

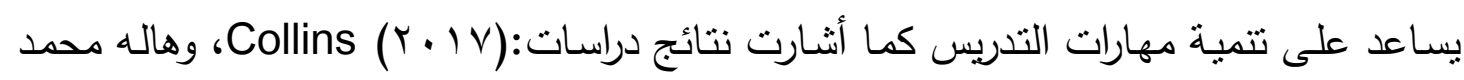

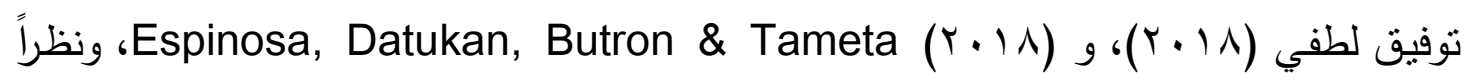
لأن مهارات التدريس التأملي تساعد على تحسين الممارسات التدريسية، وتتمية مهارات التفكير التأملي إذا فقد يمكن تتمية مهارات التدريس التأملي باستخدام استراتيجية دراسة الدرس.

كمـا إنه من خـلال استراتيجية دراسـة الدرس يتعلم المعلمون السؤال حول كيفية تعلم

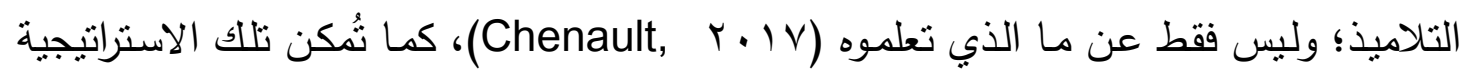
المعلمين من الحصول على تغذية راجعة من الزملاء من خلال النصائح والتشجيع الذي ينالوه،

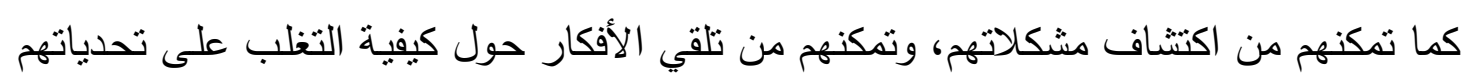

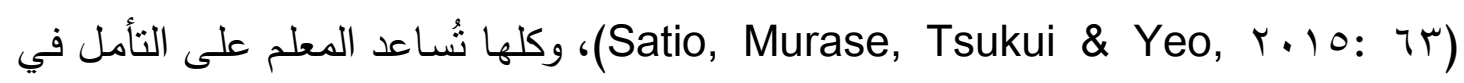

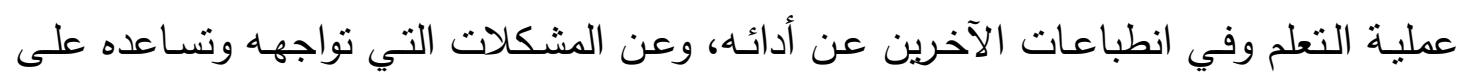

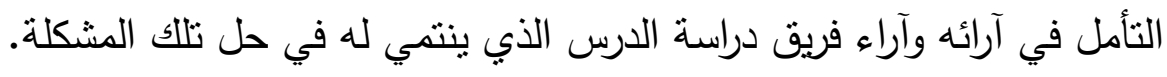

\section{إجراءات الاراسة:-}

للإجابة على سؤال الاراسة، والتحقق من صحة فرضيها؛ تثمّ اتباع الإجراعات التالية:

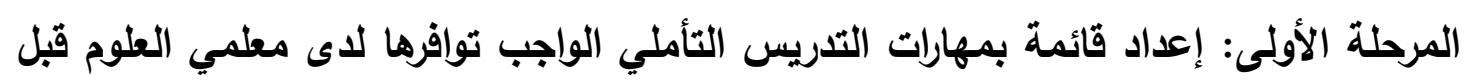

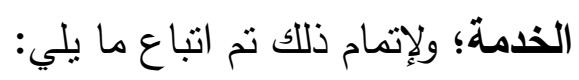
أولاً: الاطلاع على المراجع والدراسات السابقة التي تتاولت مهارات التدريس التأملي. 
ثانياً: إعداد قائمة مبدئية بمهارات التدريس التأملي الواجب نوافرها لدى معلمي العلوم قبل الخدمة، ولتحقيق هذه الخطوة تمّ اتباع التالي: م تحديد الهدف المرجو من قائمة بمهارات التدريس التأملي الواجب نوافرها لدى معلمي العلوم قبل الخدمة (تتمية مهارات التدريس التأملي لديهم). م تحديد مهارات التدريس التأملي الواجب توافرها لدى معلمي العلوم قبل الخدمة.

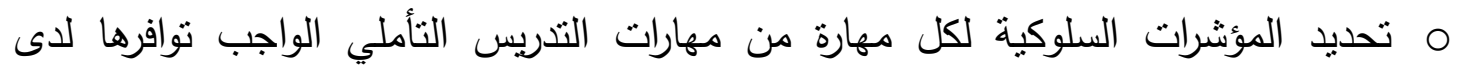
معلمي العلوم قبل الخدمة.

ثالثاً: عرض القائمة على مجموعة من السادة المحكمين؛ لاستطلاع رأيهم حول صلاحية القائمة، وطلب من كل منهم إبداء الرأي حول مدى ارتباط المهارات المقترحة بمهارات التدريس التأملي، التهاء ومدى مناسبة المهارات المقترحة لمعلمي العلوم قبل الخدمة، ومدى مناسبة المؤشرات السلوكية إنبات

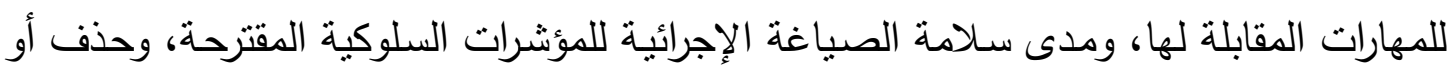

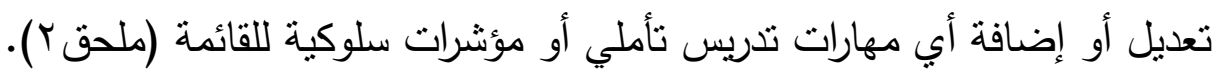

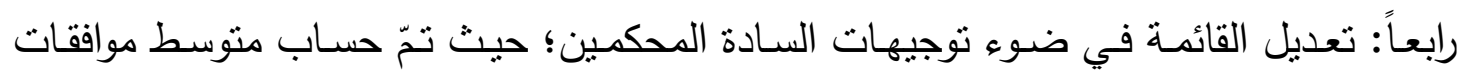

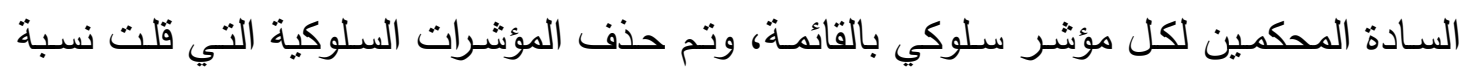

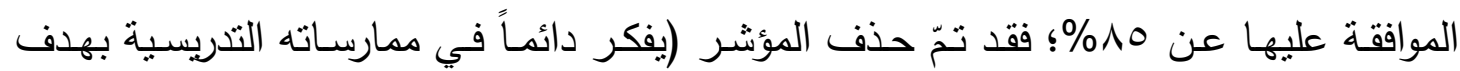

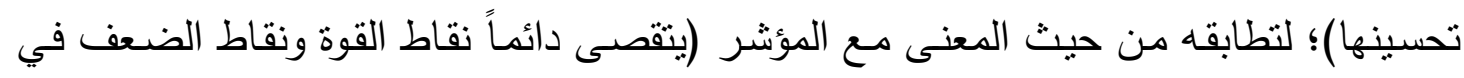

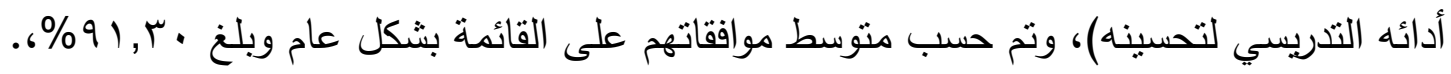

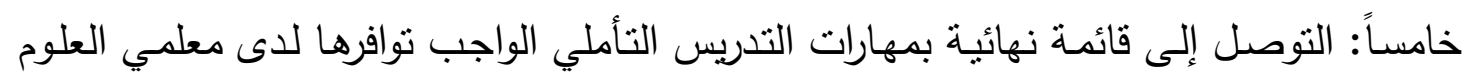
قبل الخدمة (ملحق امب).

المرحلة الثانيـة: إعداد اختبار مدى توافر مهارات التدريس التأملي لاى معلمي العلوم قبل

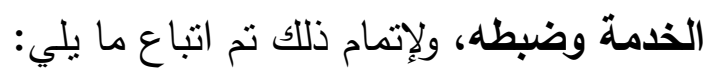

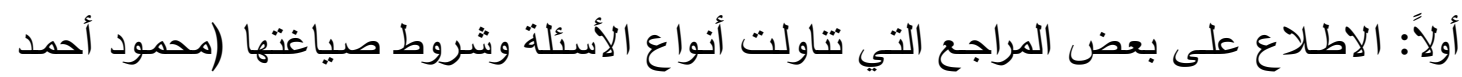

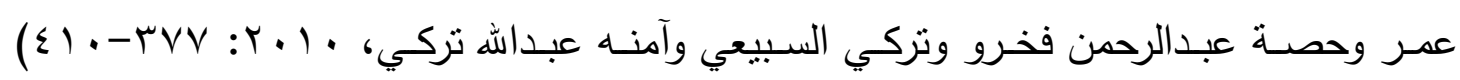

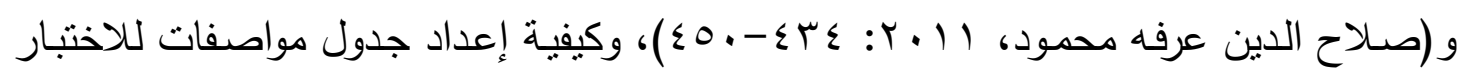

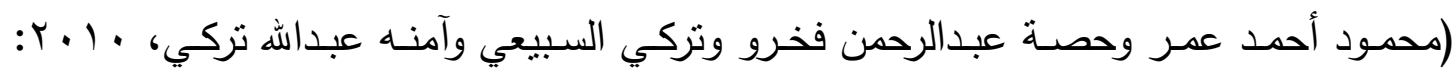

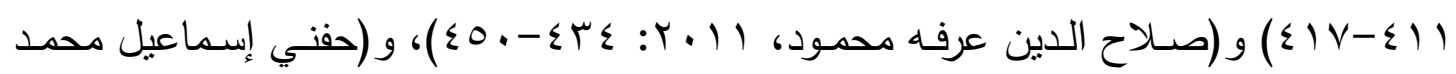

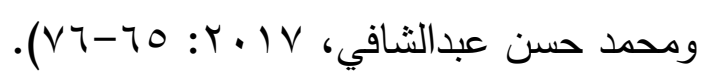

ثانياً: تحديد الهدف من الاختبار ؛ الذي يتمثل في قياس مدى توافر مهارات التدريس النأملي لدى لدى معلمي العلوم قبل الخدمة. 
ثالثاً: صياغة مفردات الاختبار ؛ فمن خلال المؤشرات السلوكية لمهارات التدريس التأملي الواجب

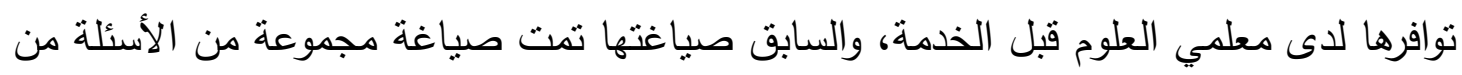
نوع الاختبار من متعدد، وأسئلة الصواب والخطأ، بحيث تتم الإجابة عنها في نفس ورقة الخئة الأسئلة،

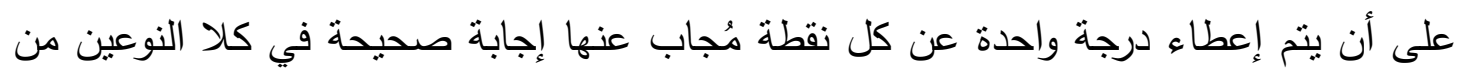
الأسئلة.

رابعاً: تحديد وصياغة تعليمات الاختبار.

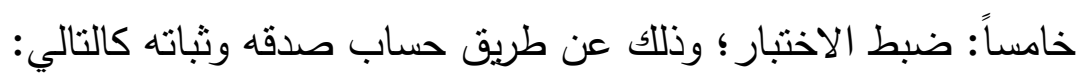

\section{- - حساب صدق الاختبار:}

الاختبار الصادق هو الذي يقيس ما وضع لقياسه، وللتأكد من صدق الاختبار تمّ استخدام

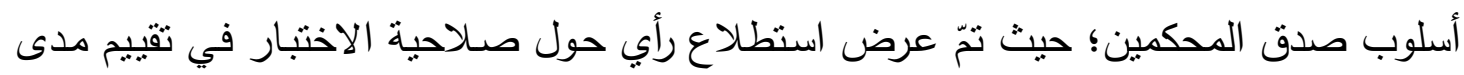

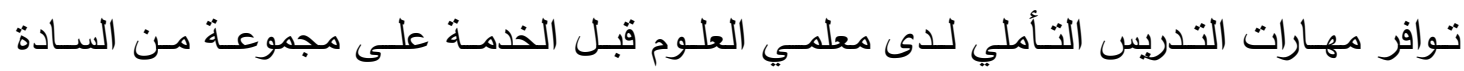

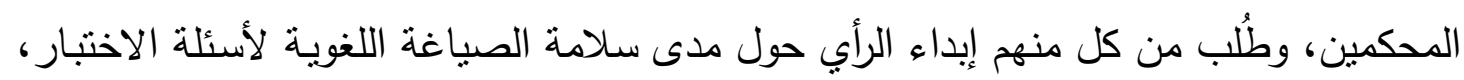

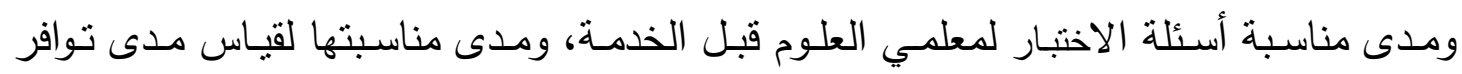
مهارات التدريس التأملي لاى معلمي العلوم قبل الخدمة، وحذف أو تعديل أو إضافة أبي أسئلة

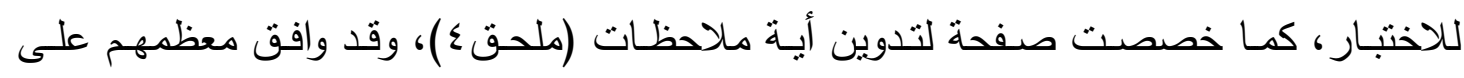

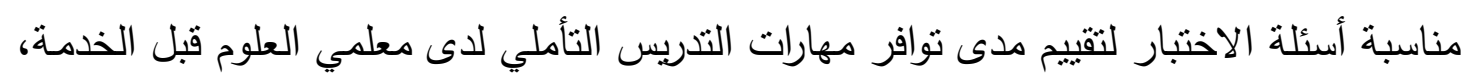

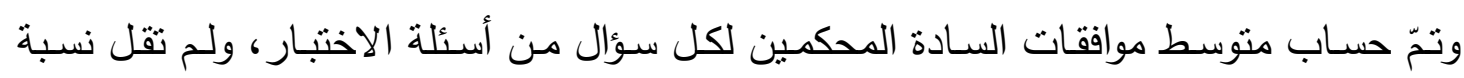

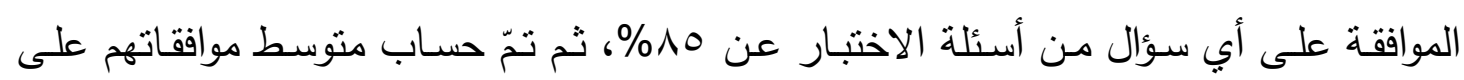

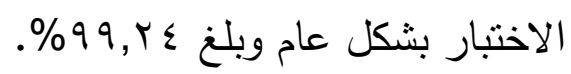

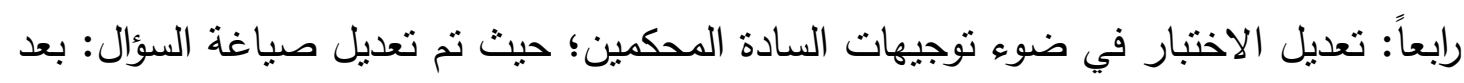

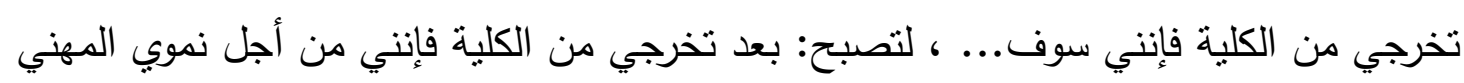
سوف...

خامساً: التوصل إلى الصورة النهائية لاختبار مدى توافر مهارات التدريس التأملي لدى معلمي العلوم قبل الخدمة (ملحق ه). سادساً: إعداد مفتاح تصحيح اختبار مدى نوافر مهارات التدريس التأملي لدى معلمي العلوم قبل الخدمة (ملحق ؟). 
لتحقيق هذا الغرض تمّ تطبيق الاختبار على عينة استطلاعية من معلمي العلوم قبل الخدمة قوامها عشر معلمين من غير عينة الدراسة، وتم استخدام طريقة إعادة تطبيق الاختبار

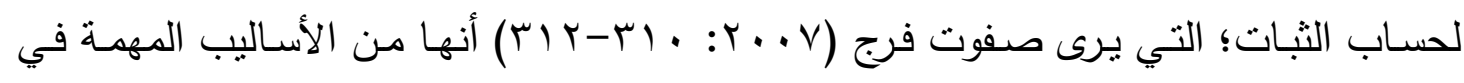

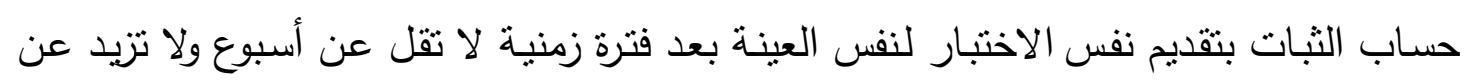

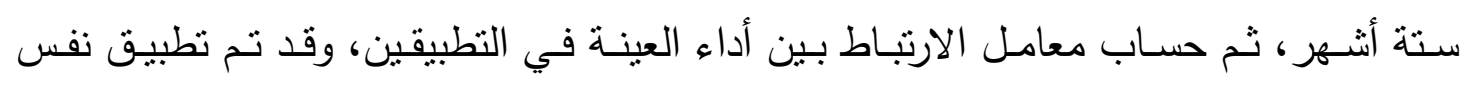

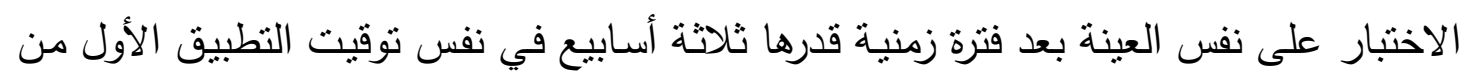
اليوم وفي نفس اليوم لضمان أن يكونوا في نفس الحالة والظروف نقريباً، لعدة أسباب منها:

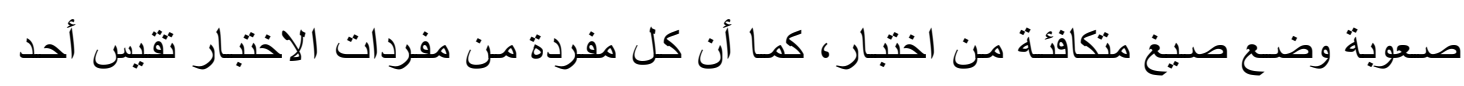

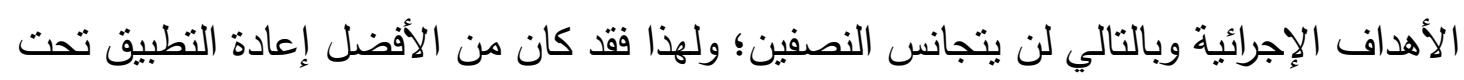

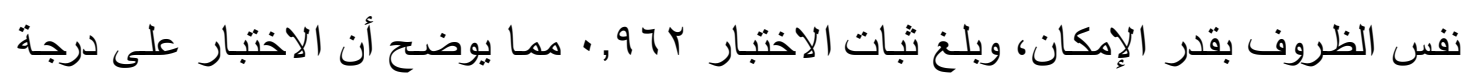
مرتفعة من الثبات.

- حساب الزمن المناسب للإجابة عن أسئلة الاختبار:

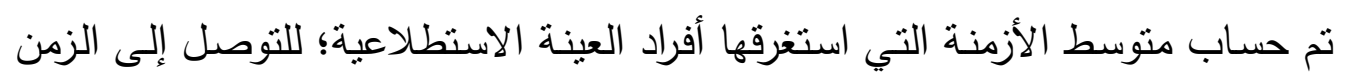

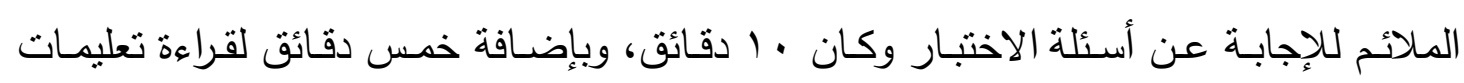

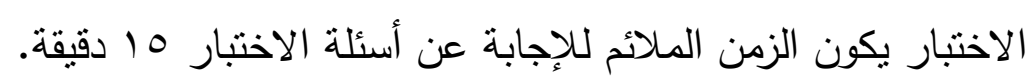

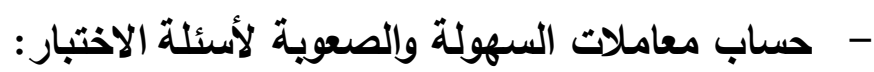

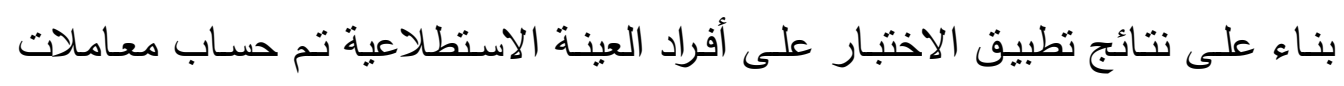

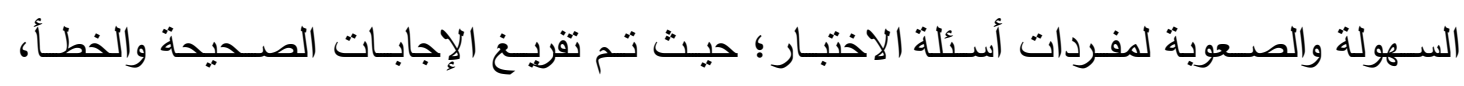

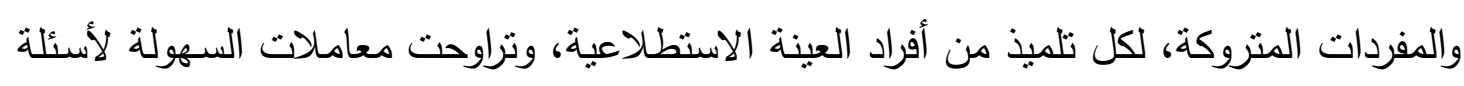

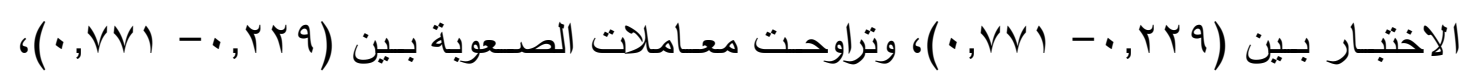

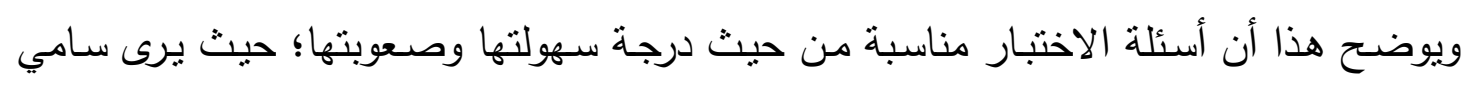

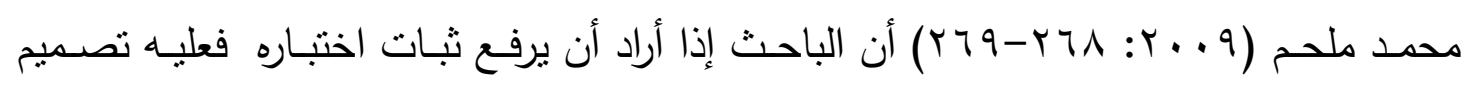

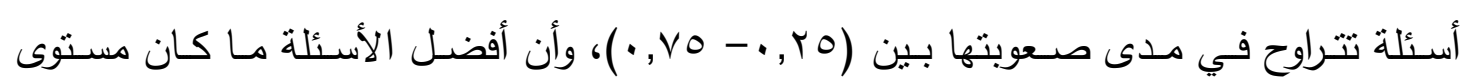

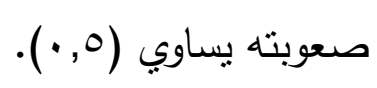




\section{- - حساب معاملات التباين لأسئلة الاختبار :}

بعد حساب معاملات السهولة والصعوبة لكل مفردة من مفردات الاختبار تم حساب الابار

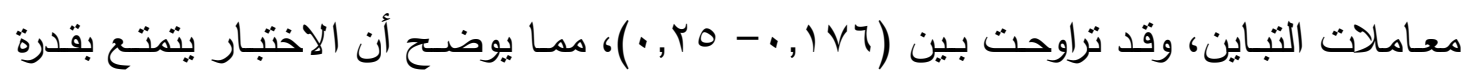
مناسبة على التمييز بين التلاميذ الضعاف والأقوياء. بالتأكد من صدق وثبـات الاختبار وتمتع مفرداته بمعدلات سـهولة وصـعوبة وتمييز مناسبة، تم الاطمئنان إلى مناسبة الاختبار ، وصلاحيته للاستخدام.

المرحلة الثالثة: إعداد بطاقة ملاحظة مدى توافر مهارات التدريس التأملي لدى معلمي العلوم قبل الخدمة وضبطها، ولإتمام ذلك تم انباع ما يلي:

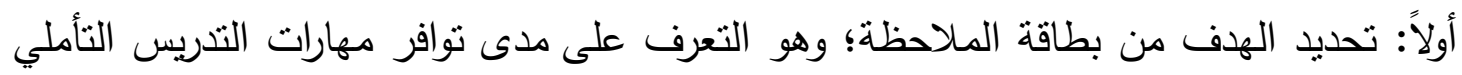

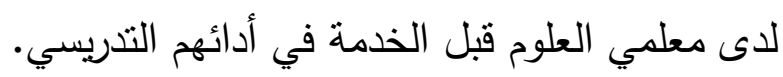

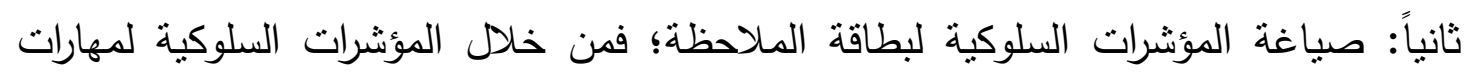

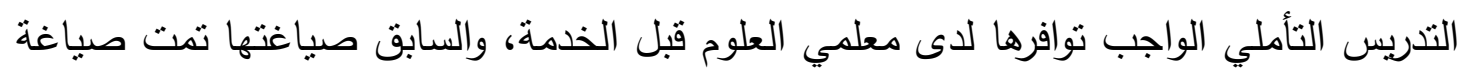

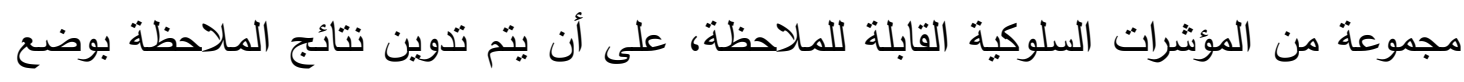
علامة (ل) أسفل الخانة الني توضح واقع السلوك (ممتاز - جيد- ضعيف) في أداء المهارة

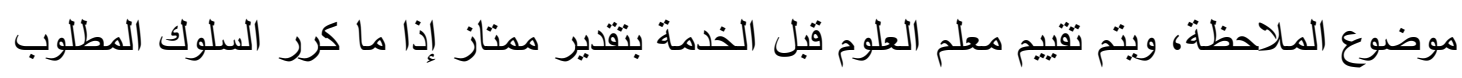

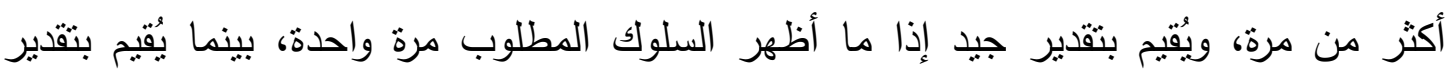

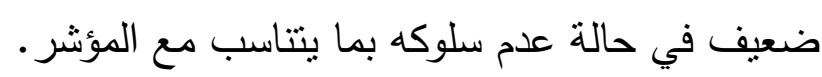
ثالثاً: تحديد وصياغة تعليمات بطاقة الملاحظة لإرشاد القائم بعملية الملاحظة. رابعاً: ضبط بطاقة الملاحظة، وذلك عن طريق حساب صدقها وثباتها كالتالي:

\section{- مساب صدق بطاقة الملاحظة:}

ولتحقيق هذا الغرض تم استخدام أسلوب صدق المحكمين حيث تم عرض استطلاع رأي حول مدى صلاحية بطاقة الملاحظة في الكثف عن مدى توافر مهارات التريس التأملي لدى معلمي

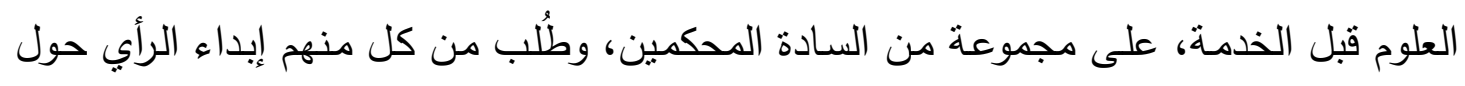

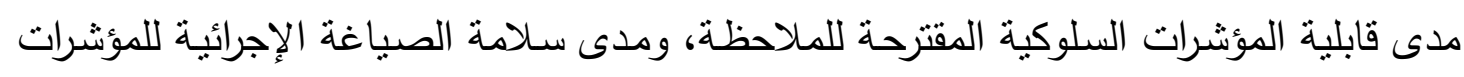

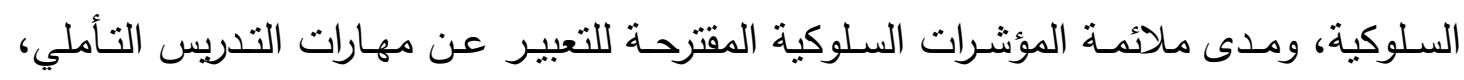

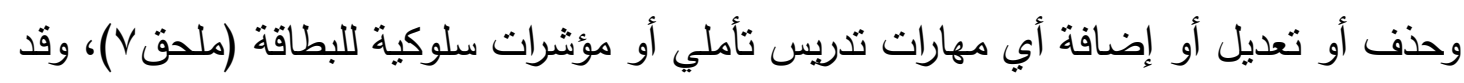

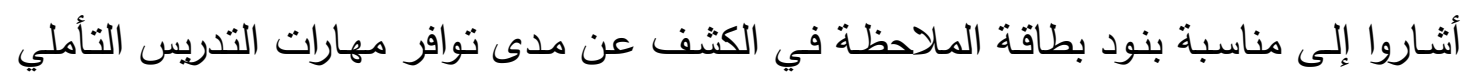
لاى معلمي العلوم قبل الخدمة، وقابلية نلاك المؤشرات للملاحظة. 
ثالثاً: أبدى السادة المحكمين موافقته على بنود بطاقة الملاحظة بدون تعديل.

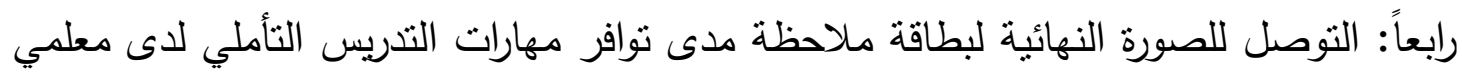
العلوم قبل الخدمة (ملحق^).

\section{- حساب ثبات بطاقة الملاحظة:}

لتحقيق هذا الغرض تم استخدام أسلوب اتفاق الملاحظين وفقاً لمعادلة كوبر (إخلاص محمد بطو

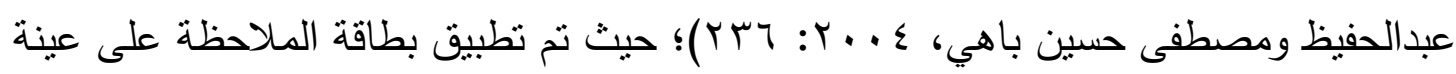

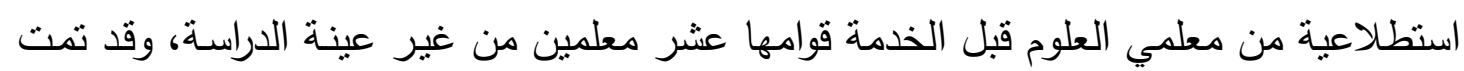

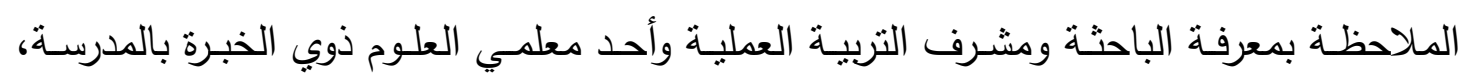

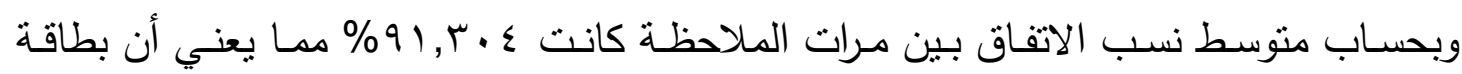
الملاحظة تتمتع بدرجة ثبات مرتفعة.

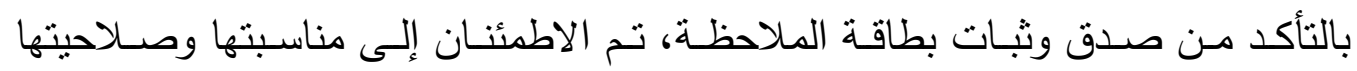
لاستخدام.

المرحلة الرابعة: اعداد كتيب المُتدرب ودليل المُدرب لبرنامج قائم على استراتيجية دراسة

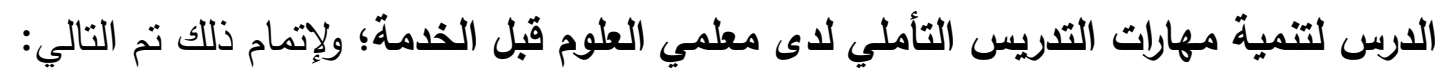

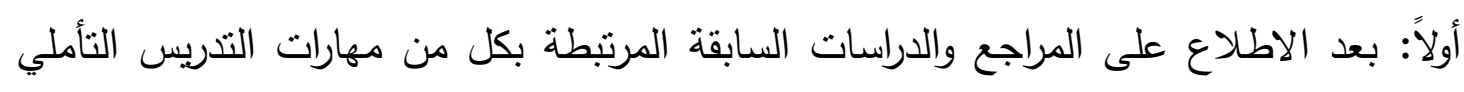

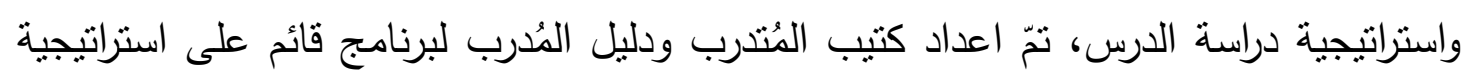
دراسة الدرس لتتمية مهارات التدريس التأملي لدى معلمي العلوم قبل الخدمة، ولتحقيق هذه

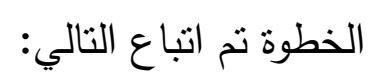
- تحديد وصياغة الأهداف العامة للبرنامج في ضوء قائمة مهارات التدريس التأملي الواجب أباء توافرها لدى معلمي العلوم قبل الخدمة السابق اعدادها. - تحديد وصياغة الأهداف الإجرائية للبرنامج.

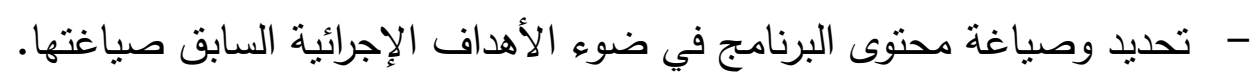

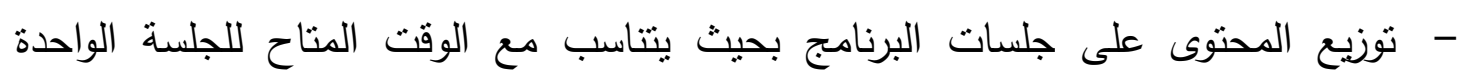

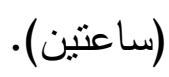
- تحديد الوسائل التعليمية الني يمكن الاستعانة بها لتحقيق أهداف البرنامج.

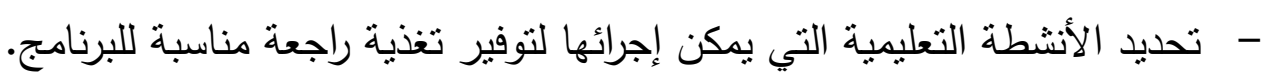
- - تحديد طرق التدريس المستخدمة بكل جلسة تدريبية بما ينتاسب مع تحقيق الأهداف المرجوة. - - تحديد أساليب تقويم تتاسب أهداف البرنامج وتقيسها، مع الحرص على لثلى تتوع تلاك الأساليب. 
ثنانياً: تمّ عرض استطلاع رأي حول كتيب المُتدرب ودليل المُدرب لبرنامج قائم على استراتيجية

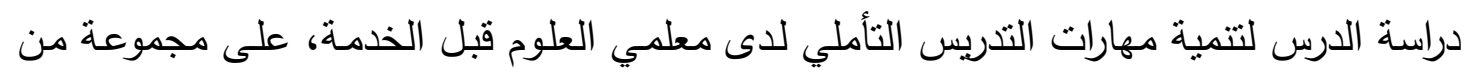

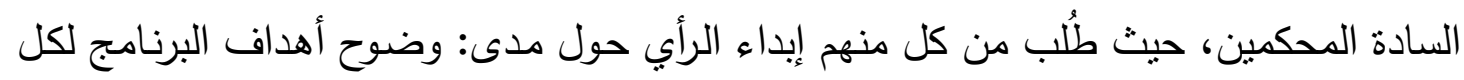

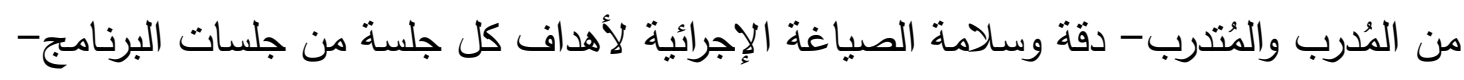

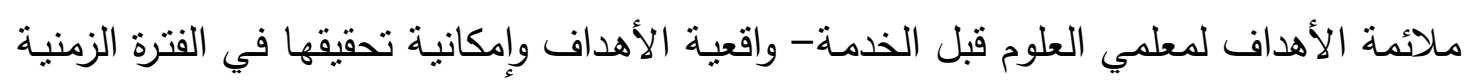

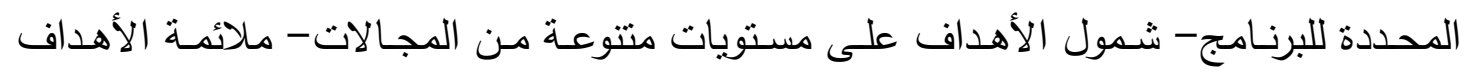

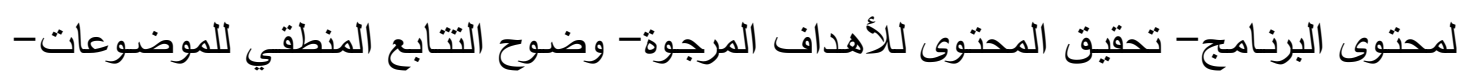

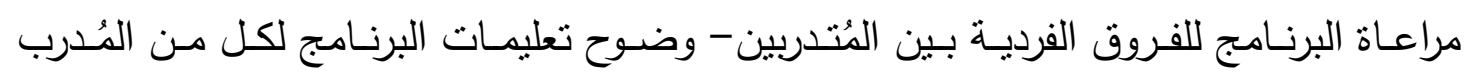

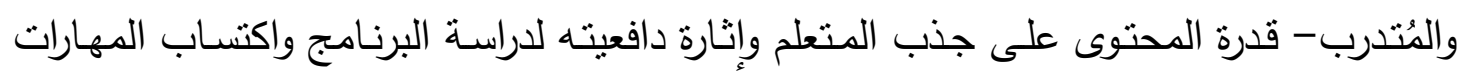

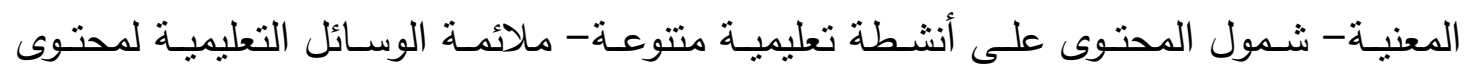

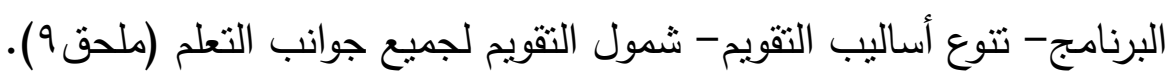

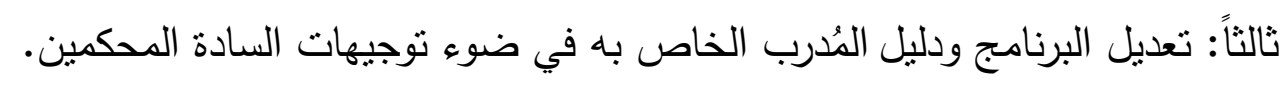

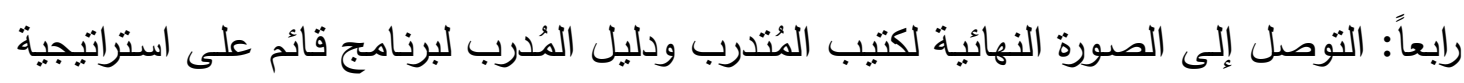

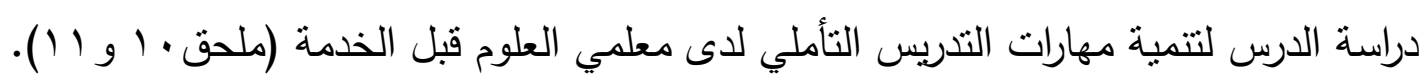

\section{المرحلة الخامسة: اختيار عينة الدراسة:}

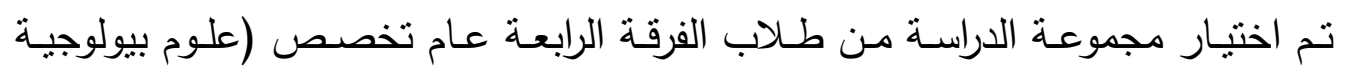

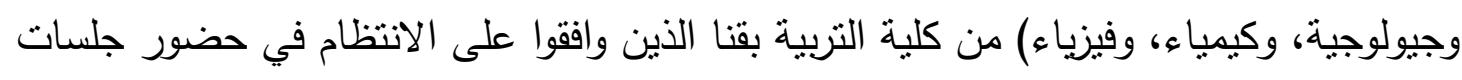

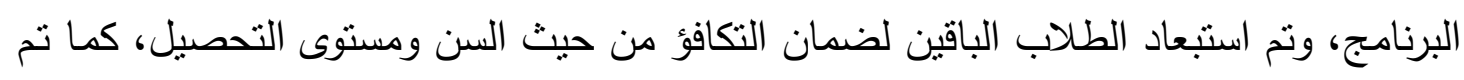

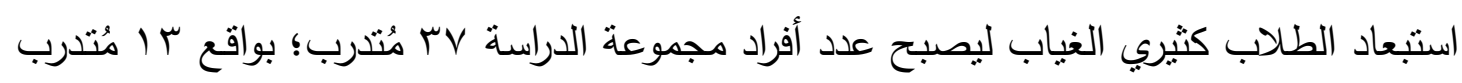

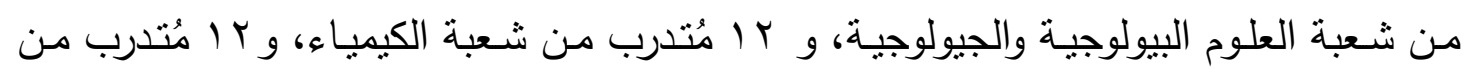
شعبة الفيزياء.

المرحلة السادسة: الاستعداد لتنفيذ تجرية الدراسة:

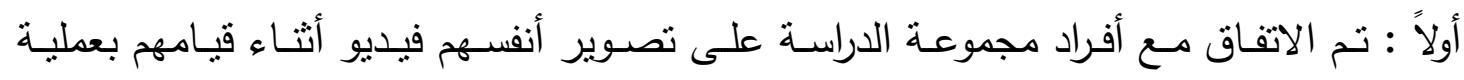

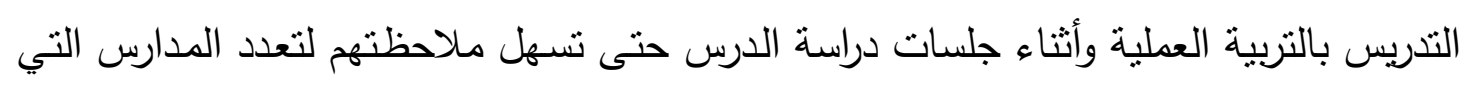
يندربون بها. ثنانياً: تم تخصيص عدد ساعتين أسبوعياً لتدريس البرنامج يوم الخميس (ץ-؟))، وقد روعي تفرغ

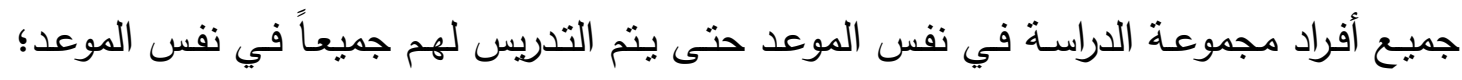


لضمان عدم اختلاف الحالـة النفسية والمزاجيـة للمُدرب والمُتندبين مـن وقت لآخر ، وضمان تنساوي تأثثر الموعد على كافة المندربين بنفس الدرجة. ثالثاً: تخطيط جدول لتوزيع جلسات البرنامج (ملحق ب الم ).

\section{المرحلة السابعة: تنفيذ تجرية الدراسة:}

تم تتفيذ تجربة الدراسة وفقاً للخطوات التالية: أولاً: تطبيق أداتا الدراسة قبلياً على مجموعة الدراسة؛ حيث تم تطبيق بطاقة الملاحظة من خلاد

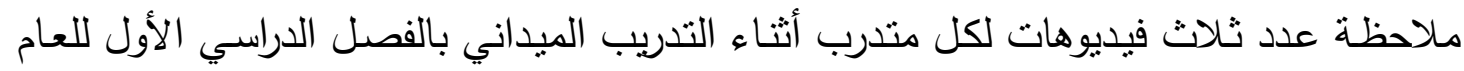

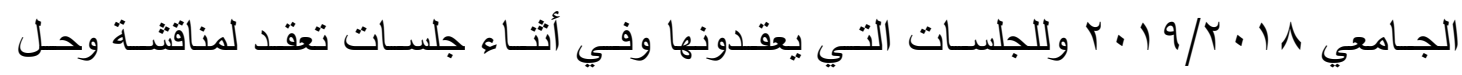
المشكلات التدريسية التي تواجههم، كما تم تطبيق الاختبار عليهم.

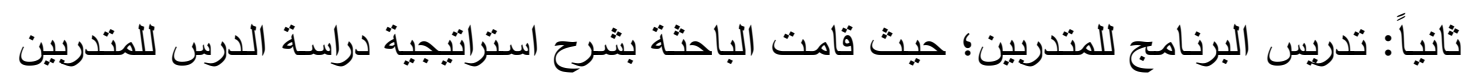

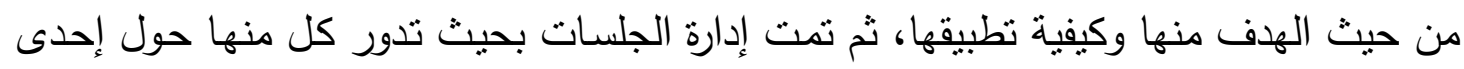

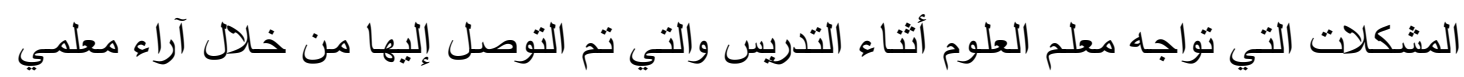

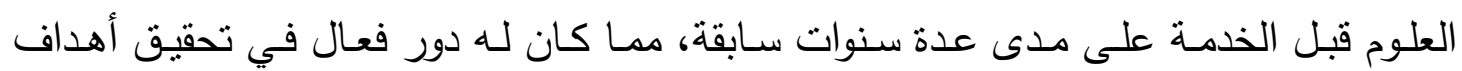
البرنامج لثعورهم بأهمية الموضوعات التي تدور حولها الجلسات بالنسبة لمستقبلهم المهني. ثالثاً: تطبيق بطاقة الملاحظة والاختبار بعدياً على مجموعة الدراسة. رابعاً: تم تحويل التقديرات التي حصل عليها المتدرب في بطاقة الملاحظة إلى قيم رقمية بإعطاء

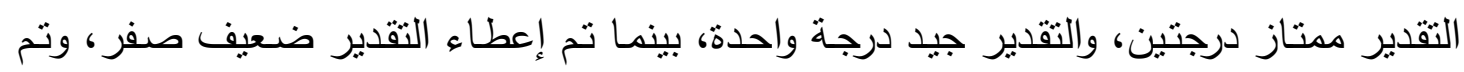

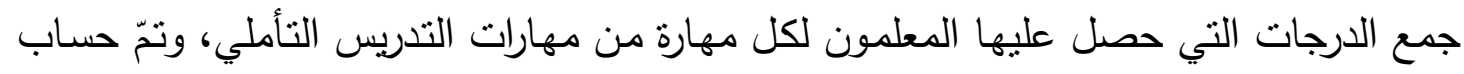

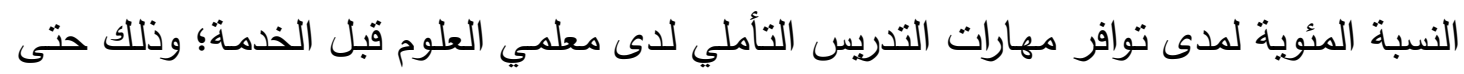
يمكن حساب درجات كل متدرب في الأداء القبلي والأداء البعدي على بطاقة الملاحظة بصورة كمية. خامساً: عقب انتهاء البرنامج طُلب من المتدربين، كتابة رأيهم في البرنامج، مع التأكيد عليهم

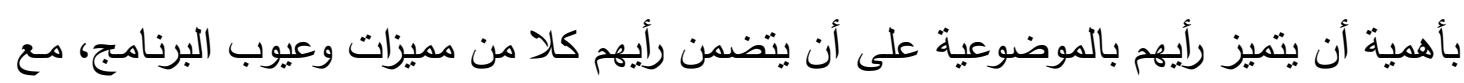
عدم كتابة الاسم طلباً للموضوعية.

\section{ملاحظات على التطبيق:}

- اعجاب اليُنتربون باستراتيجية دراسة الدرس التي ساعدت على تتميتهم مهنياً كما نمت لفت لديهم النقة بالنفس. 
- عبر المُتدربون عن سعادتهم بالمهارات الاجتماعية التي وفرتها لهم استراتيجية دراسة

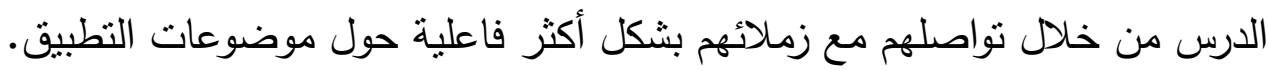

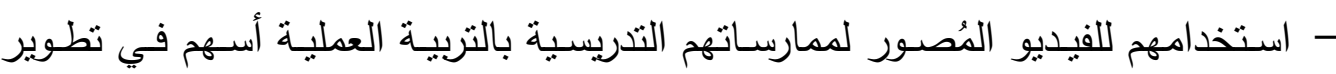
آدائهم ونمو القدرة على التقييم الذاتي لديهم.

\section{الصعويات التي واجهت الباحثة أثناء تنفيذ إجراءات الاراسة:}

م تكس جدول الطلاب بالمواد الدراسية، لاسيما أن الثعب العلمية تدرس معظم المواد عملياً

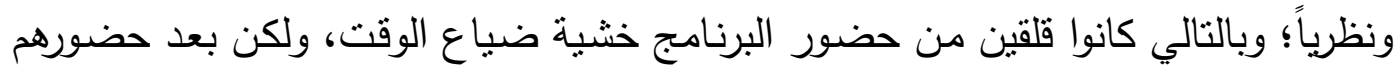

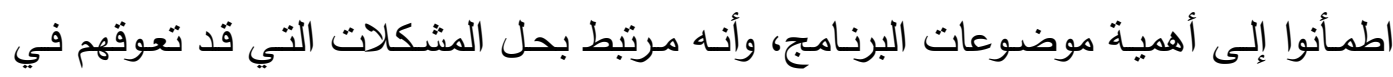

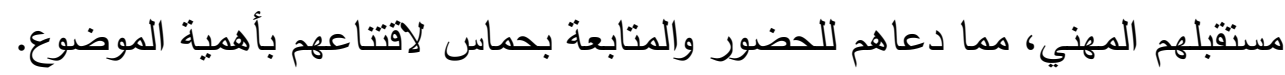

نتائج الاراسة: للتوصل لنتائج الدراسة تم اتباع الخطوات التالية: أولاً: الاجابة على سؤال الاراسة وهو: ما فاعلية برنامج قائم على استراتيجية دراسة الدرس في تتمية مهارات التدريس التأملي لاى معلمي العلوم قبل الخدمة؟ بامبه

تمت الإجابة على سؤال الدراسة من خلال اختبار صحة فرضي الدراسة؛ كالتالي:

\section{اختبار صحة الفرض الأول وهو:}

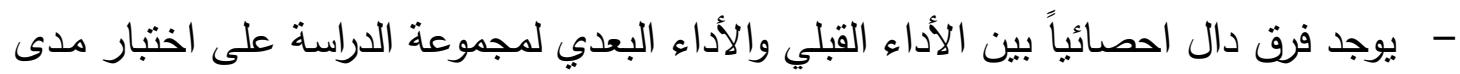
توافر مهارات التدريس التأملي لدى معلمي العلوم قبل الخدمة لصالح التطبيق البعدي.

وقد نم التحقق من صحة هذا الفرض بحساب قيمة "ت" للفرق بين الأداء القبلي والأداء

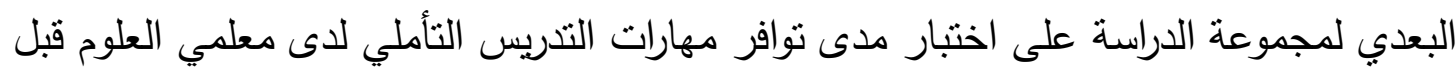

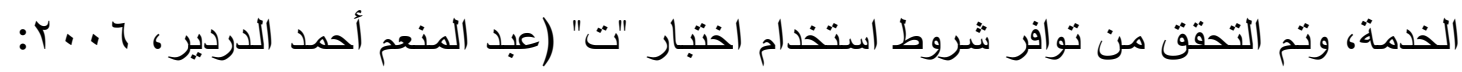

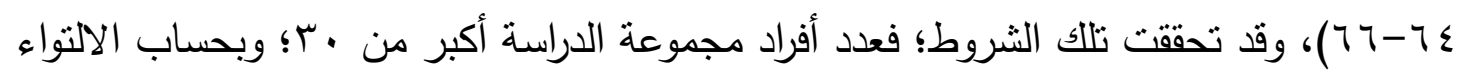

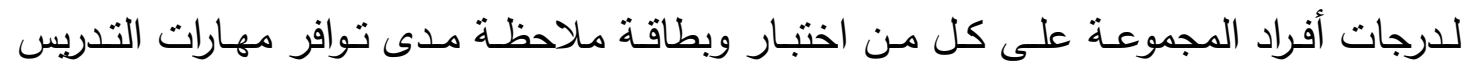

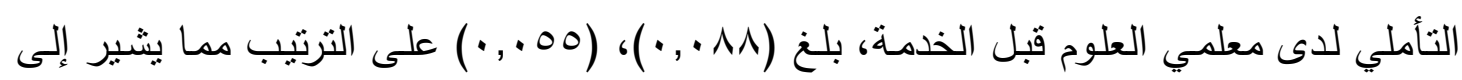

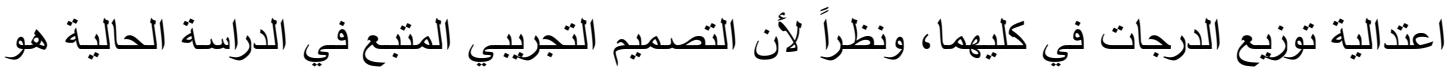


تصميم المنهج شبه التجريبي (تصميم المجموعة الواحدة مع قياس قبلي- بعدي)؛ فإن المعادلة المناسبة لهذا المنهج تكون معادلة اختبار "ت" لحساب الفرق بين متوسطين مرتبطين أو لعينة

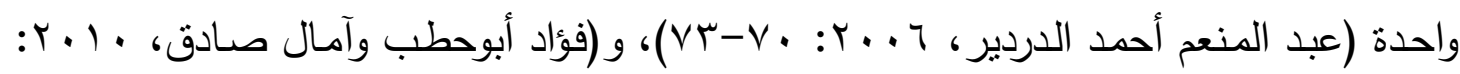

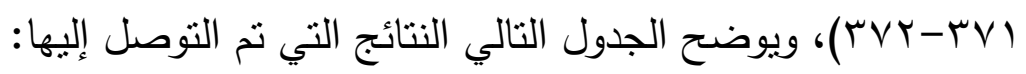
جدول (1) قيمة "ت" المحسوبة والجدولية للفرق بين منوسطي درجات أفراد مجموعة الدراسة في التطبيقين القبلي والأداء البعدي لاختبار مدى نوافر مهارات التدريس التأملي لاى معلمي العلوم قبل الخدمة (الدرجة

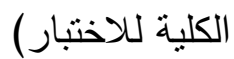

\begin{tabular}{|c|c|c|c|c|c|c|c|}
\hline 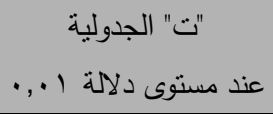 & الحرية & التأثير & 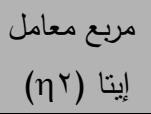 & " المحسوبة & الانعراف & متوسط الدرجات & القياس \\
\hline \multirow{2}{*}{$r, v \cdot \varepsilon$} & \multirow{2}{*}{ ז } & \multirow{2}{*}{ 11,VAr } & \multirow{2}{*}{$\cdot, 9 \vee Y$} & \multirow{2}{*}{ ro, זד } & $1, \wedge \vee$. & $r, q \leq 0$ & قبلي \\
\hline & & & & & $r, Y \vee \wedge$ & $10, \cdot r V$ & بعدي \\
\hline
\end{tabular}

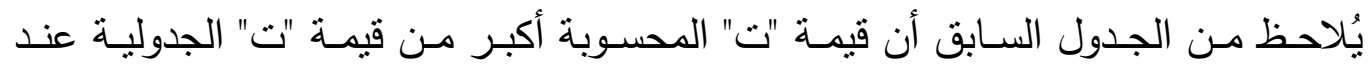
مستوى دلالة ( ( ., )؛ مما يعني وجود فرق ذي دلالة إحصائية بين متوسطي درجات

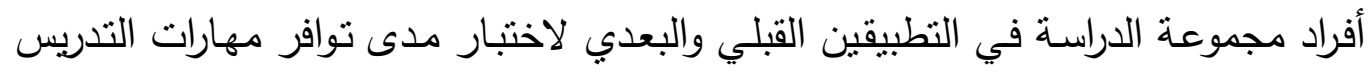

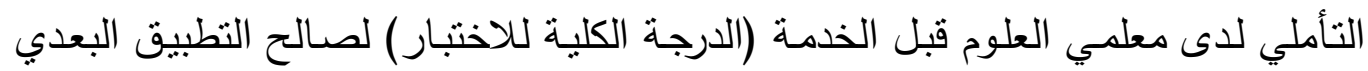
عند مستوى دلالة (1 (., ).).

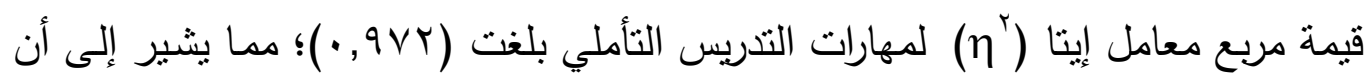

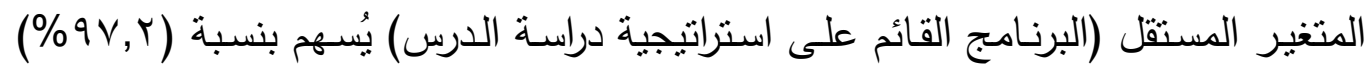

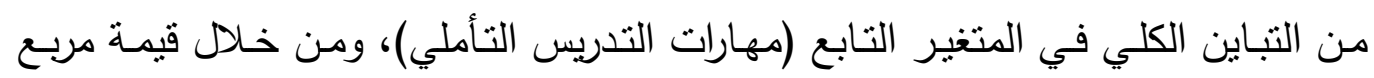

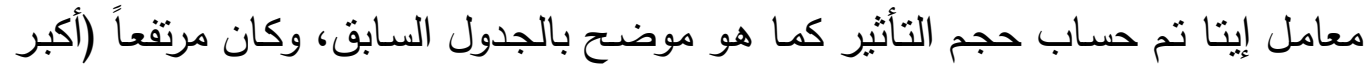

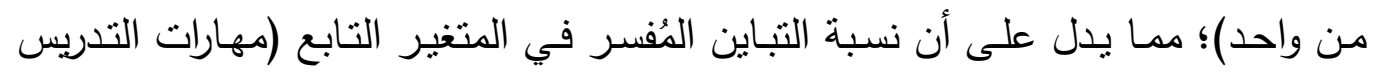

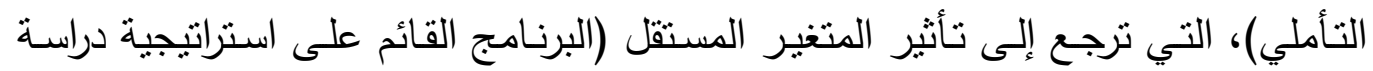
الدرس) مرتفعة، ويوضح الثكل التالي تلك النتائج بيانياً:

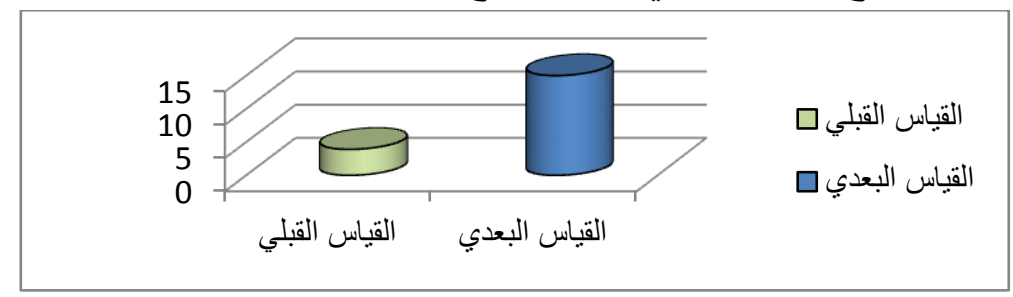

شكل (1)

شكل بياني يوضح الفرق بين متوسطي درجات أفراد مجموعة الدراسة في التطبيقين القبلي والبعدي لاختبار مدى نوافر مهارات التدريس التأملي لدى معلمي العلوم قبل الخدمة (الدرجة الكلية للاختبار) 
وللتأكد من مدى توافر كل مهارة مهارات التدريس التأملي لدى معلمي العلوم قبل

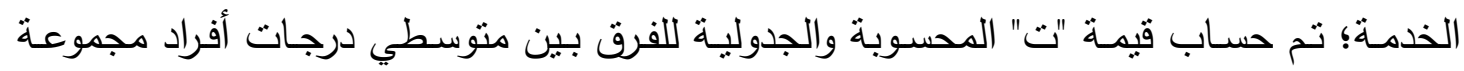
الدراسة في التطبيقين القبلي والبعدي لاختبار مدى توافر كل مهارة من مهارات التدريس التأملي لاى معلمي العلوم قبل الخدمة كما يتضح من خلال الجدول التالي: جدول (r)

قيمة "ت" المحسوبة والجدولية للفرق بين متوسطي درجات أفراد مجموعة الدراسة في التطبيقين القبلي والبعدي لاختبار مدى توافر كل مهارة من مهارات التدريس التأملي لئي لاى معلمي العلوم قبل الخدمة

\begin{tabular}{|c|c|c|c|c|c|c|c|c|}
\hline عند مستوى دلالة ال •, •. & الحرية & التأثنير & 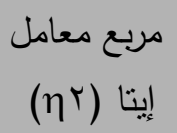 & المسوبة & الانحراف & الدرجات & القياس & مهارات التدريس \\
\hline \multirow{14}{*}{$r, V \cdot \Sigma$} & \multirow{14}{*}{ 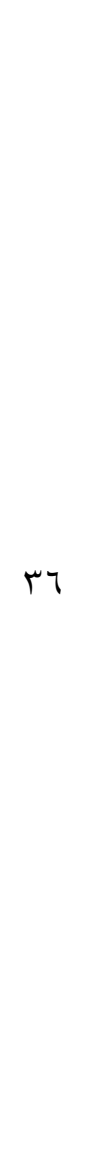 } & \multirow{2}{*}{ r,OVA } & \multirow{2}{*}{$\cdot, V T r$} & \multirow{2}{*}{$1 \cdot, V \mu V$} & $\cdot, \vee \vee 97$ & $1, r \leqslant r$ & قبلي & \multirow{2}{*}{ جمع المعلومات } \\
\hline & & & & & $\cdot, \vee \vee 90$ & $r, \cdot \Lambda l$ & بعدي & \\
\hline & & \multirow{2}{*}{$0,1 Y \wedge$} & \multirow{2}{*}{$\cdot, \wedge \neg \wedge$} & \multirow{2}{*}{$10, \leqslant \mu_{0}$} & $\cdot, \varepsilon \mid V$ & $\cdot, Y \backslash 7$ & قبلي & \multirow{2}{*}{ تحليل } \\
\hline & & & & & ש & I,NTV & بعدي & \\
\hline & & \multirow{2}{*}{$0,1 \vee r$} & \multirow{2}{*}{$\cdot, \wedge \vee \cdot$} & \multirow{2}{*}{10, OYT } & $\cdot, r \leq 7$ & ס & قبلي & \multirow{2}{*}{ تقييم المعلومات } \\
\hline & & & & &., 0.0 & $1,0 \leqslant$. & بعدي & \\
\hline & & \multirow{2}{*}{$\varepsilon, V \cdot 0$} & \multirow{2}{*}{$\cdot, \wedge \leq \vee$} & \multirow{2}{*}{$1 \leq, 101$} & $\cdot, \leqslant 0$. & $1, \vee Y q$ & قبلي & \multirow{2}{*}{ التأمل الت } \\
\hline & & & & & $\cdot, \wedge \wedge \vee$ & r,人т & بعدي & \\
\hline & & \multirow{2}{*}{$\varepsilon, 7)\rceil$} & \multirow{2}{*}{$\cdot, \wedge \leq r$} & \multirow{2}{*}{$1 r, \wedge 01$} & $\cdot$, rqv & $\cdot, 119$ & قبلي & \multirow{2}{*}{ التخطيط } \\
\hline & & & & & $\cdot, \leqslant 9 \vee$ & $1, \varepsilon \cdot 0$ & بعدي & \\
\hline & & \multirow{2}{*}{$\varepsilon, 099$} & \multirow{2}{*}{$\cdot, \wedge \leq 1$} & \multirow{2}{*}{$\Pi, \wedge \ldots$} & • & ., & قبلي & \multirow{2}{*}{ إدارة الأزمات } \\
\hline & & & & & $\cdot$, . १४ & $1, \varepsilon \cdot 0$ & بعدي & \\
\hline & & \multirow{2}{*}{$7, \ldots$} & \multirow{2}{*}{$\cdot, 9 \ldots$} & \multirow{2}{*}{$\mid 1, .91$} & $\cdot, \leqslant 0$. & $\cdot, r V$. & قبلي & \multirow{2}{*}{ تتفيذ الخطة } \\
\hline & & & & & • & $1, \wedge 91$ & بعدي & \\
\hline
\end{tabular}

هُعلاحظ من الجدول السابق أن قيمة "ت" المحسوبة لكل مهارة من مهارات التدريس التأملي

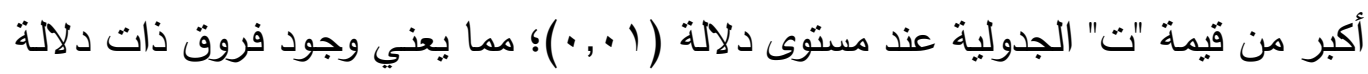

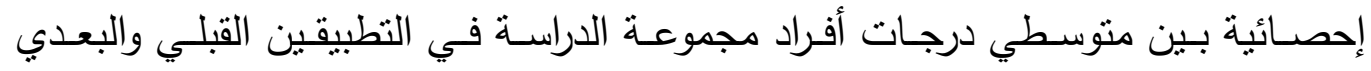
لاختبار مدى توافر كل مهارة من مهارات التدريس التأملي لدى معلمي العلوم قبل الخدمة فئس

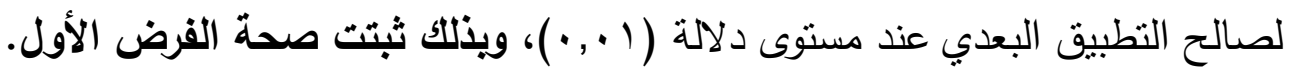




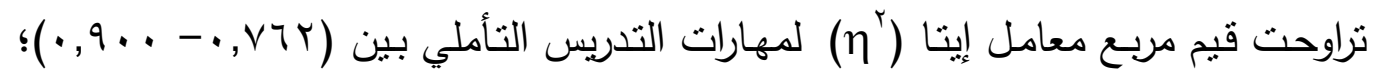

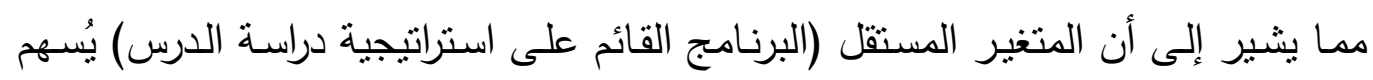

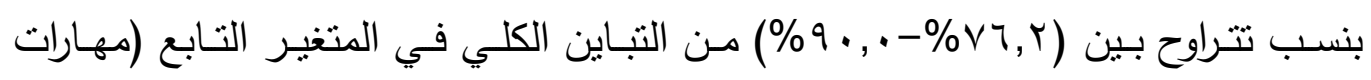

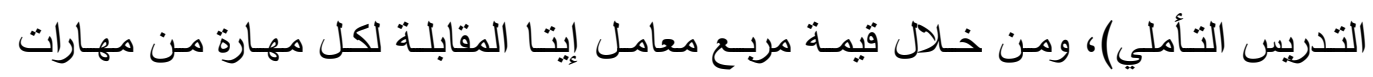

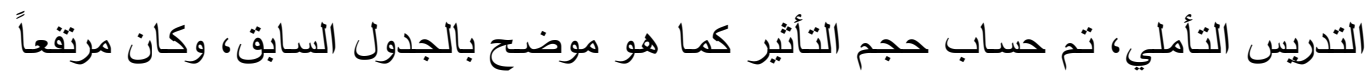

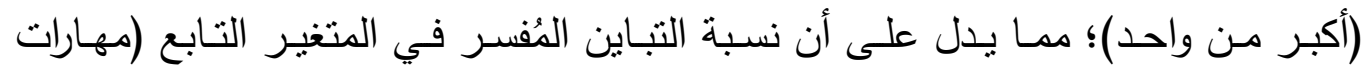

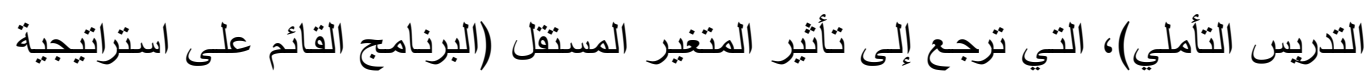
دراسة الدرس) مرتفعة، ويوضح الثكل الثالي تلك النتائج بيانياً:

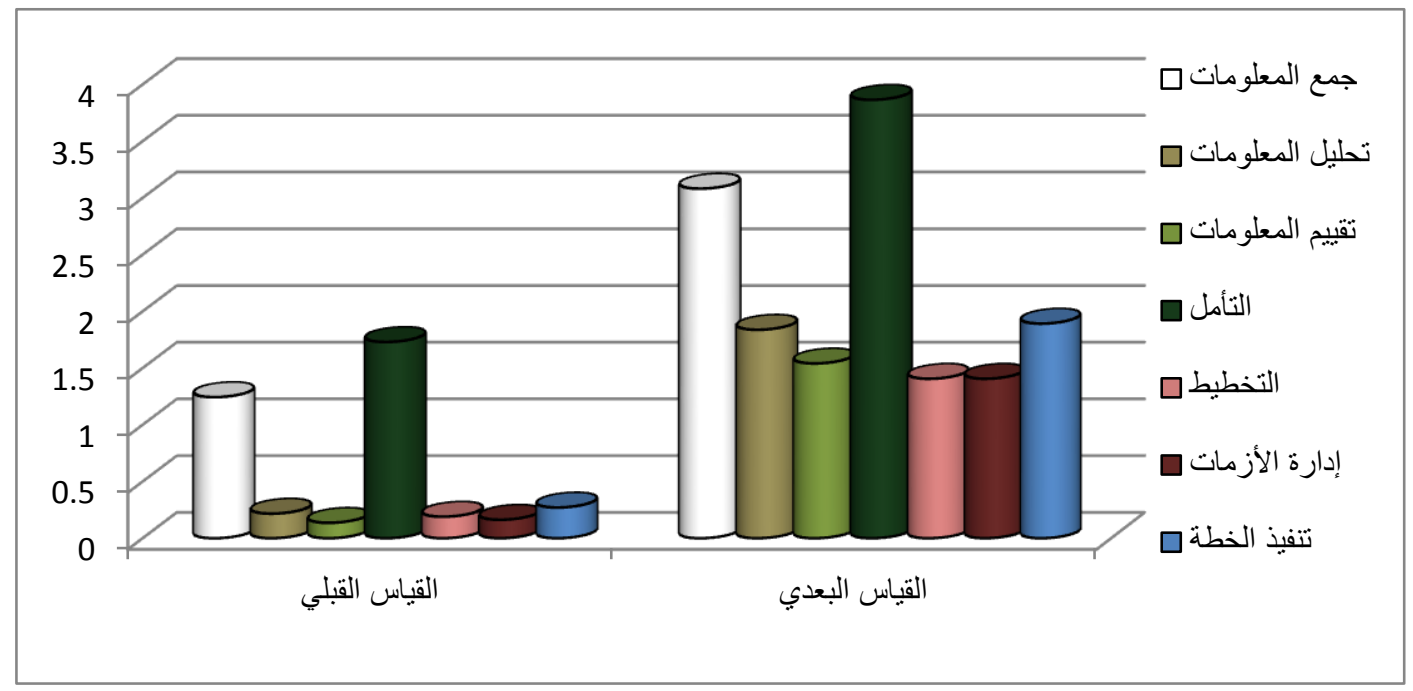

شكل (r)

شكل بياني يوضح الفرق بين متوسطي درجات أفراد مجموعة الدراسة في التطبيقين القبلي والبعدي

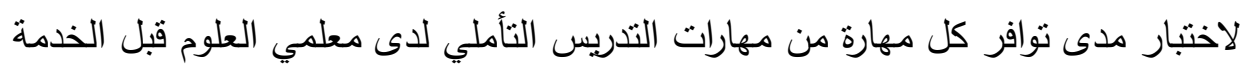

حساب فاعلية برنامج قائم على استراتيجية دراسة الدرس في تنمية مهارات التدريس التأملي لاى معلمي العلوم قبل الخدمة؛ كما يتضح من نتائج تطبيق الاختبار:

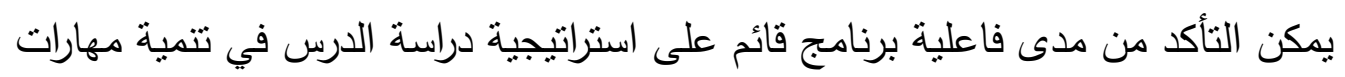

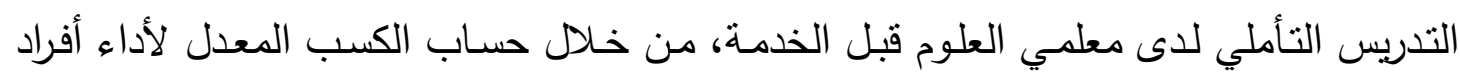

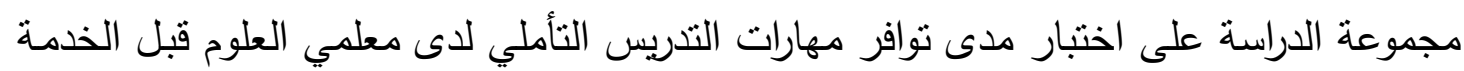

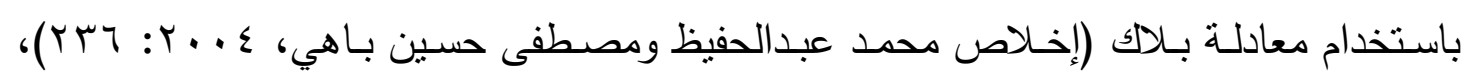

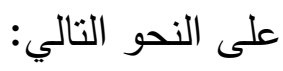


جدول (r)

الكسب المعدل لأداء أفراد مجموعة الدراسة

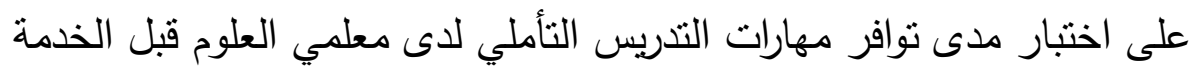

\begin{tabular}{|c|c|c|c|c|c|}
\hline دلالة الكسب & الكسب & العظمى النهاية & متوسط & القياس & مهارات التدريس \\
\hline \multirow{16}{*}{ دال احصائياً } & \multirow{2}{*}{ I, 1Yo } & \multirow{2}{*}{$\varepsilon$} & $1, r \leqslant r$ & قبلي & \multirow{2}{*}{ جمع المعلومات } \\
\hline & & & $r, \cdot \lambda l$ & بعدي & \\
\hline & \multirow{2}{*}{$1, \vee \backslash \wedge$} & \multirow{2}{*}{ r } & $\cdot, Y \backslash T$ & قبلي & \multirow{2}{*}{ تحليل المعلومات } \\
\hline & & & l, & بعدي & \\
\hline & \multirow{2}{*}{$1, \leqslant 00$} & \multirow{2}{*}{ r } & or & قبلي & \multirow{2}{*}{ تقييم المعلومات } \\
\hline & & & $1,0 \leqslant$. & بعدي & \\
\hline & \multirow{2}{*}{$1, \cdot \vee 9$} & \multirow{2}{*}{0} & $1, \vee Y q$ & قبلي & \multirow{2}{*}{ 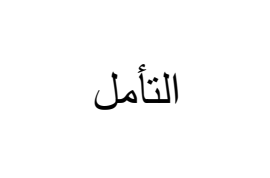 } \\
\hline & & & r,人т & بعدي & \\
\hline & \multirow{2}{*}{$1, r \vee q$} & \multirow{2}{*}{ r } &., 119 & قبلي & \multirow{2}{*}{ التخطبط } \\
\hline & & & $1, \varepsilon .0$ & بعدي & \\
\hline & \multirow{2}{*}{ I, rqv } & \multirow{2}{*}{ r } &., $17 r$ & قبلي & \multirow{2}{*}{ إدارة الأزمات } \\
\hline & & & $1, \varepsilon .0$ & بعدي & \\
\hline & \multirow{2}{*}{$1, V \leqslant 7$} & \multirow{2}{*}{ r } & $\cdot, Y V \cdot$ & قبلي & \multirow{2}{*}{ تتفيذ الخطة } \\
\hline & & & 1,199 & بعدي & \\
\hline & \multirow{2}{*}{$1, \pi 19$} & \multirow{2}{*}{19} & $r, q \leq 0$ & قبلي & \multirow{2}{*}{ الاختبار كامل } \\
\hline & & & $10, \cdot T V$ & بعدي & \\
\hline
\end{tabular}

يُلاحظ من الجدول السـابق أن قيم الكسب المعدل لكل مهارة مـن مهارات التدريس التأملي

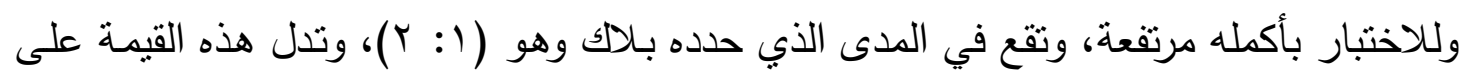
فاعلية برنامج قائم على استراتيجية دراسة الدرس في تتمية مهارات التدريس التأملي لدى معلى معلمي

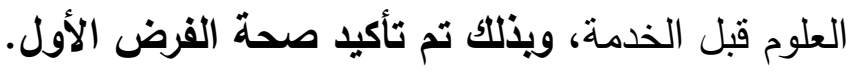


اختبار صحة الفرض الثاني وهو:

- - يوجد فرق دال احصـائياً بين الأداء القبلـي والأداء البعدي لمجموعـة الدراسـة على بطاقـة ملاحظة ددى نوافر مهارات التدريس التأملي لدى معلمي العلوم قبل الخدمة لصالح التطبيق البعدي.

وتم التحقق من صحة هذا الفرض بحساب قيمة "ت" للفرق بين الأداء القبلي والأداء

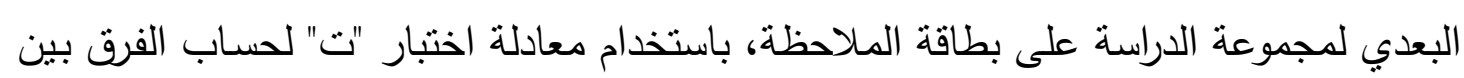

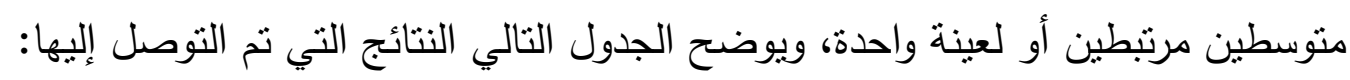

$$
\text { جدول (ع) }
$$

قيمة "ت" المحسوبة والجدولية لمتوسطي درجات أفراد مجموعة الدراسة في التطبيقين القبلي والبعدي لبطاقة الملاحظة (الدرجة الكلية للبطاقة)

\begin{tabular}{|c|c|c|c|c|c|c|c|}
\hline 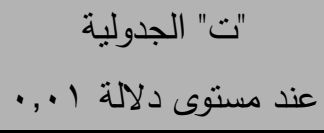 & الحرية & التأثير & 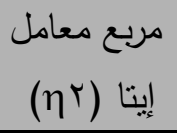 & المحسوبة & الانحراف & منوسط الدرجات & القياس \\
\hline \multirow{2}{*}{$r, v \cdot \varepsilon$} & \multirow{2}{*}{ ru } & \multirow{2}{*}{$\mid r, r \leqslant 1$} & \multirow{2}{*}{$\cdot, 9 \vee \leq$} & \multirow{2}{*}{$r q, \Lambda \cdot r$} & l, $2 \pi r$ & $r, \cdot r v$ & قبلي \\
\hline & & & & & $r, Y, r$. & $1 \leq, 1 \cdot 1$ & بعدي \\
\hline
\end{tabular}

• يُلاحظ من الجدول السابق أن قيمة "ت" المحسوبة أكبر من قيمة "ت" الجدولية عند مستوى

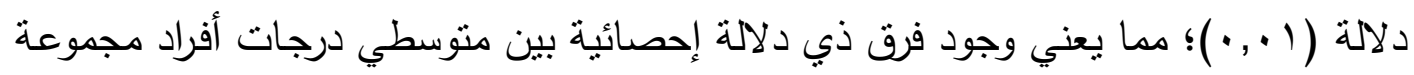

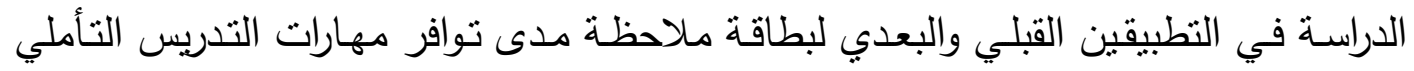

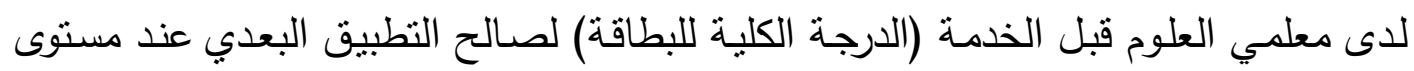

$$
\text { دلالة (1., (·).). }
$$

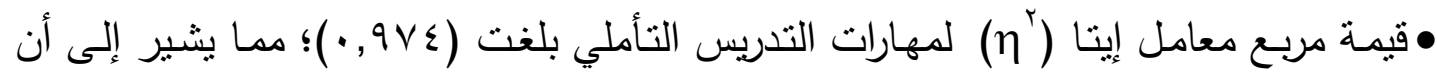

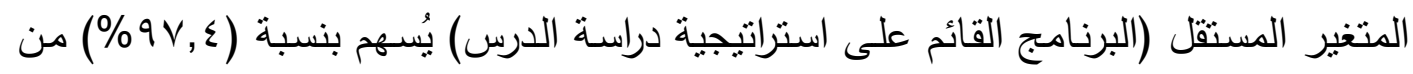

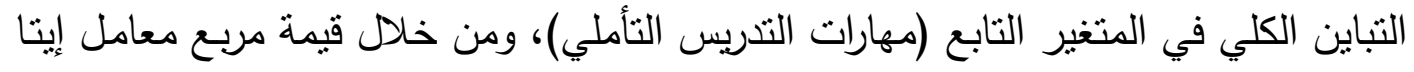

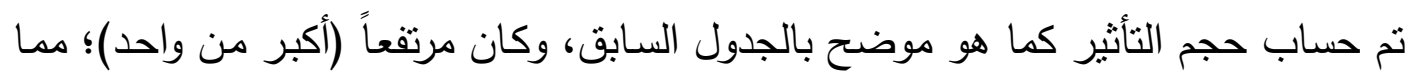

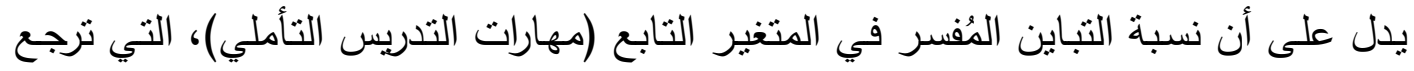

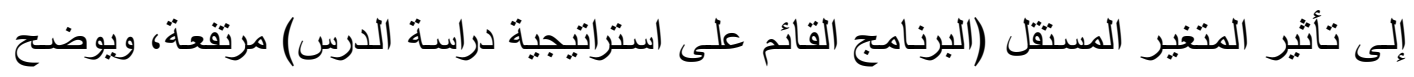
الثكل التالي تلك النتائج بيانياً: 


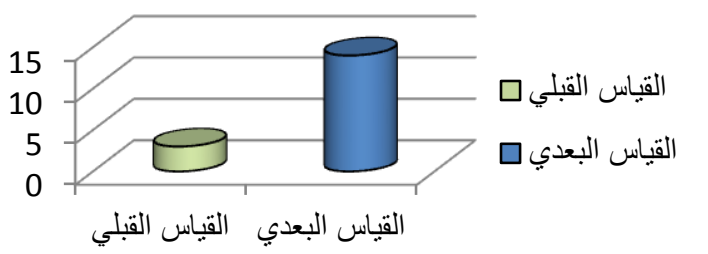

شكل (r)

شكل بياني يوضح الفرق بين متوسطي درجات أفراد مجموعة الدراسة في التطبيقين

القبلي والبعدي لبطاقة الملاحظة (الدرجة الكلية للبطاقة)

وللتأكد من مدى توافر كل مهارة مهارات التدريس التأملي لدى معلمي العلوم قبل

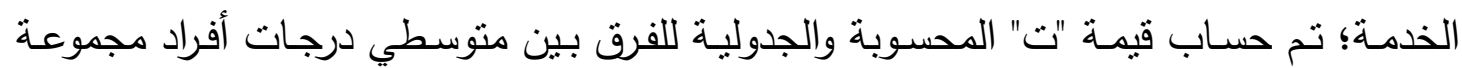
الدراسة في التطبيقين القبلي والبعدي لبطاقة ملاحظة مدى توافر كل مهارة من مهارات التدريس

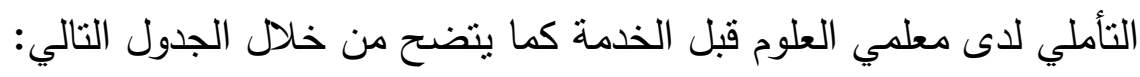

جدول (0)

قيمة "ت" المحسوبة والجدولية للفرق بين متوسطي درجات أفراد مجموعة الدراسة في النطبيقين

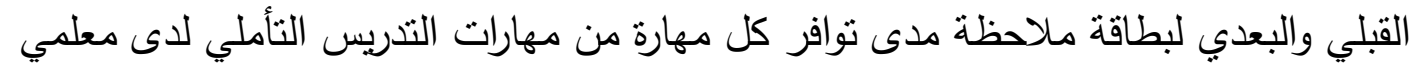
العلوم قبل الخدمة

\begin{tabular}{|c|c|c|c|c|c|c|c|c|}
\hline عند مستوى دلالة ات ـ, , • & الحرية & التأثبر & 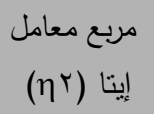 & المسوبة & الانحراف & منوسط الدرجات & القياس & مهارات التدريس \\
\hline \multirow{14}{*}{$r, V \cdot \varepsilon$} & \multirow{14}{*}{ ru } & \multirow{2}{*}{$0, \cdot 1 \leq$} & \multirow{2}{*}{$\cdot$, , } & \multirow{2}{*}{$10, r V}$. & •, Iו & $\cdot, 1 \cdot 1$ & قبلي & \multirow{2}{*}{ جمع المعلومات } \\
\hline & & & & & $1, \leqslant 09$ & $1, \leqslant 09$ & بعدي & \\
\hline & & \multirow{2}{*}{ E,rAr } & \multirow{2}{*}{$\cdot, \wedge T \mid$} & \multirow{2}{*}{ Ir,人৭r } & •, & $\cdot, 1 \cdot 1$ & قبلي & \multirow{2}{*}{ تحليل المعلومات } \\
\hline & & & & & $1, r \leq r$ & $1, r \leqslant r$ & بعدي & \\
\hline & & \multirow{2}{*}{7,791} & \multirow{2}{*}{$\cdot, 911$} & \multirow{2}{*}{$r \cdot, 199$} & $\cdot, \leqslant 0$ & $\cdot, \vee Y q$ & قبلي & \multirow{2}{*}{ تقييم المعلومات } \\
\hline & & & & & Y,OTV & r,07V & بعدي & \\
\hline & & \multirow[b]{2}{*}{$V, \cdot Y T$} & \multirow[b]{2}{*}{. 9ro } & \multirow[b]{2}{*}{$r 1,1 \leq}$. & $\cdot, \leq 71$ & 1,119 & قبلي & \multirow{2}{*}{ 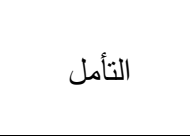 } \\
\hline & & & & & $r, \Sigma \wedge T$ & $\Gamma, \Sigma \wedge \uparrow$ & بعدي & \\
\hline & & \multirow{2}{*}{0,74} & \multirow{2}{*}{$\cdot, \wedge \wedge 9$} & \multirow{2}{*}{$17,91 \varepsilon$} & $\cdot,\{91$ & . & قبلي & \multirow{2}{*}{ التخطيط } \\
\hline & & & & & $r, T \leqslant \Lambda$ & $r, T \leqslant \Lambda$ & بعدي & \\
\hline & & \multirow{2}{*}{$7, \cdots$} & \multirow{2}{*}{$\cdot, 9 \ldots$} & \multirow{2}{*}{$11, \cdot 91$} & $\cdot, r Y q$ & $\cdot, .0 \leqslant 1$ & قبلي & \multirow{2}{*}{ إدارة الأزمات } \\
\hline & & & & & 1,1, & $1,1 \pi 0$ & بعدي & \\
\hline & & \multirow{2}{*}{$\varepsilon, 701$} & \multirow{2}{*}{$\cdot, \wedge \leq \varepsilon$} & \multirow{2}{*}{$\mid r, q \wedge \wedge$} & $\cdot, \Sigma \mid V$ & $\cdot, Y \backslash 7$ & قبلي & \multirow{2}{*}{ تتفيذ الخطة } \\
\hline & & & & & $1,07 \mathrm{~V}$ & $1,07 \mathrm{~V}$ & بعدي & \\
\hline
\end{tabular}


هُماحظ من الجدول السابق أن قيمة "ت" المحسوبة لكل مهارة من مهارات التدريس التأملي

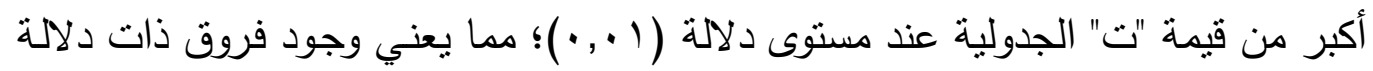
إحصائية بين متوسطي درجات أفراد مجموعة الدراسة في التطبيقين القبلي والبعدي لبطاقة

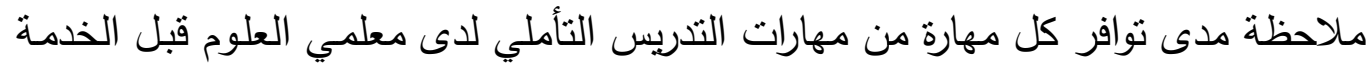

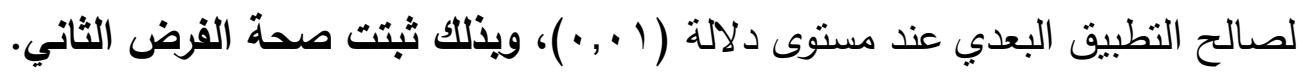

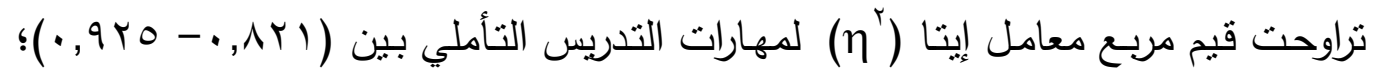

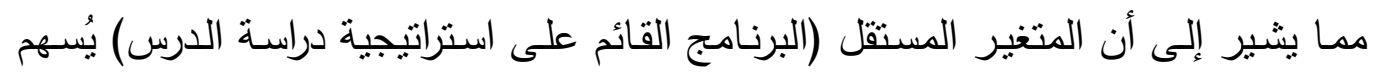

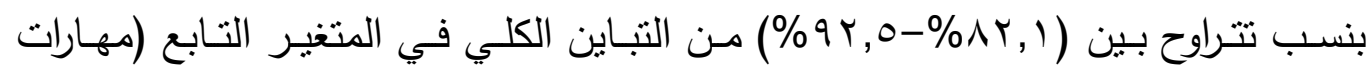

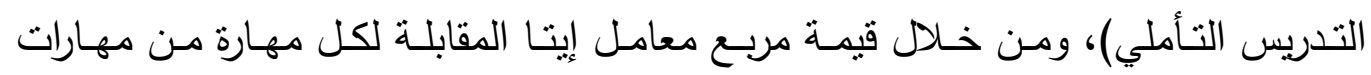

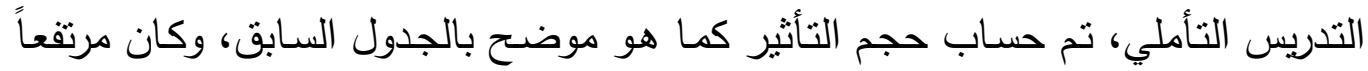

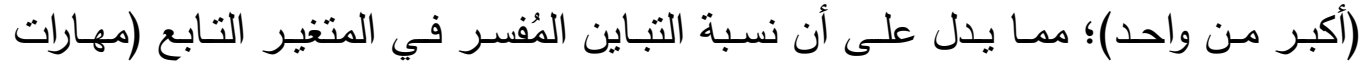

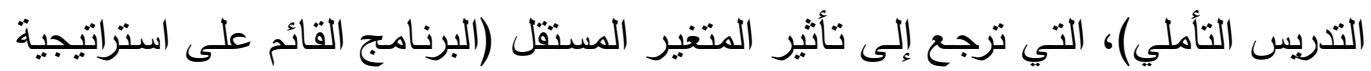
دراسة الدرس) مرتفعة، ويوضح الثكل الثالي تلك النتائج بيانياً:

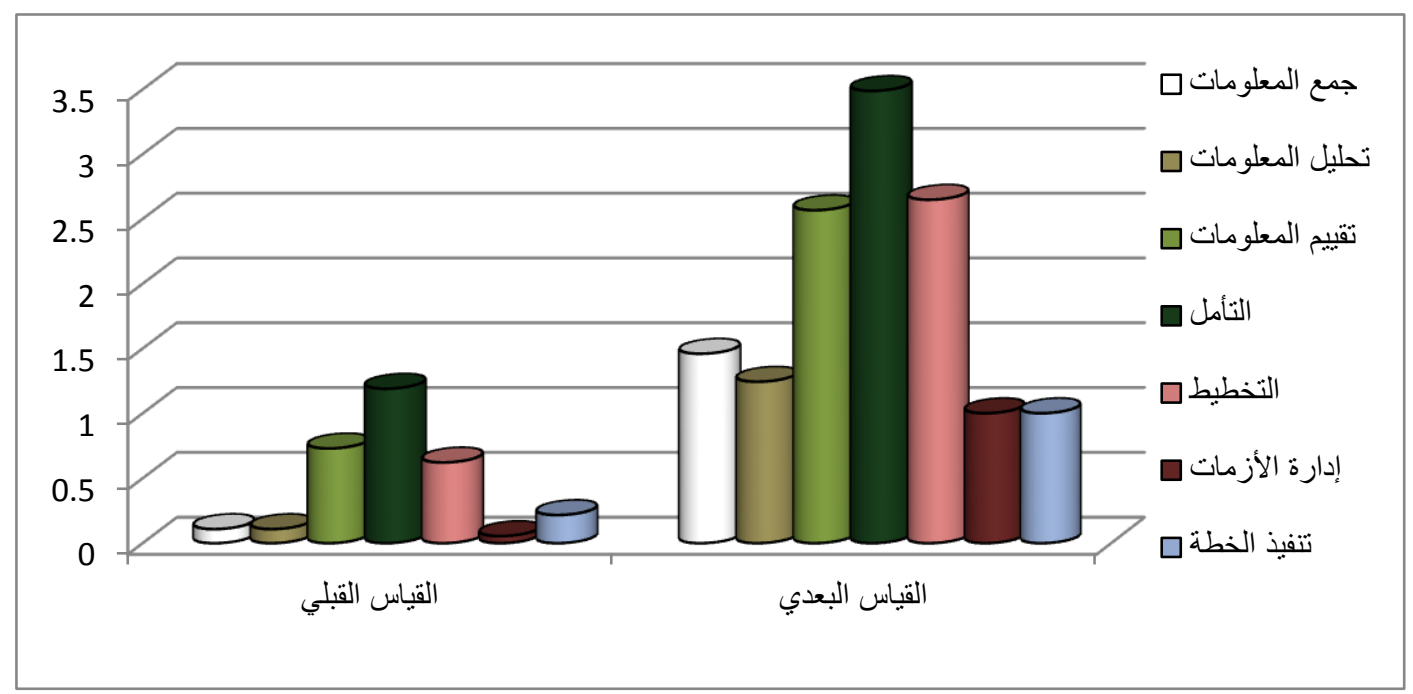

شكل (飞)

شكل بياني يوضح الفرق بين متوسطي درجات أفراد مجموعة الدراسة في التطبيقين القبلي والبعدي

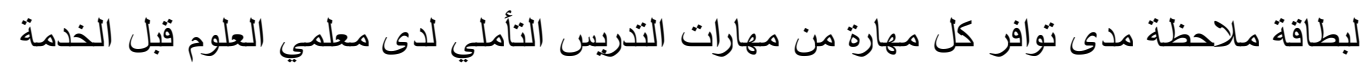

حساب فاعلية برنامج قائم على استراتيجية دراسة الدرس في تنمية مهارات التدريس التأملي لاى معلمي العلوم قبل الخدمة؛ كما يتضح من نتائج الملاحظة:

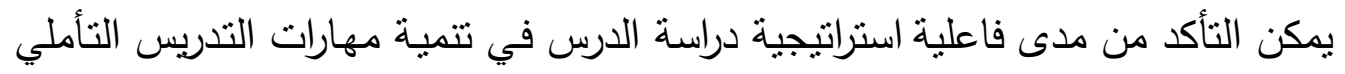

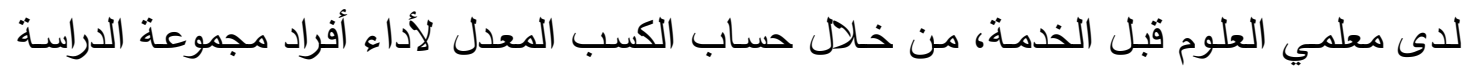




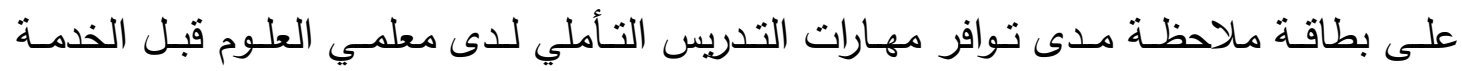

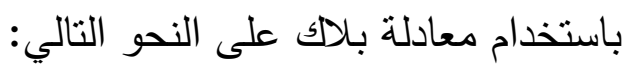

جدول (7)

الكسب المعدل لأداء أفراد مجموعة الدراسة

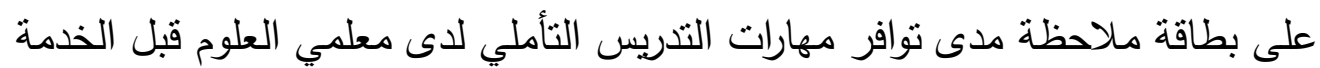

\begin{tabular}{|c|c|c|c|c|c|}
\hline دلالة الكسب & الكسب المعدل & العظمى النهاية & الدرجات & القياس & مهارات التدريس \\
\hline \multirow{16}{*}{ دال احصائياً } & \multirow{2}{*}{$1, \pi \wedge 9$} & \multirow{2}{*}{ r } & $\cdot, 1 \cdot 1$ & قبلي ق & \multirow{2}{*}{ جمع المعلومات } \\
\hline & & & $1, \leqslant 09$ & بعدي & \\
\hline & \multirow{2}{*}{$1,17 \mathrm{~V}$} & \multirow{2}{*}{ r } & $\cdot, 1 \cdot 1$ & قبلي & \multirow{2}{*}{ تحليل المعلومات } \\
\hline & & & $1, r \leqslant r$ & بعدي & \\
\hline & \multirow{2}{*}{$1, \varepsilon r Y$} & \multirow{2}{*}{ r } & $\cdot, \vee Y q$ & قبلي ق & \multirow{2}{*}{ تقييم المعلومات } \\
\hline & & & $r, 07 V$ & بعدي & \\
\hline & \multirow{2}{*}{1,491} & \multirow{2}{*}{$\varepsilon$} & 1,119 & قبلي ق & \multirow{2}{*}{ التأمل الت } \\
\hline & & & $\Gamma, \Sigma \wedge \uparrow$ & بعدي & \\
\hline & \multirow{2}{*}{$1,0 Y V$} & \multirow{2}{*}{ r } & $\cdot, 7 Y)$ & قبلي & \multirow{2}{*}{ التخطيط } \\
\hline & & & $r, T \leqslant \Lambda$ & بعدي & \\
\hline & \multirow{2}{*}{$1, .90$} & \multirow{2}{*}{ r } &., $0 \leqslant 1$ & قبلي & \multirow{2}{*}{ إدارة الأزمات } \\
\hline & & & $1,1 \pi 0$ & بعدي & \\
\hline & \multirow{2}{*}{ 1, } & \multirow{2}{*}{ r } & $\cdot, r \mid 7$ & قبلي & \multirow{2}{*}{ تتفيذ الخطة } \\
\hline & & & $1,07 \mathrm{~V}$ & بعدي & \\
\hline & \multirow{2}{*}{$1, \pi 00$} & \multirow{2}{*}{11} & $1 \varepsilon, 1 \cdot 1$ & قبلي & \multirow{2}{*}{ بطاقة الملاحظة } \\
\hline & & & $r, \cdot r V$ & بعدي & \\
\hline
\end{tabular}

يُلاحظ من الجدول السابق أن قيم الكسب المعدل لكل مهارة من مهارات التدريس التأملي ولبطاقة

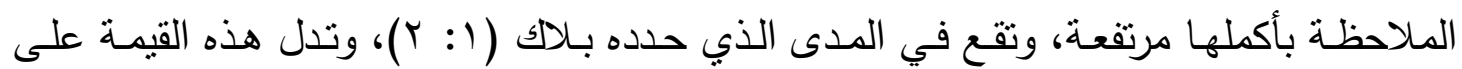


فاعلية برنامج قائم على استراتيجية دراسة الدرس في تتمية مهارات التدريس التأملي لدى معلمي العلوم قبل الخدمة، مما يؤكد صحة الفرض الثاني.

\section{تفسير نتائج الاراسة :}

تشير نتائج الدراسـة إلى فاعلية برنـامج قائم على استراتيجية دراسـة الدرس في تتميـة

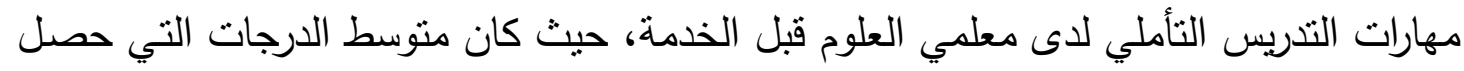

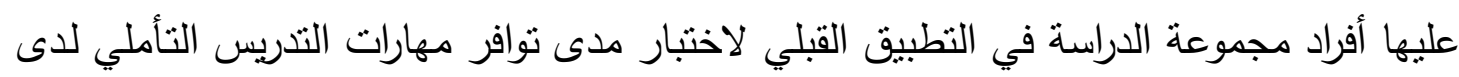

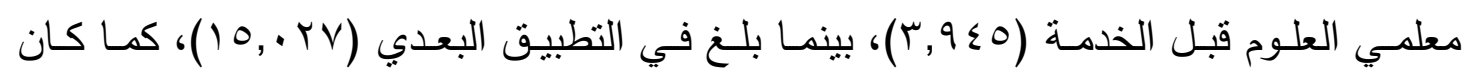
متوسط درجاتهم على بطاقة ملاحظة مدى توافر مهارات التدريس التأملي لدى معلمي العلوم قبل

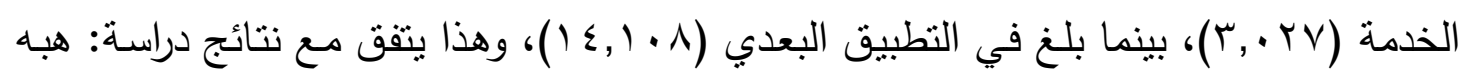

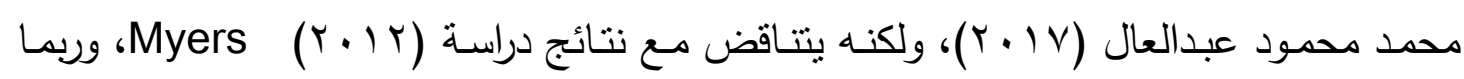

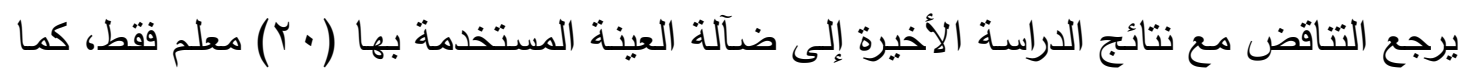

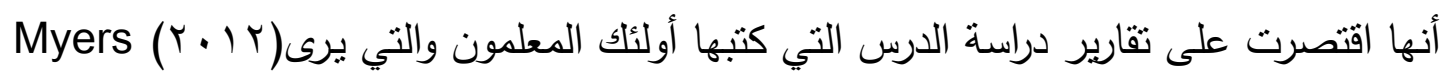

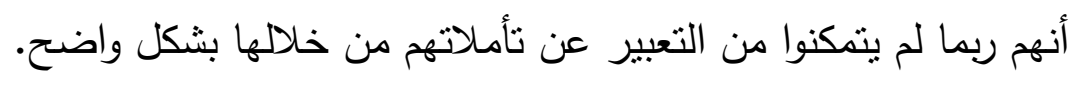

وقد ترجع فعالية البرنامج القائم على استراتيجية دراسة الدرس في تتمية مهارات التدريس التأملي لاى معلمي العلوم قبل الخدمة إلى :

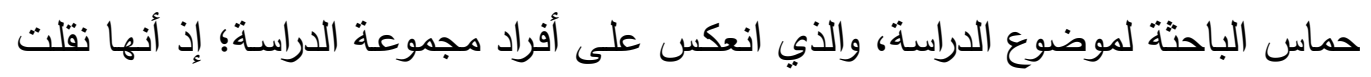

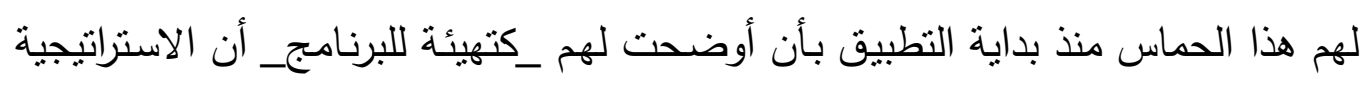

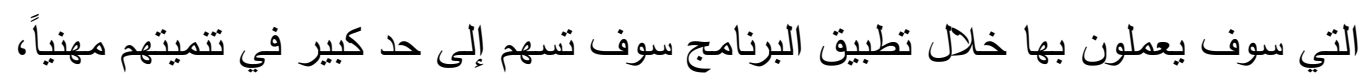

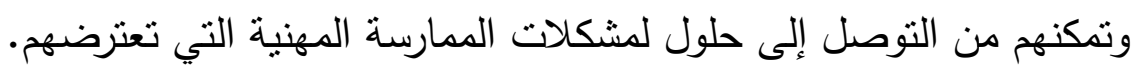

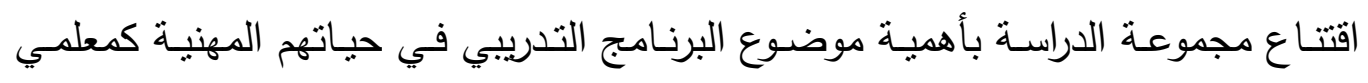

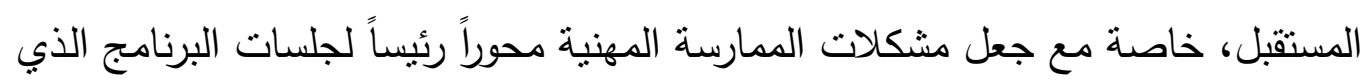
تدور حوله دراسة الدرس.

طبيعـة استراتيجية دراسـة الدرس التي سـاعدتهم على النقاش حول مشكلات الممارسـة المهنيـة كل منها على حدة بثكل موضـوعي، ممـا أسـهم في التقارب بينهم والتفكير الجماعي واكتساب مهارات اجتماعية متعددة، كالحوار والانصـات واحترام الآخر والثقة بالنفس... وغيرها. الاستفادة من التربية العملية في التطبيق الفعلي لحل كل مشكلة تم تتاولها بالبرنامج، مما جعل الحل واقعاً مُعاشاً وليس مجرد اقتراحات نظرية مما أشعرهم بجدوى الاستراتيجية. 
العمـل والتفكير الجمـاعي اللـذين تتطلبهــا اسـتراتيجية دراســة الــرس، واللـذين سـاعدا المندربين على الاستفادة من آراء بعضهم البعض مما ساهم في رفع فعالية الاستراتيجية.

$$
\text { توصيات الدراسة ومقترحاتها: }
$$

في ضوء النتائج التي توصلت إليها الدراسة الحالية، بمكن تقديم التوصيات التالية: - - توجيه إهتمام مخططي ومنفذي برامج إعداد المعلم إلى تتمية مهارات التدريس التأملي.

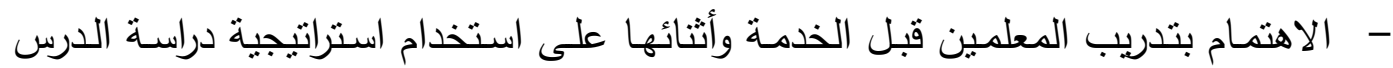
للاستفادة من مميزاتها المتعددة في التتمية المهنية.

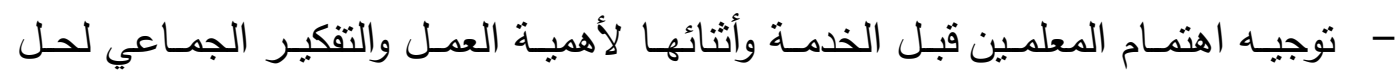

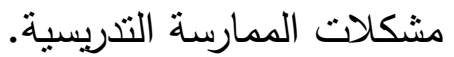

\section{: مقترحات الاراسة}

في ضوء النتائج التي تمّ التوصل إليها، يمكن اقتراح إجراء البحوث التالية:

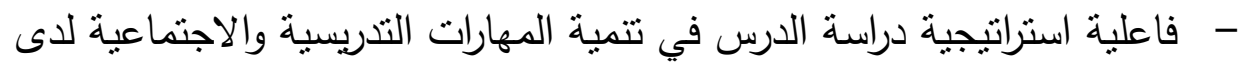

$$
\text { معلمي العلوم قبل الخدمة. }
$$

- فاعلية استراتيجية دراسة الدرس في نتمية مهارات التفكير التأملي والناقد لدى

$$
\text { معلمي العلوم قبل الخدمة. }
$$

- تقويم برامج إعداد معلمي العلوم بكليـة التربيـة في ضـوء مهارات التدريس التأملي. 


\section{المراجع}

\section{أولاً: المراجع العربية}

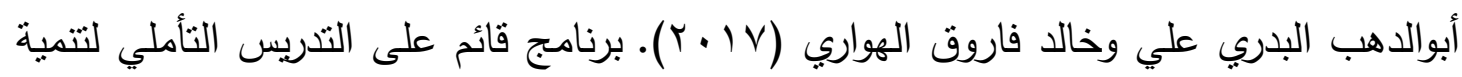

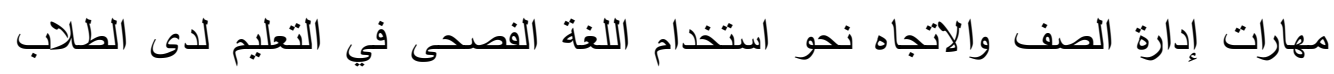

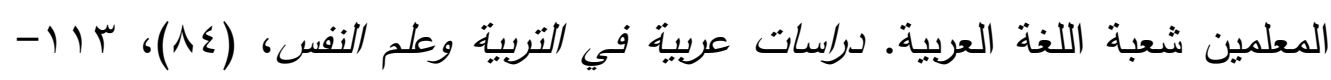
. 17

أحلام الباز حسن و الفرحاتي السيد محمود (^ ...ץ). الاعتماد الدهني للمعلم: مدخل تطوير التعليم. الإسكندرية: دار الجامعة الجديدة.

إخلاص محمد عبدالحفيظ ومصطفى حسين باهي (؟ . . ب). التحليل الإحصائي في العلوم التربوية. القاهرة: مكتبة الأنجلو المصرية.

أمل السيد خلف (9 . . ب). التدريس المصغر التأملي كوسيلة لتتمية بعض المهارات التدريسية

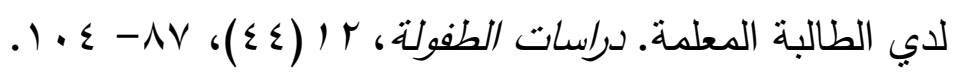

أيمن محمد النبوي (^ ..ץ). مجتدعات التعلم والاعتماد الأكاديهي للمدارس. القاهرة: الدار المصرية اللبنانية.

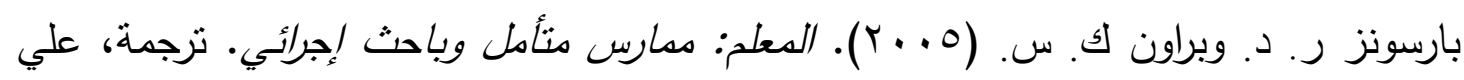

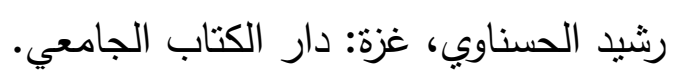

توم فيندر آرك وتوني واغنر وروبرت كيغان وليزا لاشي وريتشارد ليمونز وجود غارنييه ودييورا

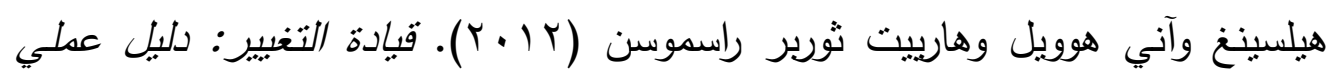
لتطوير مدارسنا ـ ترجمة: زهير السمهوري. الرياض: العبيكان.

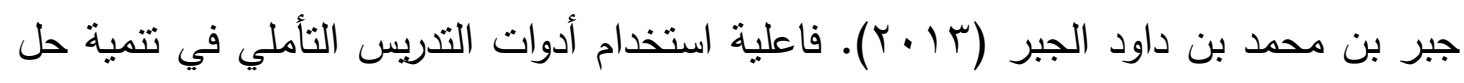

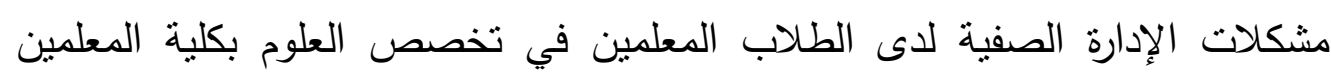

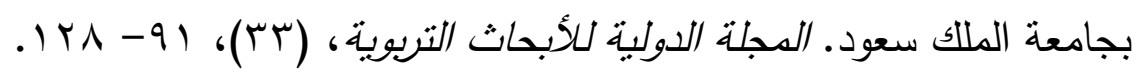

حفني إسماعيل محمد ومحمد حسن عبدالثافي (Y. V). الإحصاء التربوي في الهناهج. القاهرة: مكتبة الأنجلو المصرية.

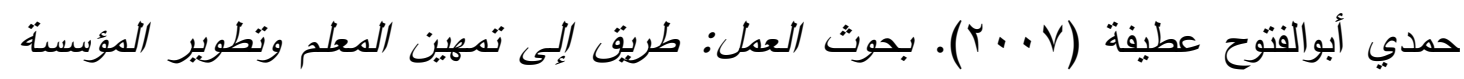
التتربية. القاهرة: دار النشر للجامعات. 


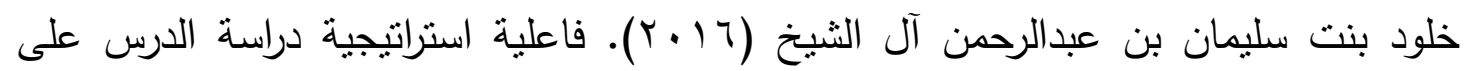
المعتقات المرتبطة بكفاءة التدريس لطالبات الأقسام العلمية المعلمات في كلية التربية

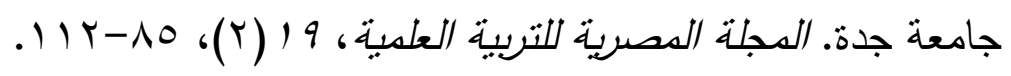

رجاء محمود أبوعلام (11 • (1). مناهج البحث في العلوم النفسية والتربوية (طج). القاهرة: دار

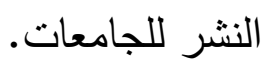

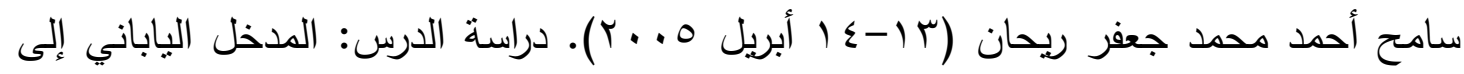
تكوين المعلم. المؤتمر العلمي الثالث: تكوين الدعلم في ضوء معابير الجودة الثاملة

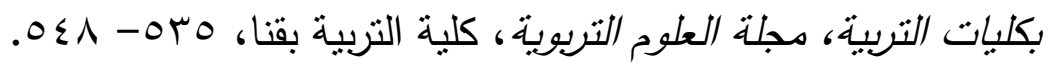

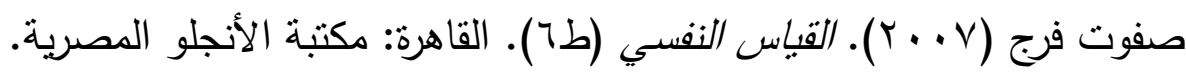
صلاح الدين عرفه محمود (11) ب). تعليم وتعلم مهارات التدربس في عصر الدعلومات: رؤية تربوية دعاصرة (طr). القاهرة: عالم الكتب.

طاهر محمد الهادي محمد (Y (Y). أسس الدناهج الدعاصرة. عمان: دار المسيرة للنشر

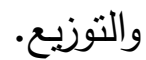

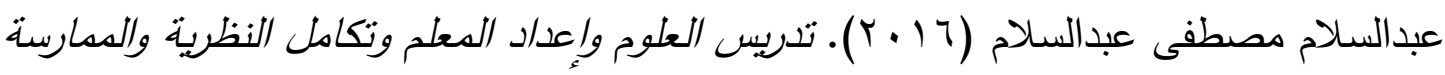

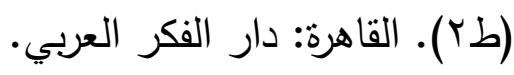

عبدالمنعم أحمد الدردير (T + . ץ). الإحصاء البارامتري واللابارامتري في اختبار فروض البحوث النفسية والتتربوية والاجتماعية. القاهرة: عالم الكتب.

عبد النبي فتحي أبو سلطان ومحمد فؤاد أبو عسكر (Y V V). الممارسات التأملية لمعلمي العلوم في المرحلة الأساسية العليا بمحافظة شمال غزة. مجلة جامعة فلسطبن للأبحاث

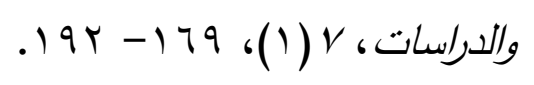

عطية السيد عطية عبدالعال وعصام أحمد محمد أبوالخير وعلي محمد حسين سليمان (10 ب ب). فاعلية برنامج تدريبي مقترح قائم على التدريس المُصغّر في تتمية مهارات التدريس

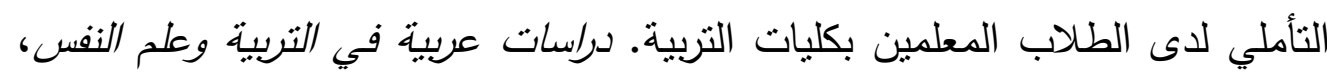

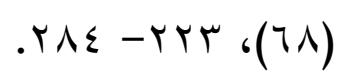

عفت مصطفى الطناوي (9 . . ץ). معايير الجودة في تعليم العلوم. المنصورة: المكتبة العصرية. 
فاطمة سحاب الرشيدي (1) • ( ). تقدير درجة استخدام الممارسات التأملية لدى معلمي المرحلة

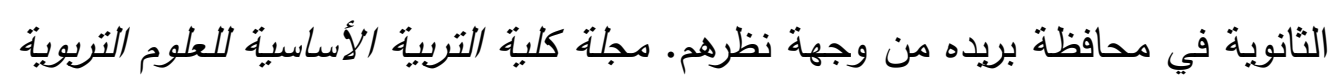

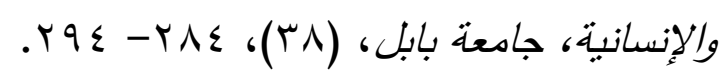

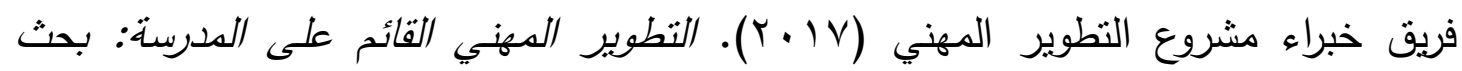
الدس. الرياض: المركز الوطني للنطوير المهني التعليمي، وزارة التعليم.

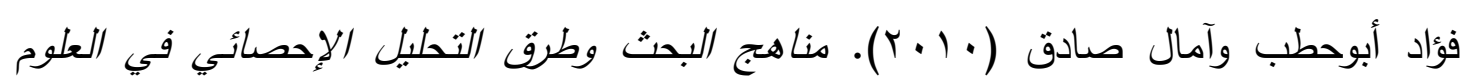

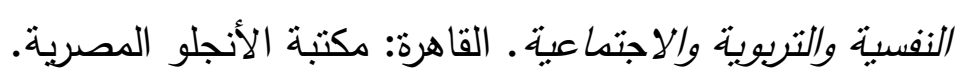

كوثز جميل سالم بلجون (· ( ( ). مدى إتقان معلمي العلوم لممارسات التدريس التأملي وعلاقته

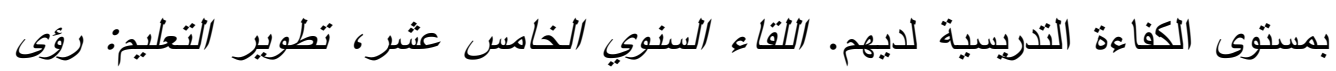

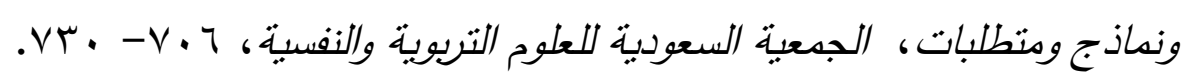

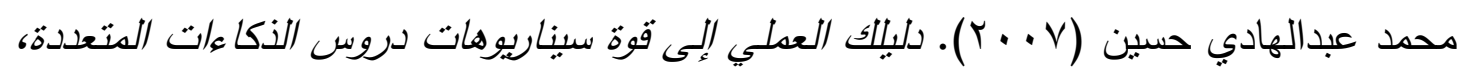

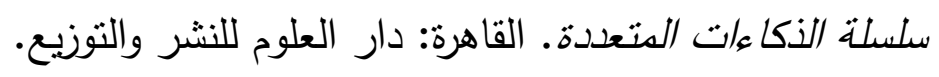

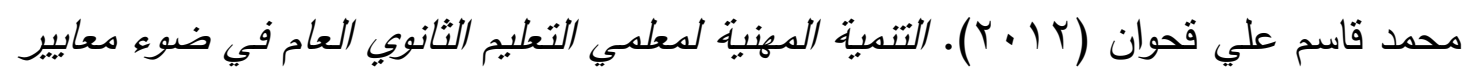

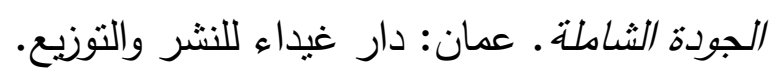

محمود أحمد عمر وحصـة عبدالرحمن فخرو وتركي السبيعي وآمنه عبداله نركي ( • • ؟). القياس النفسي والتربوي. عمان: دار المسيرة.

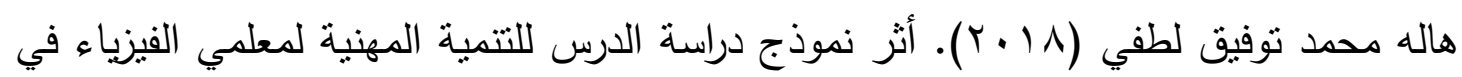
تتمية التحصيل والدافعية للإنجاز لدى طلاب المرحلة الثنانوية والتعرف على لهى اتجاه

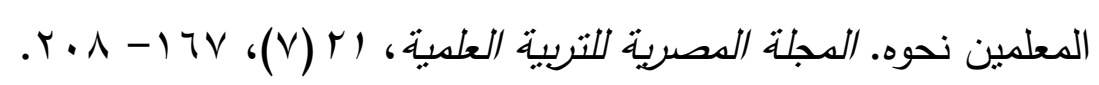

هبه محمد محمود عبدالعال (Y V V Y). برنامج قائم على دراسة الدرس لتتمية مهارات التفكير

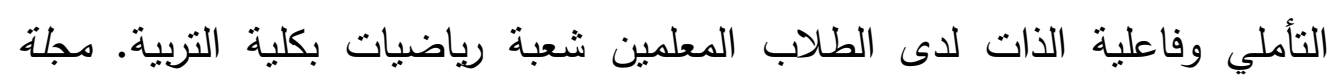

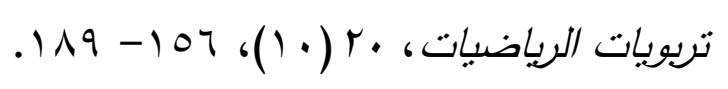

ياسر عواد المغامسي (10 • ب). استراتيجية دراسة الدرس طريقنا نحو تطوير المعلم مهنياً.

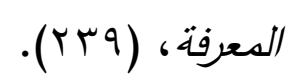

http://www.almarefh.net/index.php?CUV=\{r/\&Model=M متاح على:

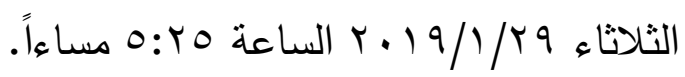




\section{ثانياً: المراجع الأجنبية}

Chenault, K., H. ( $(\cdot \mid \vee)$. Building collaborative pedagogy: Lesson study in higher education. College Quarterly, $r \cdot(1)$.

Retrieved from: https://files.eric.ed.gov/fulltext/EJ/1T1109.pdf

Wednesday $17 / 1 / 4.19$ at $11 . .0 \mathrm{pm}$.

Cheng, E., C., K. (ץ.19). Successful transposition lesson study: A knowledge management perspective, Springer Briefs of Education (e book). Singapore: Springer.

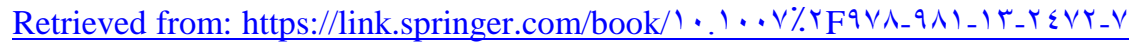

Friday $r r / r / r .1911 . .00 \mathrm{pm}$.

Coenders, F. \& Verhoef, N. $(r \cdot 19)$. Lesson study: Professional development (PD) for beginning and experienced teachers. Professional Development Education, $z \mathcal{O}(r), r \mid V_{-} r \mu \cdot$

Collins, T., M., N. (Y.|V). Lesson study as professional development within secondary physics teacher professional learning communities, (Doctoral dissertation, The University of Alabama, Tuscaloosa, Alabama).

Retrieved from

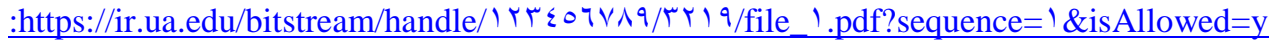

Wednesday $17 / 1 / r \cdot 19$ at $\Lambda: 1 \cdot \mathrm{pm}$.

Doig, B. \& Groves, S. $(\uparrow \cdot 11)$. Japanese lesson study: Teacher professional development through communities of inquiry, Mathematics Teacher Education and Development, I I ( ) , VV_qr.

Espinosa, A., A., Datukan, J., T., Butron, B., R., \& Tameta, A., C. $(r \cdot \mathcal{N})$. Perceptions of pre-service chemistry teachers on the utilization of productive lesson study as a framework for teaching and learning. International Journal for the Scholarship of Teaching and Learning, $1 \mathrm{Y}(\mathrm{l})$.

Retrieved from: https://files.eric.ed.gov/fulltext/EJ/IVrrr .pdf Wednesday $17 / 1 / \mathrm{r} .19$ at $9: 10 \mathrm{pm}$.

Impedovo, M., A., \& Malik, S., Kh. (Y.1 $)$ ). Becoming a reflective in_service teacher: Role of research attitude. Australian Journal of Teacher Education, $₹(1), 99_{-} 11 \mathrm{r}$.

Kadroon, Th., \& Inprasitha, M. (Y./r). Professional development of mathematics teachers with lesson study open approach: The 
process for changing teachers values about teaching mathematics. Psychology, $\varepsilon(r), 1 \cdot 1-1 \cdot 0$.

Kanellopoulou, E., M., \& Darra, M. $(\Upsilon \cdot \mid \wedge)$. The planning of teaching in the context of lesson study: Research finding. International Education Studies, I'( $\mathrm{r})$, TV $\mathrm{V}_{-}$10.

Kevin, S. $\left(r_{\cdot} \mid 0\right)$. Planning and evaluating lessons. In R., Toplis (Ed.), Learning to teach science in the secondary school: A companion to school experience ( $\Sigma^{\text {th }}$ ed., pp. $\left.1 \leqslant \Lambda_{-}\right) \uparrow \cdot$ ). Abingdon: Routledge.

Lewis, C., Perry, R., \& Friedkin, Sh. ( $\left.{ }^{\prime} .9\right)$. Lesson study as action research. In S., E., Noffke \& B., Somekh (Eds), The SAGE handbook of educational action research ( $\left.1 \leqslant Y_{-}-10 \leqslant\right)$. London: SAGE Publication Ltd.

Lupinski, K., Jenkins, P., Beard, A., \& Jones, L. ( $\left.r^{\prime} \mid r\right)$. Reflective practice in teacher education programs at a HBCU. Educational

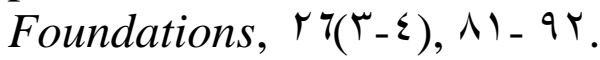

Mann, S., \& Walsh, S. $(\uparrow \cdot 10)$. Reflective dimensions of CPD: Supporting self-evaluation and peer evaluation. In A., Howard \& $\mathrm{H}$., Donaghue (Eds), Teacher evaluation in second language

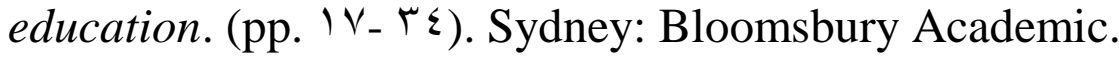

Matanluk, K., Johari, Kh., \& Matanluk, O. $(r \cdot 1 r)$. The perception of teachers and students toward lesson study implementation at rural school of Sabah: A pilot study. th $^{\text {th }}$ International Conference on University Learning and Teaching (In CULT r.I r), ProcediaSocial and Behavioral Sciences, $9 \cdot$, r $\leqslant 0_{-}$ro.

Mee, L., Sh., \& Oyao, Sh., G., $(r \cdot 1 r)$. Establishing learning communities among science teachers through lesson study. Journal of Science and Mathematics, ${ }^{4}$ ( ( ) , I-rY.

Moore, A. $(r \cdot \mid r)$. Teaching and learning: Pedagogy, curriculum, and culture ( $r^{\text {nd }}$ ed.). Abingdon: Routledge.

Myers, J. $(Y \cdot \mid r)$. Lesson study as a means for facilitating preservice teacher reflectivity. International Journal for the Scholarship of Teaching and Learning, '(').

Retrieved from : https://files.eric.ed.gov/fulltext/EJ 1$) \leq 0 r . r . p d f$

Friday $r T / r / r \cdot 191 \cdot: \varepsilon \cdot \mathrm{pm}$.

Ryan, K., \& Cooper, J., M. $\left.\left(Y_{\cdot}\right) \cdot\right)$. Those who can teach. Boston: Wadsworth, Cengage Learning. 
Satio, E., Murase, M., Tsukui, A., \& Yeo, J. (ץ+10). Lesson study for learning community: A guide to sustainable school reform. Abingdon: Routledge.

Tuckman, B., W., \& Monetti, D., M. (Y. 1$)$ ). Educational psychology, Belmont: Wadsworth, Cengage Learning.

Yakar, Z., \& Turgaut, D. $(Y \cdot \mid \vee)$. Effectiveness of lesson study approach on preservice science teachers' beliefs. International Educational Sciences, $1 \cdot(\uparrow), r^{\top} \tau_{-} \varepsilon r$.

Yendol-Hoppey, D., \& Dana, N., F. $(Y \cdot 1 \cdot)$. Powerful professional development: building expertise within the four walls of your school. Thousand Oaks: Crown Press.

Yu, P. W., D. $(Y \cdot \mid l)$. Lesson study as a framework for preservice teachers' early field_based experiences. In L., C., Hart, A., S., Alston, \& A., Murata (Eds), Lesson study research and practice in mathematics education: Learning together. (pp. IIV- IY ). Dordrecht: Springer.

Zhou, G., \& Yu, J. ( $\vdash$ • V $)$. Microteaching lesson study: An approach to prepare teacher candidates to teach science through inquiry. International Journal of Education in Mathematics, Science and Technology, $\mathcal{O}(r), r T O_{-} r \leqslant V$. 